NBER WORKING PAPER SERIES

\title{
CHANGES IN THE CHARACTERISTICS OF AMERICAN YOUTH: IMPLICATIONS FOR ADULT OUTCOMES
}

\author{
Joseph G. Altonji \\ Prashant Bharadwaj \\ Fabian Lange \\ Working Paper 13883 \\ http://www.nber.org/papers/w13883
NATIONAL BUREAU OF ECONOMIC RESEARCH
1050 Massachusetts Avenue
Cambridge, MA 02138
March 2008

\begin{abstract}
Altonji: Yale University, NBER and IZA; Bharadwaj: Yale University; Lange: Yale University and IZA. We are grateful to the Yale Economic Growth Center for research support. We thank Daniel Black, James Heckman, Patrick Kline, Paul LaFontaine, Costas Meghir, Robert Michael, Derek Neal and seminar participants at the Bureau of Labor Statistics, Duke, the Institute for Poverty Research, U. of Aarhus, University College London, U. of Washington, and the European Summer Symposium in Labour Economics (Sept 2007) for valuable comments. Thanks to Steven McClaskie for support with the NLSY data and to Daniel Segall for assistance with the AFQT data. The views expressed herein are those of the author(s) and do not necessarily reflect the views of the National Bureau of Economic Research.
\end{abstract}

NBER working papers are circulated for discussion and comment purposes. They have not been peerreviewed or been subject to the review by the NBER Board of Directors that accompanies official NBER publications.

(C) 2008 by Joseph G. Altonji, Prashant Bharadwaj, and Fabian Lange. All rights reserved. Short sections of text, not to exceed two paragraphs, may be quoted without explicit permission provided that full credit, including $\left({ }^{\circ}\right.$ notice, is given to the source. 
Changes in the Characteristics of American Youth: Implications for Adult Outcomes Joseph G. Altonji, Prashant Bharadwaj, and Fabian Lange

NBER Working Paper No. 13883

March 2008

JEL No. J01,J11,J15,J16,J31,J82

\begin{abstract}
We examine changes in the characteristics of American youth between the late 1970s and the late 1990s, with a focus on characteristics that matter for labor market success. We reweight the NLSY79 to look like the NLSY97 along a number of dimensions that are related to labor market success, including race, gender, parental background, education, test scores, and variables that capture whether individuals transition smoothly from school to work. We then use the re-weighted sample to examine how changes in the distribution of observable skills affect employment and wages. We also use more standard regression methods to assess the labor market consequences of differences between the two cohorts. Overall, we find that the current generation is more skilled than the previous one. Blacks and Hispanics have gained relative to whites and women have gained relative to men. However, skill differences within groups have increased considerably and in aggregate the skill distribution has widened. Changes in parental education seem to generate many of the observed changes
\end{abstract}

Joseph G. Altonji

Department of Economics

Yale University

Box 208269

New Haven, CT 06520-8269

and NBER

joseph.altonji@yale.edu

Prashant Bharadwaj

Department of Economics

Yale University

P.O. Box 208269

New Haven, CT 06520-8269

prashant.bharadwaj@yale.edu
Fabian Lange

Department of Economics

Yale University

P.O. Box 208269

New Haven, CT 06520-8269

fabian.lange@yale.edu 


\section{INTRODUCTION}

Labor and growth economists typically look to the process of skill formation as a primary driving force of both economic inequality and economic development. Consequently, the literature on economic inequality and economic development abounds with studies that investigate how overall skill formation contributes to growth and inequality. ${ }^{1}$ But, while the central role of skill acquisition is well understood, relatively little is known about how young people today compare to their predecessors along various dimensions of skill. Without this knowledge there are many questions that we can not begin to address.

For example, how will the adult labor market outcomes of American youth compare to the previous generation? Will gaps between race and ethnic groups narrow or widen? How will other key outcomes, such as marriage and fertility and incarceration rates differ across generations? Of course the answers to these questions hinge on broad changes in social processes, culture, government policy, and the economy that are very difficult to forecast decades in advance. However, the answers also depend on the distribution of cognitive and noncognitive skills among the today's youth, a distribution that is already partially observed. In particular, we can measure the parental background, race and ethnicity, cognitive test scores, educational achievements and early labor market outcomes of those aged 20-24. From past studies, we know that these measures explain a substantial portion of the variance across people in employment rates, hourly wage rates, and hourly earnings and other outcomes at ages 40-45. These skill measures therefore allow us to glimpse one of the major determinants of labor market outcomes in 2025, when today's youth reach their prime earning ages.

In this paper, we compare the distribution of skills in two cohorts. The specific cohorts that we compare are determined by the availability of panel data from National Longitudinal Survey of Youth, 1997 (NLSY97) on individuals who were aged 12 to 16 in 1997 and from the National Longitudinal Survey of Youth, 1979 (NLSY79) on individuals who were aged 14 to 22 in $1979 .{ }^{2}$ We examine the implications of changes in the characteristics of American youth for a set of adult labor market outcomes, in particular wages and employment. Wages and employment provide a natural metric through which to aggregate various skill

\footnotetext{
${ }^{1}$ For example, Denison (1974) and Jorgensen et al. (1987) measure how the American labor force changed on the basis of education, work hours, and change in the age and gender mix of the labor force. Using these as inputs in growth accounting, they found that the acquisition of individual skills represents the largest contributing factor to economic growth in the first half of the 20th century. Lange and Topel (2007) find that much of the convergence in earnings across US states between 1940-2000 can be attributed to reductions in skill gaps across states. Other researchers have examined the role of differences in the conditions of skill acquisition to understand economic inequality across and within demographic groups. Juhn, Murphy and Pierce (1991) for instance rely heavily on skill difference between blacks and whites to explain why the decline in the black-white wage gap halted after 1975. They emphasize that the halt in the black-white wage gap reflected how increasing skill prices interacted with pre-existing skill differences between blacks and whites.

${ }^{2}$ In this study we use the word "cohort" to refer to either the NLSY79 or the NSLY97. We use the word "birth-year" to refer to groups of individuals defined by their birth year.
} 
measures into a single skill index. In our study, this skill index is provided by wages and employment of individuals of the NLSY79 cohort during the 1998-2004 survey years. ${ }^{3}$ To avoid misunderstanding, note that throughout the paper we use the term "skill index" to refer to variables that are correlated with labor market outcomes. In the case of race and gender, part of that relationship may be due to discrimination.

The first step in our study is to create a set of youth characteristics that correlate with adult outcomes and are comparable across NLSY97 and NLSY79. The second step is to examine the consequences of differences between the characteristics of the 1979 and 1997 cohorts for various adult outcomes. Specifically, we assess what the adult outcomes of the 1997 cohort will be if the relationship between characteristics and adult outcomes turns out to be the same for the 1997 cohort as it has been for 1979. To accomplish this, we draw on the re-weighting procedure employed by Dinardo, Fortin, and Lemieux ((1995), hereafter, DFL). ${ }^{4}$ Basically, we re-weight the 1979 sample to have the same distribution of characteristics as the 1997 sample. We can then compare how outcomes are distributed in the re-weighted 1979 sample and in the sample prior to re-weighting and can thus measure how the changes in characteristics between 1979 and 1997 affects the outcomes of interest. For example we can estimate how adult wages of the 1979 cohort would have been distributed if the 1979 cohort had had the characteristics of the 1997 cohort. Furthermore, we can decompose the difference between this counterfactual and the actual distribution into the contributions of various subsets of characteristics.

The DFL procedure can be interpreted as a generalization of the Blinder-Oaxaca decomposition procedure, since it is not based on an outcome equation that is linear in parameters. In fact, the general approach following DFL has the advantage that is does not require any parametric model relating outcomes to characteristics. It also generalizes the BlinderOaxaca approach since it allows examining the impact of changes in particular characteristics on statistics other than the mean. The main disadvantage is that the DFL approach does not estimate parameters that relate outcomes to characteristics and that can potentially be interpreted.

An alternative approach proposed by Machado and Mata (2005), Melly (2005) and Goesling et al. (2000) explores semi-parameteric approaches that restrict the quantiles of the outcome conditional on the characteristics. These approaches strive to partially relax the parametric restrictions imposed by the Blinder-Oaxaca approach, but still provide interpretable

\footnotetext{
${ }^{3}$ At this point the respondents to the NLSY79 were 39-47 years old and typically had more than 10 years of experience.

${ }^{4} \mathrm{DFL}$ is one of a number of papers in the literature that use propensity scores to re-weight samples. See for example Hirano, Imbens, and Ridder (2003) who show that efficient estimates of average treatment effects of binary treatments on scalar outcomes can be obtained by weighing with the inverse of a nonparametric estimate of the propensity score. This is closely related to the weighing procedure adopted in this paper with the exception that we are relying on parametric estimates of the propensity score. Since we are re-weighting the 1979 cohort to have the characteristics of the 1997 cohort, the "treatment" in our case is giving the 1997 cohort the 1979 wage function.
} 
parameter estimates. However, the parameters are hard to interpret when the number of conditioning variables is large and interactions among the various characteristics are allowed for. We therefore rely mainly on a DFL type procedure, but present some results based on the Blinder-Oaxaca regression procedure for a simple specification.

Regardless of method, we require representative samples for both the 1979 and the 1997 cohort that contain characteristics that can be compared across cohorts. Much of the empirical work described below aims to ensure that these conditions are met. We pay particular attention to the AFQT-scores which were administered at different ages and based upon different test formats. Another crucial issue is whether the 1979 and 1997 cohorts are representative, particularly after attrition and missing data on two key variables are accounted for.

Our main results are as follows.

(1) The 1997 cohort is stronger than the 1979 cohort in most dimensions that matter for wages. In particular, the 1997 cohort is stronger than 1979 cohort in education, parental education, and test scores. However, the fraction of individuals who lived with both parents at age 14 declined substantially between 1979 and 1997.

(2) The increase in skills of the younger cohort implies on average a wage increase of about $5 \%$ for whites and more for minorities.

(3) The implied difference in employment rates are small, but they show a small increase for blacks and Hispanics gain relative to white males.

(4) Skill gaps across race and gender decrease. Black and Hispanic males and females gain relative to their white counterparts. White women gain more than white men. The sources of the gains vary across race/gender groups.

(5) The skill distribution widens within race/gender groups as well as for the entire population.

(6) Much of the increase is associated with increases in parental education.

The paper continues in section 2, where we present our methodology. In section 3, we describe the data. We also present evidence on and ways of accounting for biases that may arise due to problems with the NLS97 base year sample, missing data on key variables, and attrition. In section 4 we discuss the specifications of the probit models used to adjust the 1979 sample to match the characteristics of 1997. In sections 5 and 6 we present our basic results. In the final section, we summarize our main findings and outline the next steps in our project

\section{ECONOMETRIC Methods}

We now describe our procedure for assessing the changes in the skill distribution across the NLSY79 and NLSY97. There are many dimensions of skill one could look at. Skill measures such as years of education and test scores are not reported in a natural metric that allows one to aggregate variations in observed skill distributions. We measure and aggregate 
the contributions of the various skills using the labor market outcomes (primarily wages and employment) of the NLSY79 cohort during the 1998-2004 survey years. At this point the 1979 cohort has reached the peak of its life-cycle earnings profile. ${ }^{5}$

Our estimates of counterfactual wage distributions answer the question, "What wages will the NLSY97 cohort earn at the peak of their life-cycle earnings if the wage distribution conditional on skills stays unchanged between the NLSY79 and NLSY97 cohort?" Our estimates also answer the question, "What wages would the NLSY79 cohorts have earned if they had had the observed skills of the NLSY97 cohort?" To answer these equivalent questions, we re-weight the NLSY79 to have the same distribution of skills as the 1997 cohort and then use the re-weighted data to generate the counterfactual wage distribution for the NLSY97 cohort.

2.1. Basic Approach. For each observation from the NLSY79 we obtain a realization $(z, w)$ of the random vectors $Z$ and $W$. Observations from the NLSY97 consist of realizations of $Z$ only. We lack realizations of $W$ for NLSY97 and strive to obtain counterfactual distributions of $W$. Let $t$ and $t^{\prime}$ stand for the populations that the NLSY79 and NLSY97 are drawn from, respectively. ${ }^{6}$ We will sometimes refer to the cohorts by "1979" and "1997" rather than $t$ and $t^{\prime}$.

Wages in the economy faced by 1979 are determined by $w=W^{79}(z, u)$, where the vector $z$ is observed and the vector $u$ is not. The function $W^{79}(z, u)$ serves as our metric for aggregating components of the skill vector $z$.

Let $g(u \mid z, t)$ and $g\left(u \mid z, t^{\prime}\right)$ be the conditional densities of $u$ given $z$ for the two cohorts. We make the following key assumption on the relation between observed and unobserved skills:

Assumption A1: The distribution of $u$ conditional on $z$ is the same for 1979 and 1997 cohorts:

$$
g(u \mid z, t)=g\left(u \mid z, t^{\prime}\right)
$$

This assumption allows us to construct a counterfactual distribution of wages using $W^{79}(z, u)$ and the observed distribution of $Z$ for the 1997 cohort. Of course, A.1 is not likely to hold exactly. Behavioral responses to differences between $t$ and $t^{\prime}$ in skill prices, unobserved differences across cohorts in school quality, neighborhood environment, or family environment might lead the assumption to fail. Furthermore, changes in compulsory schooling laws, college tuition subsidies, or race and gender discrimination should alter the relationship between parental education and innate characteristics that are transmitted to children.

Let $f(w \mid t, z)=\int 1\left(W^{t}(u, z)=w \mid t, z\right) g(u \mid z, t) d u$ be the density of adult wages of the cohort $t$ (the 1979 cohort) conditional on $z$. Here $1\left(W^{t}(u, z)=w \mid t, z\right)$ denotes the Dirac function - it takes the value 1 when $W^{t}(u, z)$ equals w. Assumption (A.1) implies that the

\footnotetext{
${ }^{5}$ Mean wages typically rise rapidly during the first 10 years of experience but do not grow much subsequently. In 1998 the NLSY79 cohort was between 33 and 41 years old, and even the youngest respondents typically had more than 10 years of labor market experience.

${ }^{6}$ The birth years are 1957-1964 for NLSY79 and 1980-1984 for the NSLY97.
} 
conditional wage density for cohort $t$ and $t^{\prime}$ are the same:

$$
\begin{aligned}
f(w \mid t, z) & =\int 1\left(W^{t}(u, z)=w\right) g(u \mid z, t) d u \\
& =\int 1\left(W^{t}(u, z)=w\right) g\left(u \mid z, t^{\prime}\right) d u \\
& =f\left(w \mid t^{\prime}, z\right) .
\end{aligned}
$$

In the remainder of the paper, we will suppress the " $t$ " superscripts on the wage function $W$ because we will always be considering the 1979 wage function. ${ }^{7}$

Note that $f(w \mid t)=\int f(w, z \mid t) d z$. Equation (2.1) implies that

$$
f\left(w \mid t^{\prime}\right)=\int f(w, z \mid t) \psi(z) d z
$$

where

$$
\psi(z)=\frac{f\left(z \mid t^{\prime}\right)}{f(z \mid t)}=\frac{p\left(t^{\prime} \mid z\right)}{p(t \mid z)} \frac{p(t)}{p\left(t^{\prime}\right)}
$$

and $p\left(t^{\prime} \mid z\right)$ and $p(t \mid z)=1-p\left(t^{\prime} \mid z\right)$ are the probabilities or "propensity scores" of appearing in sample $t^{\prime}$ and sample $t$, respectively, conditional on $z{ }^{8}$ The ratio $\frac{p(t)}{p\left(t^{\prime}\right)}$ is the unconditional odds that the observation is from cohort $t$. Thus the second equality in (2.3) says that $\psi(z)$ is also equal to the product of the odds that an observation comes from cohort $t^{\prime}$ conditional on $z$ multiplied by $\frac{p(t)}{p\left(t^{\prime}\right)}$, the unconditional odds that the observation is from cohort $t$. The term following the first equality says that the weight function $\psi(z)$ may also be expressed as the relative frequency (density) of the skill vector $z$ in 1997 versus 1979.

Equation (2.2) shows that under Assumption 1 one can obtain the density of adult wages for a population that faces the 1979 wage function but has the observed characteristics of the 1997 sample. One simply multiplies the density from $t$ by the weight function $\psi(z)$. Clearly, multiplying by $\psi(z)$ ensures that the re-weighted distribution of skills for 1979 is identical to the actual distribution of skills in 1997.

We implement (2.2) as follows. First, we pool data from NLSY79 and NLSY97 and estimate the propensity score $p\left(t^{\prime} \mid z\right)$ using skill measures $Z$ that are observed for both the NLSY79 and the NLSY97 cohort. We then generate the "propensity weights" $\psi(z)$ and apply these weights to the NLSY79 data. The re-weighted data are used to generate various statistics of the counterfactual wage distribution $f\left(w \mid t^{\prime}\right)$. In particular, we estimate $f\left(w \mid t^{\prime}\right)$ itself and compare it to $f(w \mid t)$. We also derive the counterfactual wage distribution conditional on various sub-components of $Z$. Note, that in applying these procedures we must account for the

\footnotetext{
${ }^{7}$ If one were to assume a parametric form $W^{79}(z, u)=W\left(z, u ; \beta_{79}\right)$ and make assumptions about how $\beta_{97}$ will relate to $\beta_{79}$, then one could use $W\left(z, u ; \beta_{97}\right)$ to forecast the wage distribution for the 97 cohort. We do not explore such assumptions and instead simply focus on the counterfactual distribution generated by changing endowments of observed skills between the 1979 and 1997 cohort.

${ }^{8}$ First note that $f\left(w \mid t^{\prime}\right)=\int f\left(w, z \mid t^{\prime}\right) d z=\int f\left(w \mid z, t^{\prime}\right) f\left(z \mid t^{\prime}\right) d z$. Then apply assumption (A.1) to get $f\left(w \mid t^{\prime}\right)=$ $\int f(w \mid z, t) f\left(z \mid t^{\prime}\right) d z$. Substitute $f(w \mid z, t)=\frac{f(w, z \mid t)}{f(z \mid t)}$ and then use $\frac{f\left(z \mid t^{\prime}\right)}{f(z \mid t)} * \frac{p\left(t^{\prime}\right)}{p(t)}=\frac{f\left(z, t^{\prime}\right)}{f(z, t)}=\frac{p\left(t^{\prime} \mid z\right)}{p(t \mid z)} * \frac{f(z)}{f(z)}=\frac{p\left(t^{\prime} \mid z\right)}{p(t \mid z)}$.
} 
sampling weights provided by the NLSY79 and NLSY97 to achieve population representative samples. ${ }^{9}$

\subsection{Identifying the Contribution of Subsets of Variables to Differences between the 1979} and 1997 Wage Distributions. Above we showed how to generate a counterfactual distribution of wages that is implied by a shift in the distribution of the skill vector $Z$ from $t$ to $t^{\prime}$. It is natural to ask how much various components of the random vector $Z$ (say $Z_{1}$ and $Z_{2}$ ) contribute to the overall change in the distribution of wages from $f(w \mid t)$ to $f\left(w \mid t^{\prime}\right)$. That is, one would like to decompose the differences between the observed wage distribution of the NLSY79 sample and the counterfactual wage distribution of the NLSY97 sample into variation due to $Z_{1}$ or $Z_{2}$.

The first thing to note is that in general there is more than one way to decompose the change in $f(w \mid t)$ into the contributions of $Z_{1}$ and $Z_{2}$. Any particular decomposition is of interest only because it corresponds to an implicit or explicit understanding of the underlying structure of the economy. Below we propose a decomposition of the change from $f(w \mid t)$ to $f\left(w \mid t^{\prime}\right)$ that is based on a partition of the skill vector $Z$ into subvectors $Z_{1}$ and $Z_{2}$ that can be interpreted as determined recursively in the sense that $Z_{1}$ is determined prior to $Z_{2}$. This decomposition provides useful insights into the changing skill distribution between 1979 and 1997.

To present the decomposition, we need some additional notation. Let $G_{W, Z_{1}, Z_{2}}^{t}$ denote the joint distribution of $\left(W, Z_{1}, Z_{2}\right)$ at $\mathrm{t}$. Also let $G_{W, Z_{1} \mid Z_{2}}^{t}$ to denote the distribution of $\left(W, Z_{1}\right)$ conditional on $Z_{2}$ and let $G_{Z_{1}}^{t}$ to denote the distribution of $Z_{1}$. Define the distributions for different conditioning sets and period $t^{\prime}$ analogously. Now, consider the pdf of $w$ which is implied by the joint distribution $G_{W, Z_{1}, Z_{2}}^{t}$. We denote this pdf as $f\left(w \mid G_{W, Z_{1}, Z_{2}}^{t}\right)$ and note that by definition $f(w \mid t)=f\left(w \mid G_{W, Z_{1}, Z_{2}}^{t}\right)$ and $f\left(w \mid t^{\prime}\right)=f\left(w \mid G_{W, Z_{1}, Z_{2}}^{t^{\prime}}\right)$.

Using equation (2.2) we get:

$$
\begin{aligned}
f\left(w \mid t^{\prime}\right) & =f\left(w \mid G_{W, Z_{1}, Z_{2}}^{t^{\prime}}\right) \\
& =\int f(w \mid z, t) f(z \mid t) \psi(z) d z \\
& =\iint f(w \mid z, t) f\left(z_{1} \mid z_{2}, t\right) f\left(z_{2} \mid t\right) \psi(z) d z_{1} d z_{2}
\end{aligned}
$$

Next consider the counterfactual pdf of $w$ that would be observed if $Z_{2}$ was distributed as in $t^{\prime}$ but $W$ and $Z_{1}$ were distributed as in $t$ conditional on $Z_{2}$. Denote this counterfactual distribution as $f\left(w \mid G_{W, Z_{1} \mid Z_{2}}^{t}, G_{Z_{2}}^{t^{\prime}}\right)$. It is defined as

$$
f\left(w \mid G_{W, Z_{1} \mid Z_{2}}^{t}, G_{Z_{2}}^{t^{\prime}}\right)=\iint f\left(w, z_{1} \mid z_{2}, t\right) f\left(z_{2} \mid t^{\prime}\right) d z_{1} d z_{2}
$$

\footnotetext{
${ }^{9}$ We also generate weights to account for attrition and non-response for crucial variables. Details are provided in Section 3.
} 
To obtain $f\left(w \mid G_{W, Z_{1} \mid Z_{2}}^{t}, G_{Z_{2}}^{t^{\prime}}\right)$ requires weights $\psi\left(z_{2}\right)$ generated using only the vector $z_{2}$ :

$$
\begin{aligned}
f\left(w \mid G_{W, Z_{1} \mid Z_{2}}^{t}, G_{Z_{2}}^{t^{\prime}}\right) & =\iint f\left(w, z_{1} \mid z_{2}, t\right) f\left(z_{2} \mid t^{\prime}\right) d z_{1} d z_{2} \\
& =\iint f\left(w, z_{1} \mid z_{2}, t\right) f\left(z_{2} \mid t\right) \psi\left(z_{2}\right) d z_{1} d z_{2} \\
& =\iint f(w, z \mid t) \psi\left(z_{2}\right) d z_{1} d z_{2} .
\end{aligned}
$$

Expression (2.5) gives the distribution of $w$ if (i) the distribution of $\left(w, z_{1}\right)$ conditional on $z_{2}$ is that of period $t$ and (ii) the marginal distribution of $z_{2}$ is that of period $t^{\prime}$. To obtain $f\left(w \mid G_{W, Z_{1} \mid Z_{2}}^{t}, G_{Z_{2}}^{t^{\prime}}\right)$ using (2.5), we estimate propensity weights based on $z_{2}$ only. We can then decompose the difference in the 1997 and 1979 wage densities as:

$$
\begin{aligned}
f\left(w \mid t^{\prime}\right)-f(w \mid t)= & f\left(w \mid t^{\prime}\right)=f\left(w \mid G_{W, Z_{1}, Z_{2}}^{t^{\prime}}\right)-f\left(w \mid G_{W, Z_{1} \mid Z_{2}}^{t}, G_{Z_{2}}^{t^{\prime}}\right) \\
& +f\left(w \mid G_{W, Z_{1} \mid Z_{2}}^{t}, G_{Z_{2}}^{t^{\prime}}\right)-f\left(w \mid G_{W, Z_{1}, Z_{2}}^{t}\right)
\end{aligned}
$$

Comparing the terms in (2.6) with the expressions (2.3) and (2.5) shows that we can estimate the components in (2.6) by sequentially applying the propensity weights. One estimates the second term $f\left(w \mid G_{W, Z_{1} \mid Z_{2}}^{t}, G_{Z_{2}}^{t^{\prime}}\right)-f\left(w \mid G_{W, Z_{1} \mid Z_{2}}^{t^{\prime}}, G_{Z_{2}}^{t^{\prime}}\right)$ by first applying $\psi\left(z_{2}\right)$ to the NLSY79 data, as in (2.5), to obtain $f\left(w \mid G_{W, Z_{1} \mid Z_{2}}^{t}, G_{Z_{2}}^{t^{\prime}}\right)$ and then subtracting $f(w \mid t)=$ $f\left(w \mid G_{W, Z_{1}, Z_{2}}^{t}\right)$. To obtain the first term, one applies $\psi\left(z_{1}, z_{2}\right) \equiv \psi(z)$ to the NLSY79 data to obtain $f\left(w \mid t^{\prime}\right)=f\left(w \mid G_{W, Z_{1}, Z_{2}}^{t^{\prime}}\right)$ and subtracts $f\left(w \mid G_{W, Z_{1} \mid Z_{2}}^{t}, G_{Z_{2}}^{t^{\prime}}\right)$. Note that this decomposition procedure can be undertaken sequentially with as many subvectors as desired.

In general, the decomposition will be sensitive to the order in which it is performed. An alternative to (2.6) is given by: ${ }^{10}$

$$
\begin{aligned}
f\left(w \mid t^{\prime}\right)-f(w \mid t)= & f\left(w \mid G_{W, Z_{1}, Z_{2}}^{t^{\prime}}\right)-f\left(w \mid G_{W, Z_{2} \mid Z_{1}}^{t}, G_{Z_{1}}^{t^{\prime}}\right) \\
& +f\left(w \mid G_{W, Z_{2} \mid Z_{1}}^{t}, G_{Z_{1}}^{t^{\prime}}\right)-f\left(w \mid G_{W, Z_{1}, Z_{2}}^{t}\right)
\end{aligned}
$$

The first term of this alternative decomposition and the second term of (2.6) both measure the contribution of the change in the distribution of $Z_{2}$ to the change in the distribution of $w$ between $t$ and $t^{\prime}$. However, the two measures are not identical. The first term of (2.7) will be equal to the second term of (2.6) only under special circumstances, such as independence between $Z_{1}$ and $Z_{2}{ }^{11}$.

The decomposition is sensitive to order, because the order of the decomposition reflects different implicit assumption about how $Z_{1}$ and $Z_{2}$ are related. In other words, the order

\footnotetext{
${ }^{10}$ Note that $f\left(w \mid t^{*}\right)=f\left(w \mid G_{W, Z_{1} Z_{2}}^{t^{*}}, G_{Z_{2}}^{t^{*}}\right)=f\left(w \mid G_{W, Z_{1} \mid Z_{2}}^{t^{*}}, G_{Z_{2}}^{t^{*}}\right)=f\left(w \mid G_{W, Z_{2} \mid Z_{1}}^{t^{*}}, G_{Z_{1}}^{t^{*}}\right)$ for $t^{*}=t$ or $t^{*}$.

${ }^{11}$ The Blinder-Oaxaca decomposition of differences in means is unique even if there is dependence between $Z_{1}$ and $Z_{2}$ provided that the data generating mechanism $W\left(Z_{1}, Z_{2}\right)$ is additively separable in $Z_{1}$ and $Z_{2}$. This result only applies to the mean and not to other statistics of $f(w \mid t)$ and $f\left(w \mid t^{\prime}\right)$.
} 
of the decomposition is not arbitrary but reflects structural assumptions about the world. The non-uniqueness of the above decomposition method requires the researcher to take a stand on how $Z_{1}$ and $Z_{2}$ are causally related.

We impose an order on the decomposition that flows from the timing of variables. We start by including race and gender in the prediction model. We then add parental background variables followed by variables capturing individual characteristics such as education and cognitive ability scores. Finally we add variables describing the transition into the work force. This order of the decomposition assumes that the relation between parental background variables and individual characteristics is the same in 1979 and 1997. Thus, changing distributions of parental background will entail changes in the resulting individual education and ability distributions. The decomposition therefore implicitly assumes that the crosssectional relation between family background variables and education and ability in 1979 is causal in the sense that changes in the distribution of parental background result in changes in the individual variables. Similar assumptions are made regarding the relation between parental background, individual education and ability scores on the one hand and the variables describing the speed with which individuals transition into the workforce on the other hand. Clearly these are strong assumptions, but any alternative order of the decomposition imposes similarly strong assumptions. ${ }^{12}$ The advantage of the above method is to make these assumptions explicit.

In addition to the above decomposition method, we also implement a more conventional Blinder-Oaxaca decomposition. Contrary to the above method, the Blinder-Oaxaca decomposition reveals whether a variable contributes significantly to the change in wages because this variable has a strong link with wages or because the variable itself changed a lot between the 1979 and 1997 cohorts. Furthermore, the Blinder-Oaxaca decomposition allows one to examine the effect on the mean of $w$ of shifting the marginal distribution of $Z_{1}$ holding $Z_{2}$ constant. Below we refer to such an effect of $Z_{1}$ as the "partial effect". Such a decomposition might be of interest even if there is a natural causal ordering to $Z_{1}$ and $Z_{2}$, as is the case with race and gender and parental background "causing" HGC, AFQT, and the school to work transition measures. However, unless the feature of $w$ of interest is an additively separable function of $Z_{1}$ and $Z_{2}$, one cannot analyze the effect of a change in the distribution of $Z_{2}$ without specifying the change in the joint distribution of $Z_{1}$ and $Z_{2} \cdot{ }^{13}$ This is true even

\footnotetext{
${ }^{12}$ Belley and Lochner (2007) present evidence that the link between parental background and educational attainment is stronger for the NLSY97 cohort and the NLSY79 cohort.

${ }^{13}$ The Blinder-Oaxaca decomposition applies to the case when the statistic of interest is the mean and $W(Z, u)$ is linear in $Z_{1}, Z_{2}$, and $u$. It then decomposes changes in the mean of $W$ into a change due to a shift in the marginal distribution of $Z_{1}$ that leaves the mean of $Z_{2}$ unchanged as well as the corresponding shift of the marginal distribution of $Z_{2}$ that keeps the mean of $Z_{1}$ fixed. The Blinder-Oaxaca decomposition is unique in the sense that any such shifts in the marginal distributions will deliver the same contribution for $Z_{1}$ and $Z_{2}$ respectively. The Blinder-Oaxaca decomposition is not unique if we consider decomposing the change in $f\left(Z_{1}, Z_{2} \mid t\right)-f\left(Z_{1}, Z_{2} \mid t^{\prime}\right)$ into changes that do not keep the means of the respective variables unchanged. Furthermore, an analog to the Blinder-Oaxaca decomposition does not exist for statistics that are not linear in $Z_{1}, Z_{2}$ and /or if $W(Z, u)$ is not linear.
} 
for the mean of the wage. Furthermore, the conceptual experiment of changing the marginal distribution of parental education without changing the marginal distribution of individual education represents a very different set of economic assumptions than that implicit in the hierarchy of variables that underlies our decompositions based on the re-weighting method. The latter attributes to parental education not just its direct effect on wages, but also the indirect effect that arises because a change in parental education affects individual education. By extension, the hierarchical decomposition attributes to individual education only the change in $w$ that is generated by the changes in the component of individual education that is orthogonal to family background, race, and gender.

We view the sequential decompositions based on the re-weighting method and the Blinder-Oaxaca decompositions as complements. In Section 5.4 we therefore impose additive separability restrictions on the conditional mean function and use multivariate linear regression as the basis for a decomposition of the overall shift in the mean.

\section{DATA}

The above procedure requires comparable skill measures across surveys. The NLSY79 and NLSY97 surveys are designed for the same purpose: to examine the transition of young Americans into the work-place. Consequently, these surveys provide many variables that are comparable across both the 1979 and 1997 cohorts. Nevertheless, the surveys vary sufficiently to pose challenges to achieving comparability. In this section we describe the samples and the variables used in the analysis.

3.1. The Samples. We use survey years 1979-2004 for the NLSY79 and 1997-2005 for the NLSY97, which were the latest available when we created the data sets for this paper. To maximize sample sizes for minority groups we utilize both the cross-sectional samples and the supplemental samples in the NLSY79 and NLSY97 and use the base year weights provided by the Bureau of Labor Statistics (BLS) to achieve representativeness of the population. ${ }^{14} \mathrm{We}$ drop 83 individuals with race/ethnicity code "other" from the NLSY97, since no comparable category exists in NLSY79. The NLSY79 is drawn from the resident US population of 14-21 year olds on Dec 31st 1978, while the NLSY97 samples from the resident population aged 1216. Consequently, the NLSY79 includes immigrants who arrive after age 16 while the NLSY97 does not. We adjust the weights for the NLSY79 to match the scope of the NLSY97, dropping drop 96 individuals from the NLSY79 who first entered the US between age 16 and $21 .{ }^{15}$ We

\footnotetext{
${ }^{14}$ We do not utilize the panel-weights that are designed to account for (conditionally random) attrition but instead estimate our own weights, as discussed below.

${ }^{15}$ These weights effectively drop all immigrants after age 16. Individuals who migrated into the US prior to age 12 are equally weighted. Those who migrated at earlier ages are weighted by the ratio of the probability of being observed in 1997 over that in 1979. This implies weights of 4/5 for those arriving at age 13, 3/5 for age 14, 16/35 for age 15 and $4 / 15$ for age 16.

It is necessary to account for the differences in the scope of both cohorts because age of arrival correlates with skill. Appendix table C displays the variation in various skill measures for the NLSY1979 by age of arrival for the Hispanic population. It also displays the variation in education by age of arrival as observed in Census data (1\% and 5\% IPUMS samples) for those aged 22 in 1980 and 2000 respectively. In the NLSY 1979 we can also show the
} 
also exclude 4 individuals born before 1957 or after 1964 from the NLSY79. When we refer to the BLS base year weights in the text and tables below, we mean the adjusted weights.

We exclude the economically disadvantage non-black/non-Hispanic supplemental sample and the military supplemental sample from the analysis of NLSY79. The non-black/nonHispanic oversample and most of the military sample were discontinued in 1990 and 1984 respectively, and so do not provide labor market outcomes in the age range that we use. In the NLSY79 there are 3,650 people in the supplemental sample of blacks and non-Hispanics and 6,111 in the cross-section. In NLSY97 the supplemental and cross-section samples contain 2,236 and 6,712 respondents respectively. ${ }^{16}$

In both surveys we construct our skill measures in a similar manner using the waves up to the survey year when these individuals were 22. We retain the observation that is closest to 22 years and 6 month old and then measure variables such as highest grade completed and early work experience by reference to this observation. ${ }^{17}$ While all base year respondents of the NLSY79 cohort have reached age 22, only cohorts 1980-1983 and a few respondents from cohort 1984 had turned 22 by the 2005 survey. We have a sample of 9,661 respondents for the NLSY79 cohorts and 7,148 respondents for the NLSY97 who should have been observed at age 22 .

3.2. Representativeness of the Base Year Samples. In this section we discuss whether the NLSY97 base year sample is representative and then turn to the problems of attrition and of non-response to the AFQT in Section 3.3.

MaCurdy and Vytlacil (2003) have raised concerns about the representativeness of NLSY97. In particular, they show that the screening procedures for the NLSY97 found less than two-thirds of the young adults one would have expected to be present based on the 1997 Current Population Survey (CPS). This shortfall in respondents occurred precisely in

average log wage during adulthood by age of arrival. Clearly, observable skills of those arriving at older ages are much lower than those arriving at younger ages. Especially for those arriving after age 10 there is a substantial decline in skills. This might be true because of differential selection for those arriving at different ages, because those arriving at younger ages start investing at higher rates when faced with the US education system, and because of the effect of age of arrival on facility to learn English (see Chin and Bleakley (2004)). The Census data show that the gap by age of arrival tends to be smaller in the 2000 than in 1980 . This is possibly due to increasing education levels in the sending countries.

${ }^{16}$ In constructing weights we account for excluding the non-black/non-Hispanic sample by using the crosssection weights for whites and the weights for the combined cross-section and supplemental sample of blacks and Hispanics. Excluding the military does lead to a difference with the population represented by NLSY97, which was too young to be in the military when the sample was constructed but may have entered between the ages of 17 and 21 and thus would have been in scope for the NLSY79 military supplement. According the NLSY documentation, 51 persons who might have been included as part of a representative of youth, including the military were continued, as were an additional 150 observations. In principle, we could include these observations and construct base year weights that make the sample representative of the non- institutionalized youth population aged 14-22 in 1979, including the military. Since the military is a very small fraction of the total, we doubt this would make much difference.

${ }^{17}$ The interviews of a given individual are not exactly one year apart. Consequently, some individuals respond twice at age 22 and some do not respond at age 22 but instead are surveyed twice at age 21 or twice at age 23. We retain the observation that is closest to 22 years and 6 month old and then measure variables such as highest grade completed and early work experience as of this age $=22$ observation. 
the age range that the screener interviews sought to identify (12-23), whereas in other ages the expected number of respondents was found. Apparently, families were "hiding" children in the 12-23 age range, perhaps to avoid participating in the survey. MaCurdy and Vytlacil analyze ETP97, a related sample of 18-23 year olds from the same screening interviews, and find that those responding to the ETP97 are more educated than comparable CPS respondents. They also have more educated mothers. ${ }^{18}$ Moore et al's (2000) technical sampling report on NLSY97 also concludes that many parents failed to report children in the NLSY97 age range. They also discuss the substantial shortfall in the completion rate for the ASVAB, which was about $20 \%$ in NLSY97 but only $6 \%$ in NLSY79. However they conclude that the distribution of respondents in the screening interviews and the CPS is similar in the dimensions of youth education, parental income and parental education.

We do not fully understand the sources of the differences between the two studies. One difference may arise from the fact that, in the CPS, mother's education is only available for 18-23 year olds who are still living with their mothers. These youths may not be representative of 18-23 year-olds as a whole. In this case, McCurdy and Vytlacil's comparison of ETP97 to the CPS may not be directly relevant for the NLSY97 sample of 12-16 year olds.

We proceed under the assumption that the available data, after use of survey weights and adjustments for attrition prior to age 22 and for missing data on AFQT, are representative of the 1997 and 1979 populations, with the obvious caveat that our results will be affected if they are not.

3.3. Attrition and Missing Data on the AFQT. Table 3.0 summarizes the retention patterns for our sample in the NLSY97 and NLSY79. There are 9,661 $(7,148)$ individuals in the NLSY79 (NLSY97) who should have been observed at age 22 and thus fall within the scope of our study. As mentioned above this excludes the oversampled white males and females and the military sample as well as those who migrated to the US after age 16.

A total of $9,228(6,085)$ respondents within the scope of our study were actually observed at age 22. A negligible 27 (71) are lost due to missing information on highest grade completed. This leaves 9,201 (6,014) observations. Non-participation in the ASVAB eliminates an additional $379(1,132)$ respondents. We retain a total of 8,822 NLSY79 respondents and 4,882 NLSY97 respondents, which constitute $91.32 \%$ of the total eligible sample in the NLSY79 but only $68.30 \%$ for the NLSY97. ${ }^{19}$

The NLSY97 has a lower retention rate than the NLSY79 at each step of the construction of our sample. In the case of attrition by age 22 this is partly due to the fact that NLSY97 respondents are first interviewed during age 12-16 whereas those in the NLSY79 are

\footnotetext{
${ }^{18}$ Their comparisons of the PAY80 and PAY97, which are also drawn from the same screening surveys as the NLSY79 and NLSY97 (respectively) show that the fraction of the youths who completed the ASVAB tests and for whom we therefore have an AFQT test score is significantly lower in the PAY97 than in the PAY80. This evidence for PAY80 and PAY97 is consistent with the evidence for NLSY79 and NLSY97 in Table 3.1.

${ }^{19}$ Missing values for other explanatory variables, such as mother's education, are coded as a separate category so that we are able to maintain maximum coverage for our sample.
} 
first interviewed aged 14-21. The respondents in the NLSY97 had more time to attrit. In the NLSY97 we loose the largest share of respondents when we consider the availability of the AFQT score. ${ }^{20}$ If we do not condition on observing the AFQT score, we retain about $85 \%$ of the base sample. As a robustness check, we analyze a number of specifications that do not require the AFQT score on both our main sample (sample 1) and on a sample that includes those with missing AFQT scores (sample 2).

Table 3.1 shows how attriters prior to age 22 and stayers differ by observable characteristics. Several of the characteristics are related to attrition. For instance, race correlates with attrition prior to age 22, especially in the 1997 sample. However, the attrition rates are not always negatively associated with characteristics that are favorable for wages. For example, whites are more likely to leave the sample prior to age 22 than are blacks.

The average characteristics of those who remain in the sample to age 22 are very close to the averages for full population represented by NLSY79, in part because we lose only $9.7 \%$ of the sample. We also find relatively small differences between the full sample and the stayers in the 1997 cohort in spite of the higher 1997 attrition rate. For instance, the differences between the full population and stayers in the means of mother's education and father's education are only -0.05 and -0.03 years respectively. Nevertheless, we adjust for attrition based on observables using weights obtained from a probit model relating attrition to parental education, parental presence at age 14 , indicators by birth-year, urban and SMSA residence status, indicator variables for race and gender, and an interviewer coded variable describing the attitude of the respondent during the interview. For the NLSY97 we also use information on whether the respondent was first interviewed in 1998 rather than 1997. ${ }^{21}$

Non-response to the ASVAB is large enough to potentially result in significant biases, especially in the NLSY97. Table 3.2 has the same structure as Table 3.1 and shows how observable characteristics differ depending on whether they had a valid AFQT score. The numbers reported in Table 3.2 account for attrition by age 22 using the weighting procedure described in the previous paragraph. The differences in the mean characteristics by AFQT availability are not uniformly larger in the NLSY97 than NLSY79, but some of the differences between those with or without an AFQT-score are sizable. The difference in racial composition is particularly striking: whites are substantially overrepresented among those with valid AFQT scores. Furthermore, those who have AFQT scores have higher education levels by age 22 and have better educated parents. Overall, those with AFQT scores are more advantaged in both the NLSY79 and the NLSY97.

Fortunately, the difference in characteristics between those with and without the AFQT dramatically overstates the difference in mean charactistics between those with valid

\footnotetext{
${ }^{20}$ Respondents to the NLSY received financial compensation for participating in the ASVAB. The real value of this compensation was significantly higher in 1979 than in 1997, which probably accounts for part of the drop in participation.

${ }^{21}$ Initially, a number of respondents could not be found in 1997 and a substantial effort was made to locate them. Those found in this manner were interviewed in early 1998 and were substantially more likely to attrite in subsequent waves.
} 
scores and the full sample. For instance, those with valid AFQT scores in 1997 have 0.67 years more education by age 22 than those without valid scores but only 0.11 years more education than the full population. We judge these differences to be sizeable, but not forbidding.

We address the problem of attrition and non-response to the AFQT by constructing two alternative sets of weights. The first adjusts only for attrition by age 22 and is used with "sample 2", which does not condition on availability of an AFQT scores. The second set adjusts for both attrition and missing AFQT responses and is used with our main sample, "sample 1". Sample 1 is the subset of sample 2 for whom we have valid AFQT scores. Both sets of weights are estimated using probit specifications based on race, sex, parental presence at age 14, parental education, birth-year indicators, urban and SMSA residence status as well as variables describing the attitude towards the interview. In 1997 we also account for the initial interview to take place in 1998 rather than 1997. We estimate these attrition models for the NLSY79 and the NLSY97 separately and apply the weights throughout the analysis as applicable. $^{22}$

It is reassuring that our results for the models outlined in Section 4 that do not require an AFQT score (4.1,4.2, and 4.4) are not sensitive to excluding individuals with missing data on the AFQT score. ${ }^{23}$ However, our attrition and AFQT non-response weights do not correct for possible correlation between attrition and unobservables that affect wages or employment conditional on the observable skill indicators in the model.

A final problem arises because 1,383 out of the 9,228 NLSY79 sample members who respond at age 22 do not respond at any time between 1998 and 2004. We use these individuals to estimate the propensity weights, but we cannot use them for generating the counterfactual wage distributions. The results presented below assume that attrition from NLSY79 after age 22 is random. We choose not to construct an additional weight to adjust for this because attrition after age 22 in the NLY79 affects both the actual wage distribution and the counterfactual one. Consequently, it probably has only a second order affect on the difference between the two, which is our main interest.

3.4. Wages. Our main metric to measure skills are wages of the NLSY79 cohort in the years 1998-2004. This period spans 4 survey years, since the NLSY79 moved to a biannual format in 1994. We use a regression specification to standardize log real wages between 1998-2004 to the year 2002 and 23 years of potential experience. ${ }^{24}$ For each individual we have between 1 and 4 wage observations. We weight each wage observation by the reciprocal of the number of wage observations for an individual. Each individual with at least one valid wage observation receives equal weight in generating the counterfactual wage distributions. This implies that

\footnotetext{
${ }^{22}$ Since the results in table 3.2 are generated using the attrition weights, they display the attrition corrected differences across those with and without the AFQT-score among those who do not attrite by age 22.

${ }^{23}$ We cannot perform a similar check for specifications that do make use of the AFQT-score.

${ }^{24}$ For this purpose we estimate a log wage equation separately for high school drop-outs, high school graduates and individuals with more than a high school degree. We include a quartic in experience and year-effects.
} 
our wage statistics reflect the wage distribution of the population "while working". ${ }^{25}$ There is no need to re-weight the statistics for employment rates, because employment status is observed for each valid interview.

\subsection{Comparability of the Paper and Pencil (P\&P) and Computer Assisted Test (CAT) of} the ASVAB. Our measure of cognitive ability, the AFQT-score, is a composite score derived from the ASVAB. For the NLSY79 the test was administered in 1981 when respondents were between 16-21 years old, whereas for the NLSY97 the test was administered at the beginning, when individuals were between 12-16 years old. We exploit the overlap in the test-taking age across both cohorts by applying a equipercentile procedure on each cohort with the population of test takers who were 16 year olds when taking the test.

We must also account for the fact that the test-format differed between surveys. The NLSY79 cohort was administered a pencil and paper (P\&P) version of the ASVAB while the NLSY97 took a computer assisted test (CAT) format. To achieve comparability between the two test formats we rely on a mapping between the P\&P and the CAT test format. ${ }^{26}$

In Appendix B, we present evidence on the comparability of the equated, age-adjusted test scores. Within each survey, we regress the test-scores on a set of personal characteristics measured at age 22 as well as the interactions of these characteristics with the age at which the ASVAB was taken. We find that the relation between AFQT scores and race, parental education, and individual education at age 22 is the same across test taking ages. (See Appendix B Table B 2). This is true in both surveys. By matching percentiles across ages we implicitly assume that the AFQT-score is not informative about skills of an individual during adulthood once we condition on the the rank of an individual within his/her age group. Consequently, test-taking age should not be informative about individual characteristics holding the rank of the individual in the age specific test score distribution constant. The finding that the coefficients of the regression of age-adjusted test scores on individual characteristics do not vary with testtaking age supports this assumption. Appendix B says little about the quality of the mapping from the P\&P to the CAT version of the test, which is considered in Segall (1997).

3.6. School to Work Transition Variables. We construct the vector $S C H \_W O R K$ of variables that measure whether an individual's schooling career was continuous and whether the individual had a smooth transition into the working population. We define workuniv to be 1 if an individual has not attended school for at least 2 years prior to age 22 and 0 otherwise.

\footnotetext{
${ }^{25}$ If we did not weigh person/year observations in this manner, then the statistics would be representative of those who are working at a point in time. Consequently, they would give more weight to those for whom we observed a valid wage more frequently. We do not use time averages for each individual because in the presence of transitory wage variation, the distribution of the time averages depends on the distribution of the number of observations per person.

${ }^{26}$ The mapping was constructed using test results from a sample of individuals who were randomly assigned to take either P\&P or the CAT test. (See Segall 1997) The mapping assigns scores to equalizes percentiles on the various subtests of the P\&P and the CAT. By definition this amounts to transforming the P\&P subtest scores with a monotone function that matches the distributions of the CAT scores. We thank Daniel Segall for providing us with the P\&P equivalents of the CAT scores for the NLSY97 sample.
} 
The variables early, ontime, and late are indicator variables generated by comparing school leaving age for these individuals with age+6+highest grade completed. The variable work indicates whether individuals have worked for at least 14 weeks in one of the first two years after leaving school. The four $S C H \_W O R K$ variables are set to 0 for individuals who attended school at least once between ages 20-22 (workuniv $=0$ ).

3.7. Summary Statistics. Table 3.3 presents summary statistics for the key variables used in this study. Details of the construction of these variables are in the data appendix. These statistics are supposed to describe the population in 1979 and 1997 and are therefore computed using the NLSY cross-sectional weights adjusted for attrition by age 22 and AFQT non-response.

Most characteristics show improvement between NLSY79 and NLSY97. The mean of AFQT rises from 42.35 to $44.19^{27}$ and highest grade completed as of age 22 increases from 12.64 to 13.02. Average education of both mothers and fathers increased substantially over this time-period. For example, mother's education rose from 11.77 to 12.71 - an increase of about 12 months. While there are gains in most skill characteristics across cohorts the dramatic decline in the percentage of children who grow up in traditional family settings is an important exception. The percentage of individuals living with both biological parents at age 14 drops from $75.23 \%$ in 1979 to only about $52.98 \%$ in 1997 . This decline is mostly accounted for by an increase in the number of children growing up without their biological father. By $1997,35.66 \%$ of children are not living with their biological father. We were sufficiently surprised by the magnitude of the fraction of individuals living outside of traditional family structures that we have confirmed this result using Census data. Appendix C compares the measures of family structure available in the NLSY with those available in the Census data.

Panel B of the table 3.3 summarizes the main characteristics separately for whites, blacks, and Hispanics. The changes for the subgroups generally parallel those for the sample as a whole. However, the size of the increase in AFQT scores is substantially larger for blacks and Hispanics than for whites. Hispanics also gain substantially along the schooling dimension in both absolute terms and in comparison to whites. By contrast, blacks have not gained relative to whites along this dimension. While whites in the 1997 cohort completed about $1 / 2$ of a year more than the 1979 cohort, blacks only gained about $1 / 4$ th of a year along this dimension. All races have substantially more educated parents in 1997, reflecting secular gains in education over the last 50 years. These gains have been larger for minorities, which is reflected in the larger observed increases in parental education of blacks and Hispanics relative to whites.

\footnotetext{
${ }^{27}$ Large secular increases in IQ scores have been demonstrated in all countries for which data on IQ scores is available over time. This "Flynn"-effect (see Flynn (2000)) is so large as to cast doubt on the comparability of IQ scores over time. The AFQT-test is strictly speaking not an IQ test and it is not clear whether it is subject to the same concern. The increase in AFQT-scores between the 79 and 97 cohorts of about 1/10th of a standard deviation does not strike us as implausible a priori. Nevertheless, caution is necessary when comparing ability test scores across temporal and cultural distances.
} 
The decline of the traditional family structure is dramatic for whites and blacks and large for Hispanics as well. Across the two cohorts, the percentage of youths living with both biological parents at age 14 declines by $21.99 \%$-points for whites, $24.87 \%$-points for blacks and 9.49\%-points for Hispanics. Among the 1979 cohort, only a slim majority (50.21\%) of black youths lives with both parents. Continued decline results in the striking fact that only about 1 in 4 black youths in the 1997 cohort grew up in a household with both biological parents present. The decline of traditional family structures has been slower among Hispanics and the 1997 distributions of white and Hispanic youths across family types are comparable.

Panel C reports results by race and gender. These results show that females gained relative to males in all groups. In 1979 white males and females are about equal in average education and AFQT scores. Both groups show improvement, but by 1997 white females exceed males in both of these skill dimensions and have an education advantage of one half year. Hispanic females and black females gain relative to their males counterparts, particularly black females, had very large gains in AFQT scores (8.45 points) and also gained about 0.45 years in highest grade completed. Black males gained 5.6 points on the AFQT but only 0.17 years of education. Black males also had the smallest increase in the enrollment rate at age 22 .

In both cohorts, blacks and Hispanics are disadvantaged relative to whites. The gaps decreased along some but not all skill dimensions between 1979 and 1997. For example, AFQT scores rose on average by 1.48 points for white, 5.6 for black, and 4.88 for Hispanic males. However, the share of individuals who make a seamless transition between schooling and work rose faster for white males than for their black and Hispanic counterparts. On the other hand, white females stagnated along this dimension, while black and Hispanic females experienced substantial gains.

Table 3.4 looks at education in more detail. The results show increases in education for most measures across all race and demographic groups. By 1997 Hispanic females close the gap with blacks and Hispanic males surpass black males. Increases in schooling are not uniform across the distribution of schooling. Rather, we observe that among whites and blacks the share of individuals with HS diplomas stayed roughly constant, while the fraction of those with more than 14 years of education by age 22 increased substantially for all subgroups. This and the share of individuals still enrolled at age 22 implies that the conditional probability of continuing with school once a high school diploma has been obtained increases substantially across the two cohorts. The education statistics presented in Table 3.4 suggest that at the top of the education distribution there has been a significant response to the increases in the returns to education observed throughout the 1980s and 1990s. At the same time however there is a persistent fraction of the population that still does not acquire a high school degree. Our results for the two cohorts are broadly consistent with those of Heckman and Lafontaine (2007). They show using multiple data sources that high school graduation rates have stagnated over the last 20 years, while we show a small increase for the specific 
years of NLSY79 and 97. Both studies show an increase in college attendance conditional on high school graduation for the birth cohorts covered by NLSY79 and NLSY97.

\section{Estimation OF PROPENSITY SCORES}

We now turn to the estimation of the propensity score conditional on our available skill measures. Equation (2.3) shows the relation of the propensity weights to the estimated propensity scores. We estimate the propensity score using Probits based on various sets of skill measures. We use flexible functional forms for the latent index of the Probit model so as not to restrict the changes in the skill distributions across cohorts unduly.

We consider various specifications for the skill vector $Z$. We organize the variables used to estimate the propensity score into a hierarchical structure according to the degree of predetermination. Our most basic skill vector consists of variables that are outside the individual's control: race and gender (Model 4.1). We then sequentially add additional variables related to individuals skills. Each set of additional variables is fully interacted with race and gender. In Model 4.2 we add parental education and the indicators for presence of mother and father at age 14 (parents) as measures that influence skill development and economic decision-making across generations, but are predetermined relative to the skill characteristics that refer to the individual herself. Since changing social norms regarding childbearing out of wedlock may alter the relationship between the parental presence indicators and unobserved characteristics of family background, we experiment with excluding the parental presence indicators. In Model 4.3 we add a quadratic in the AFQT score. If cognitive skills are fully determined by inherited factors, environmental factors and primary schooling and are not amenable to individual investments after the early teens, then this variable will be predetermined relative to variables referring to educational attainment and the transition to work. In Model 4.5 we add education, as measured by a vector of dummy variables for highest grade completed at age 22 (HGC) as well as indicator variables for whether individuals are enrolled at age 22. To the extent that cognitive tests scores are influenced by high school and college education, as suggested by a number of studies, one might want to reverse the order of AFQT and education. ${ }^{28}$ Model 4.4 drops the AFQT terms and keeps the education terms. For the most part, our results are robust to switching the order or including AFQT and schooling at the same time. Our full model (4.6), adds the components of the vector $S C H \_W O R K$ to Model 4.5. We conjecture that spending time neither at work nor at school is a negative indicator for future employment and wage rates.

Equation (4.1) below presents the exact specification of the latent index for Model 4.6, which nests the other models. Denote the latent index determining whether an individual is observed in the NLSY97 rather than the NLSY79 as $\theta_{i}$. The first line contains race and gender (Model 4.1). The second line adds the variables $M H G C e, i$ and $F H G C e, i$, which are dummy variables for highest grade completed $e$. Missing data on parental education are treated as a

${ }^{28}$ See Neal and Johnson (1996), Korenman and Winship (2000), Hansen, Heckman, and Mullen (2004), and Cascio and Lewis (2006). 
category and observations with missing parental education are included in the analysis. The third line adds family structure indicators. Lines 1, 2 and 3 constitute Model 4.2. Line 4 adds interactions of a quadratic in the AFQT with race and sex (Model 4.3). Line 5 adds the HGC and enroll (Model 4.5). To obtain Model 4.6, we add lines 6 and 7, which contain the variables describing the transition from schooling to work.

$$
\begin{aligned}
& \theta_{i}=\sum_{s, r} \operatorname{Sex}_{s, i} \operatorname{Race}_{r, i} \beta_{s, r} \\
& +\sum_{s, r} \operatorname{Sex}_{s, i} \operatorname{Race}_{r, i}\left(\sum_{e} F H G C_{e, i} \beta_{f e, s, r}+M H G C_{e, i} \beta_{m e, s, r}\right) \\
& \left.+\sum_{s, r} \operatorname{Sex} x_{s, i} \operatorname{Race}_{r, i}\left(\operatorname{Mom} \mathbf{D}_{\text {only }} \beta_{m o, s, r}+\text { Dad_only } \beta_{f o, s, r}+\text { Mom_Dad }\right) \beta_{f m, s, r}\right) \\
& +\sum_{s, r} \operatorname{Sex}_{s, i} \operatorname{Race}_{r, i}\left(a f q t_{i} \beta_{1 a f q t, s, r}+a f q t^{2} \beta_{2 a f q t, s, r}\right) \\
& +\sum_{s, r} \operatorname{Sex}_{s, i} \operatorname{Race}_{r, i}\left(H G C_{i} \beta_{h g c, s, r}+\operatorname{enroll}_{i} \beta_{e n r, s, r}\right) \\
& + \text { workuniv }_{i} * \sum_{s, r} \operatorname{Sex}_{s, i} \text { Race }_{r, i}\left(\text { early }_{i} \beta_{\text {ear }, s, r}+\text { ontime }_{i} \beta_{o t, s},\right. \\
& + \text { workuniv }_{i} * \sum_{s, r} \operatorname{Sex}_{s, i} \operatorname{Race}_{r, i}\left(\text { late }_{i} \beta_{l t, s, r}+\text { work }_{i} \beta_{w, s, r}\right) \\
& +\epsilon_{i}
\end{aligned}
$$

The error $\varepsilon_{i}$ in the latent index function is assumed to be normal. We estimate the models by MLE-Probit after pooling the data from both samples. The base year sample weights provided by the NLSY for both surveys are used in the estimation. As noted earlier, we adjusted these weights by the age of immigration for individuals not born in the US to account for the differences in scope between NLSY79 and NLSY97. The base year sample weights are adjusted for attrition by age 22 based on observable characteristics in both cohorts for specifications estimated on sample 2, which includes all individuals observed at age 22. All specifications estimated on sample 1, which in addition excludes individuals without valid AFQT scores, are estimated with weights adjusting for both attrition by age 22 and AFQT non-response using the same variables. These sample and attrition weights are omitted from the presentation to keep the notation simpler.

We have explored even more flexible functional forms for the propensity models than Model 4.6. We are concerned that as we allow for more flexible functional forms we obtain some extreme values for the propensity weights. This is especially true for the minority groups since all specifications are fully interacted by race and gender. Table 4.1 shows the distribution of the propensity weights obtained for various models. By construction the propensity weights average to 1. Consider Model 4.6. The 1st percentile value of the weight is essentially 0 , whereas the 99 th percentile in the wage distribution has a weight of about 
7. This indicates that the combination of characteristics associated with the 99th percentile in the weight distribution is about 7 times as likely in the 1997 as compared to the 1979 cohort. If we go even further into the tail, then we observe some extreme weights. One individual, (a black female with 16 years of education and an AFQT score of 87 who was enrolled in school at age 22 and did not live with either biological parent at 14) has a propensity weight of 88 . There are 37 individuals with weights above 10 and 8 with weights above 20. These high propensity weights are disproportionally found among Hispanics. ${ }^{29}$ It seems that much of this is generated by the quadratic interaction in the AFQT-score with race and gender, leading to extreme propensity weights for individuals in parts of the support of the AFQT that is thinly populated by other members of their race and gender. To limit the influence of observations with extreme weights, we cap the propensity weights at 10 . If we do not cap the weights, then we do get some estimates of the tails of the counterfactual wage distributions that are implausible, are highly sensitive to variations in the model specification and have very large bootstrapped standard errors. Capping the highest propensity weights tends to lower the estimates of gains at the very top of the minority distributions. Once we cap, our results are typically not sensitive to varying the model specifications, the value of the cap or the weighting procedures to account for attrition and non-response.

\section{Changes IN The SKILl Distribution BetWeEn NLSY79 AND NLSY97}

In this section we present the overall changes in the skill distribution across cohorts using labor market outcomes in middle ages measured using the methodology and data presented in Section 2-4.

5.1. Overall increase in skills. The first result to note is that the 1997 cohort is more skilled than is the 1979. Table 5.1 and 5.2 show how employment and log wages are predicted to change due to the variation in skill endowments across the two cohorts. Columns 1 and 2 present the results for the observed outcomes in the 1979 cohorts. The remaining columns present the difference between counterfactual statistics and the actual 1979 values. In column 3 we match on the full set of variables including parental education, parental presence, schooling, the AFQT, work transition, and race and gender. Columns 4 and 5 refer to the specification without the work transition variables and without the AFQT score on sample 1 and 2 separately. Column 6 omits the work transition variables from the full specification. We show bootstrapped standard errors in parentheses. ${ }^{30}$ Generally results are quite robust across specifications.

\footnotetext{
${ }^{29} 7$ out of 8 with a weight larger than 20 and 23 out of 37 with a weight greater than 10 are Hispanics.

${ }^{30}$ We choose bootstrap samples by selecting individuals with replacement from subsamples stratified by race and ethnicity and gender so as to preserve the basic demographic composition of the samples. Each replication sample consists of a bootstrap sample stratified along sex and race from the NLSY 79 and NLSY 97. We then applied all of our procedures including the estimation of weights for attrition and AFQT-nonresponse to the replication sample. We repeated this process 300 times.
} 
Using the metric of employment rates we find little difference across cohorts. For men and women combined, the shift in skill components would lead to a decrease in the employment rate of about 0.001 when we use the full set of skill indicators (model 4.6, bottom row, col. 3). This is the net result of an increase of 0.005 for males and a decrease of 0.007 for women. We find more substantial increases for black men and for Hispanic men and women, particularly when we use the full set of skill indicators. For example, the shift in skill components for black men implies an increase in employment from 84.9 to 87 . The employment results by race and gender are somewhat sensitive to the specification, but the findings for the full population and for males and females separately are robust to the choice of specification.

Using the metric of wages we find that the 1997 cohort is stronger than the 1979 cohort. The bottom row of table 5.2 shows that on average skills increased between 1979 and 1997 by about 6-7\%, regardless of whether we consider the full model (column 3), exclude the AFQT and work transition variables from the model (column 4) or include persons with missing AFQT scores (column 5).

5.2. The Effects of Skill Shifts over the Wage Distribution. Table 5.2 and Figure 1 show the shift in skills across the wage distribution. ${ }^{31}$ The shift implies a wage increase of only about $5 \%$ below the 10 th percentile. Between the 20th and 85 th percentile there is a large region with gains of about $5-6 \%$ while gains are in the $10 \%$ range in the top decile. The increase at the top of the distribution and the smaller increase at the bottom imply a widening in the skill distribution. This will, all else equal, result in increased economic inequality over the next decades.

Figure 1 also shows the gains across the log wage distribution for various specifications. One can see that the changing racial composition of the work-force generates only a small, fairly uniform, predicted decline in our skill metric. Adding parental education and presence indicators (model 4.2) implies a shift in the log wage of about $5 \%$ over most of its distribution. The additional gain of adding all other components (model 4.6) is typically between 1 to 2 percent. The results with only AFQT and HGC (model 4.5) are similar to the results with AFQT, HGC, and the school to work transition variables (model 4.6). Thus, we find an increase of about 7 percent in skills between the 1979 and 1997 cohorts, about 5 percent of which is associated with shifts in parent background. It is important to remember that the shift attributed to parental background includes the effects of induced changes in schooling and AFQT scores under the assumption that the conditional distribution of schooling and AFQT constant. Nevertheless, the results here indicate that more than two thirds of the shift in skills between 1979 and 1997 is linked to parental education. Another way of putting this

\footnotetext{
${ }^{31}$ We present results from the 5 th to the 95 th percentiles. Results from the tails are consistent with our findings here, but noisy. Figure A-1 in Appendix A displays the observed and counterfactual pdf of log wages. The counterfactual is generated using the full skill specification (model 4.6). Note that the bulge on the left tail comes from the fact the wages are bound below at \$3 in 2003 values. The regression adjustment for experience and year "spreads" the censored values a little rather than leaving them as a mass point.
} 
is that conditional on parental education and family structure, other skill measures have only gained by small amounts.

We discuss the contributions of the various skill components in more detail in section 6.

5.3. Race and Gender Gaps. Overall we find a modest widening in the skill distribution for the recent generation. At the same time we find gains in skill endowments for various groups that were significantly disadvantaged in the 1979 cohort.

The two panels of figure 2 present the expected changes in the log wage distribution conditional on race and gender along with 1.65 standard error bands. The counterfactual distribution is obtained by reweighing to match the changing distributions of all our skill measures (parental education, parental presence, schooling, AFQT, and work transition). The $\mathrm{y}$-axis within each panel is forced to be the same scale and thus results across race can easily be compared. Across gender the scale differs, however.

For males we find that blacks and Hispanics gain significantly relative to whites over most of the wage distribution. Only at the very top are gains of white males similar to those of their black and Hispanic counterparts. The shift in characteristics implies a reduction in the mean log wage gap between white and black men from $32.2 \%$ to $28.2 \%$ and a reduction at the 90 th percentiles for the two groups from $36.7 \%$ to $32.4 \%$. Only above the 90 th percentile does the gap fail to narrow, as indicated by Figure 2, panel 1. The corresponding reductions in the gap between white and Hispanic men are from $18.2 \%$ to $14.3 \%$ at the mean and from $18.94 \%$ to $15.6 \%$ at the 90 th percentile The results in the upper tail are somewhat sensitive to the specification of the propensity weight model.

We find significant widening in skills within both the black and Hispanic male population. And, as already described, on average the skills of black and Hispanic males increase relative to whites. Based on these findings we expect a significant proportion of the black and especially Hispanic populations to enter the middle class. In the NLSY79 a black male at the 75th percentile of the black male wage distribution is at the 47 th percentile of the overall distribution of males. A Hispanic male at the 75th percentile of the Hispanic male distribution is at the 67 th percentile of the overall distribution. The counterfactual wage distributions using the full set of characteristics imply that in 1997 a black male at the 75th percentile would lie at the 60th percentile of the counterfactual distribution for all males and that a Hispanic male at the 75th percentile would find himself at the 72nd percentile.

Figure 2.2 suggests that the wage gains of females are likely to exceed gains among males. Again, Hispanics show the most dramatic gains. Over the entire distribution females are expected to gain between 10 and 20\%. Black females likewise are expected to gain over the entire distribution, with gains greater than $10 \%$ for about two-thirds of the distribution. Gains for white women are small near the bottom of the distribution but increase along the entire distribution. Above the 80th percentile the gains exceed 10 percent. The results imply that changes in skill components will reduce the average gap in the wages of men and women 
from $27.82 \%$ to $26 \%$. The male/female gap in the 10 th, 50 th, and 90 th quantiles will decline by $1.5 \%, 4.2 \%$, and $1.3 \%$ respectively. The narrowing gender gap reflects a larger increase for women than men in education and a somewhat larger increase in AFQT.

Overall we find that if the conditional distribution of adult wages for the 1997 cohort turns out to be similar to that of the 1979 cohort, then an increase in the skill endowments of blacks and Hispanics relative to whites and of women relative to men will contribute to a decline in economic inequality across groups as the 1997 cohort enters its prime. However, substantial group differences in wages will persist unless wage gaps conditional on skill characteristics decline. We also find that the changing distribution of skills will lead to more inequality within demographic subpopulations.

\section{IDENTIFYING THE CONTRIBUtion OF SUbSETS OF VARIABLES TO DiFFERENCES BETWEeN}

\section{THE 1979 AND 1997 WAGE DiSTRIBUTIONS}

In this section, we examine in more detail how much the different skill components contribute to the overall changes in skills between 1979 and $1997 .{ }^{32}$ First, we present decompositions based on sequential applications of (2.6) and report the marginal effects of each additional group of variables. Then we impose additive separability restrictions and use multivariate multivariate regression to report both marginal effects as additional variables are added and the partial effects of each group with all variables in model 4.6 included.

Table 6.1 breaks up the difference between the actual wage distribution for 1979 and the counterfactual distribution obtained as we sequentially add variables to the skill vector $Z$.

The first column shows the actual distribution of NLSY79 wages and is the same as Table 5.2, column 1. The second column shows the marginal effect of the shift in the race and gender on the mean and various percentiles of the wage distribution. As we have already noted, these shifts have a small negative effect. One should keep in mind that the marginal effect in column 2 is the sum of the direct effect of race and sex on wages and the indirect effect that arises because race and sex are associated with other characteristics, such as AFQT and parental education. Column 3 reports the marginal effect of adding parental education and presence indicators. (The combined effect of race and sex and the parent variables may be calculated by summing columns 2 and 3.) The parent variables are quite important. They imply an increase in the mean wage of about $.055 \log$ points. Column 4 reports the marginal effect of adding AFQT. The marginal shift in the AFQT distribution implies only a small additional increase of 0.002 across the entire distribution. In column 5 we add HGC. Adding schooling has a fairly sizable effect of $0.02 \mathrm{log}$ points at the mean and 0.002, 0.024, and 0.02 at the 10th, 50th, and 90th quantiles respectively. In column 6 we add the school to work transition variables. These variables have a small negative marginal effect on the counterfactual wage distribution. This indicates that given the observed changes in other skill characteristics

${ }^{32}$ All calculations in this section are based upon Sample 1. 
we would have expected larger gains in the work transition variable than we actually observe in the 1997 data. $^{33}$

Tables 6.2A and 6.2B break down the marginal effects for each race/sex group. The results show much larger effects of parental background for Hispanics than for whites and blacks, as we discuss in more detail below.

As we discussed in Section 2.2, the marginal effects of particular variables depend on the order in which they are introduced. There is a reasonable case for introducing race and sex followed by parental background before adding AFQT or education outcomes. But the AFQT and school outcomes are jointly determined, so it is far from obvious that causal priority should be given to AFQT. In column (7) and (8) of table 6.1 we switch the order in which we introduce AFQT and HGC. Reversing the order does not change the finding that the change in schooling has a relatively large marginal effect on the wage distribution while adding the AFQT has only a small marginal effect. Indeed, from Table 6.1, column 8 we can see that once schooling has been accounted for, the marginal effect of the AFQT is negative at the mean. This pattern holds white males, white females, and Hispanic males. On the other hand, for black males the improvement in AFQT seems to be as or more important than the increase in HGC. For black and Hispanic females the joint increase in schooling and AFQT is important, but we cannot determine the relative contribution, as it depends on the order of inclusion in the propensity model.

6.1. Regression decompositions. In this section we provide regression decompositions of the mean and compare them to the results obtained from the DFL decompositions. These comparisons give insights into the role of non-linearity and dependencies among the variables in generating the overall shift in wages. We find that non-linearities in the wage function, which include non-linear effects of particular variables and non-separability among the variables are only moderately important. In contrast, dependencies between skill variables have large impacts on how the changes in skills are decomposed among variables. In particular, the parental education has not only a large direct impact on the change in mean log wages, but also a large indirect impact through other variables.

Traditional regression decompositions report partial effects of shifts in the mean of particular variables holding the mean of all other variables constant. As we have already noted in section 2.2, the partial effects are well defined only if the regression model is additively separable. It is also possible to estimates marginal effects for regression decompositions, which account for dependencies among the variables in a manner analogous to the DFL

\footnotetext{
${ }^{33}$ Appendix Figure A-2 provides a different take on the shifts in various skill indicators. Each data-point in the figure refers to individuals in a percentile of the log wage distribution in 1979. The vertical axis displays the weight of these individuals in the sample after reweighing the 1979 data to match the 1997 distribution. We smooth the information in figure A-2 using a non-parametric kernel regression. The figure shows that matching the 1979 cohort to the 1997 distribution of parental education and parental presence means increasing the weights for those in the top half of the distribution at the expense of those in the bottom part. Accounting for schooling and AFQT scores leads to a further increase in the weights on NLSY79 cohort members who had characteristics that place them in the upper range of the wage distribution.
} 
decompositions. In order to account for dependencies in the regression decompositions we impose the sequential order of (2.6). Based on this order, we estimate auxiliary linear projections of lower order variables on higher order variables. We then attribute to a higher order variable both its direct effect on log wages as well as the contribution that arises because of the implied shift in the mean of the lower order variables.

We therefore estimate three different effects of a variable on the means: the marginal effect from the DFL decomposition, the marginal effect from the regression decomposition and the partial effect from the regression decomposition. Pairwise comparisons of these effects provide different insights into the changes in the skill distributions that took place between 1979 and 1997. Comparing the marginal effects of the DFL and the regression decomposition informs us about the role of non-linearities in the wage function. Comparing the partial effect and the marginal effect of the regression decompositions informs us about the role of dependencies between variables.

Table 6.2 reproduces the three effects for the full population. The OLS coefficients on race, sex, father's education, mother's education, HGC, AFQT, and the school to work transition dummies are in column 1 . For ease of interpretation, the education variables and AFQT enter in linear form. The second column reports the difference between the 1997 and 1979 cohorts in the means of each of the characteristics. The third column reports the implied partial effect of shifts in variables in each grouping. It is based on the coefficients in column 1 and the mean shifts in column 2. The fourth column reports the marginal effect of each additional variable, which is the sum of the partial effect in column 3 and the indirect effect of the variable on the means of the variables in the subsequent rows of the table weighted by the multiple regressions coefficients from column 1. In column 5 we display the corresponding DFL estimates of the marginal effects, some of which are also reported at the bottom of Table 6.1 .

For the full population, the marginal effects from the regression decomposition do differ from those obtained from the DFL procedure. This difference is observed for both individual variables and for the joint contribution of all variables and indicates that nonlinearity and non-separability in the wage function does play a role. Overall, the regression decomposition implies a mean log wage increase of 0.04 , which is somewhat smaller than the estimate of 0.058 that we obtain using the DFL approach. For individual variables, we find some modest differences between the marginal effects from the regression decomposition in column 4 of table 6.1 and the marginal effects from the DFL procedure that are found in column 5 . Nonlinearities among the various skill components clearly matter, and it is not sufficient to simply decompose the means with a simple additively separable linear regression to get an accurate description of the variation in skills between 1979 and 1997.

Comparing the partial and marginal effects in columns 3 and 4 indicates the important role of dependence among variables in determining how much a variable contributes to the overall increase in skills. This is particularly true for parental education and family structure. The partial effect of the increase in parental education is 0.019 . On the other hand, the 
shift away from 2 parent families implies a reduction of 0.008 . This reflects the coefficients of -0.032 on "neither mother nor father" and -0.044 on "mother only". Combining the estimates implies that the partial effect of the shift in parental background is 0.011. These estimated partial effects hold constant the effects of HGC, AFQT, and the school to work transition as family background varies. The family background variables have much larger marginal effects which account for the indirect effect through HGC, AFQT and school-to-transition. According to both the DFL and the marginal effects reported in column 4, table 6.2, the total effect of the changes in parental background variables between the two cohorts is to increase skills by about $5-6 \%$. The marginal effects are much larger than the partial effects because parental schooling correlates with individual skill measures such as HGC and the AFQT.

The regression based estimates of the marginal and the partial effects have to sum to the same number. Therefore, the relative marginal and partial effects of HGC, AFQT, and the school-to-work transition variables present a mirror image of the relative marginal and partial effects of parental education. For the regression decomposition, the marginal effect of HGC, AFQT, and school-to-work combine to -0.002 (DFL:0.012) which is much smaller than the sum of the partial effects, which is 0.022 . The partial effects are small because we observe only modest increases in skills once we account for parental education. The shift in parental background induces a large part of the increase in individual skill measures such as schooling and the AFQT.

The relative contributions of HGC and AFQT to total skills are also interesting. The means of both HGC and AFQT increase between 1979 and 1997. If we value these increases using the positive regression coefficients (Table 6.2, col.1), then we observe partial effects of HGC and of the AFQT equal to 0.017 and 0.012 respectively. In contrast, the marginal effect of the shift in HGC (with AFQT excluded) is 0.017 and once HGC is included, the marginal contribution of AFQT is negative (-0.008). The regression estimates of the partial and marginal effects of HGC and AFQT are consistent with the pattern of marginal effects found with DFL. The negative marginal effect of AFQT when HGC is already included stems from the fact that based on the shifts in race and gender, parental background and schooling we would expect the AFQT-score to increase by about 4 points, while the actual increase is only 2.4 points.

Table 6.3, panels A and B present the regression decompositions separately by race and gender. As for the aggregate population, we find that the marginal effects of parental education are strikingly large and consistently exceed the partial effects. For minority males, the marginal effects of parental education are as large as the total increase in skills. For white males and females the marginal effects of parental education actually exceed the total measured increase in skills. This implies that for white males and females, skills as measured by parental presence, HGC, AFQT, and work-transition declined after accounting for the direct and indirect effects of changes in parental education. For white males the total increase is $\log$ wages is 0.028 , while the marginal effect of parental education suggests an increase of 0.072. The difference is mainly due to the decline in the number of 14 year olds living with their parents and the decline in the work-transition variables, while HGC and AFQT together 
contribute a negligible amount (-0.003). even though both variables have substantial positive regression coefficients and partial effects. The DFL estimate is -0.004 . The combined marginal effects of HGC and AFQT are positive but relatively small for black and Hispanic males0.012 and 0.008 respectively. The partial effects of both variables are larger.

The regression estimates of marginal effects indicate that the only demographic groups that experience an increase in skills conditional on parental education are black and Hispanic females. For black and Hispanic females the observed marginal effects of parental education are as large as those observed for whites of both gender and for minority males, but black and Hispanic females have also made large gains in HGC and AFQT conditional on family background. The combined marginal effect of HGC and AFQT is 0.055 for black females and 0.06 for Hispanic females, which are about as large as the marginal effects of parental education. The partial effects of HGC and AFQT are larger than the corresponding values for black and Hispanic males.

Note also that blacks (both males and females) differ from whites and Hispanics in the relative marginal effects of HGC and AFQT. Both the regression estimates and the DFL estimates indicate that for whites and Hispanics of both genders the marginal effect of AFQT is much smaller than the marginal effect of HGC. For blacks however the marginal contribution of AFQT remains sizeable and positive even after accounting for HGC. This fact is mirrored in the large partial effects of AFQT for blacks, especially relative to whites. These results underline the role of test scores in closing the skill gap between blacks and whites between 1979 and 1997. It also makes the concern about the recent failure of closing the test score gap further (Neal, 2006) ever more relevant.

Overall, both the regression and DFL decompositions underline the important role of parental education for understanding the evolution of skills between 1979 and 1997. The partial effects generally attribute about $1 / 3$ to $1 / 2$ of the total increase in skills to parental education, while the marginal effects suggest that more than $2 / 3$ and in some case the entire increase in skills can be explained by the direct and indirects effects of the shift in parental education on wages. We also find important differences across race and gender. Cognitive tests scores of black males improved rapidly, while schooling of black males did not. For black and Hispanic females, we observe a large increase in skills even after accounting for parental education.

\section{CONCLUSION}

Changes in the level and distribution of skill play an important role in determining both economic growth and changes in the distribution of wages and employment. In this paper we examine changes in the characteristics of American youth between the late 1970s and the late 1990s, with a focus on characteristics that matter for labor market success. Drawing on the approach of DFL, we reweight the NLSY79 to look like the NLSY97 along a number of dimensions that are related to labor market success, including race, gender, parental background, education, test scores, and variables that capture whether individuals transition 
smoothly from school to work. We then use the re-weighted sample to examine how changes in the distribution of observable skills affect employment and wages. We also use more standard regression methods to assess the labor market consequences of differences between the two cohorts.

Considering the entire population, we find that the current generation is more skilled than the previous one, but also that the skill distribution in the current generation has widened. Much of these trends in skills seem to be generated by changes in the distribution of parental education. We present evidence that suggests skills for all groups combined have only increased by small amounts after we account for the change in skills that can be attributed to parental education (with the exception of Hispanics).

Interestingly, we find that the skill gaps between white males and other demographic groups have declined over this time-period. If the wage process faced by the NLSY79 cohort in their prime age years persists, our findings imply that women will gain significantly relative to men. Significant skill gaps remain, but blacks and Hispanics have narrowed the gap in skills relative to whites.

We doubt that our empirical findings will be the last word on change in labor force skills. First, more needs to be done to assess the issue of whether the NLSY97 base year sample is nonrepresentative. Second, while we believe that our corrections for attrition and for bias from missing data on test scores are adequate, one might be able to improve upon them by using a larger set of covariates from the base year sample at the cost of greater sampling error. Third, our results for NLSY79 and NLSY97 need to be supplemented with information from other sources, including the NAEP and the CPS. A cursory look at the NAEP scores for the relevant years indicate that they move in the same direction as the AFQT scores, but we need to assess this more carefully. We are currently extending our analysis to other outcomes, notably incarceration and fertility. We will also explore the role of immigration in shaping the labor market potential of the cohort represented by NLSY97, as well as the impact of immigration after age 16.

In future work, we hope to extend our methods in two directions. The first involves using vectors, say $Z_{1}$ and $Z_{2}$, of variables for which the joint distribution is available in NLSY79 but only the marginal distributions of $Z_{1}$ and $Z_{2}$ are observed for NLSY97. The second involves using variables that measure the same concepts but are based on different questions in the two data sets. 


\section{REFERENCES}

Bishop, John H., "Is the Test Score Decline Responsible for the Productivity Growth Decline?", The American Economic Review, Vol. 79, No. 1. (March): pp. 178-197.

Blau, Francine D. And Andrea H. Beller. 1992. "Black-White Earnings Over the 1970s and 1980s: Gender Differences in Trends." Review of Economics and Statistics. Vol 74:2, pp27686.

Belley, Philippe and Lance Lochner, (2007) "The Changing Role of Family Income and Ability in Determining Educational Achievement", University of Western Ontario.

Card, David and Alan Krueger (1996). "School resources and student outcomes: an overview of the literature and new evidence from North and South Carolina". Journal of Economic Perspectives 10(4), 31-50.

Cascio, Elizabeth and Ethan Lewis (2006) "Schooling and The Armed Forces Qualifying Test. Evidence from School-Entry Laws", The Journal of Human Resources, XLI, 2: 294-318.

Chin, Aimee and Hoyt Bleakley, "Language Skills and Earnings: Evidence from Childhood Immigrants." Review of Economics and

Statistics, (2004), 86(2): 481-496.

Chinloy, Peter, (1980)"Sources of Quality Change in Labor Input," American Economic Review, 70, March, 108-19.

Denison, E.F, (1974), “Accounting for United States economic growth”, 1929-1969, Brookings Institution, Washington.

DiNardo J, Fortin NM, Lemieux T (1996) "Labor Market Institutions and the Distribution of Wages, 1973-1992: A Semiparametric Approach", Econometrica 64(5): 1001-46

Eide, Eric, and Jeff Grogger 1995. "Changes in College Skills and the Rise in the College Wage Premium". Journal of Human Resources v30 n2 Spring pp 280-310.

Firpo, Sergio, Nicole Fortin and Thomas Lemieux, (2007) "Unconditional Quantile Regressions", unpublished paper, University of British Columbia.

Gosling, A., Machin, S., and C. Meghir (2000) "The changing distribution of male wages in the UK", Review of Economic Studies 67: 635-686.

Grogger, Jeffrey (1996) "Does School Quality Explain the Recent Black/White Wage Gap", Journal of Labor Economics Vol 14(2): 231-253.

Heckman, James and Paul LaFontaine (2007), "The American High School Graduation Rate: Trends and Levels", IZA Working Paper No. 3216.

Hirano, Keisuke, Guido Imbens, and Geert Ridder, (2003) "Efficient Estimation of Average Treatment Effects Using the Estimated Propensity Score" Econometrica, 71(4): 11611189.

Jorgensen, Dale, Frank Gollop, and Barbara Fraumeni, (1987), "Productivity and U.S. Economic Growth". Cambridge, MA: Harvard University Press. 
Juhn, C., K. M. Murphy, and B. Pierce (1991) "Accounting for the Slowdown in BlackWhite Wage Convergence." in Workers and their Wages: Changing Patterns in the United Stats. Ed. Marvin H. Kosters, AEI Press, Washington, DC: 107-143.

Korenman, S., \& Winship, C. (2000). "A reanalysis of The Bell Curve: Intelligence, family background, and schooling." In K. Arrow \& S. Bowles \& S. Durlauf (Eds.), Meritocracy and Economic Inequality. Princeton: Princeton University Press.

Machado, Jose and Jose Mata (2005) "Counterfactual Decomposition of Changes in Wage Distributions Using Quantile Regression", Journal of Applied Econometrics 20: 445-465.

MaCurdy, Thomas and Edward Vytlacil (2003) "Establishing New Norms for the AFQT Using Data from PAY97", Working Paper.

Melly, Blaise (2005), "Decomposition of differences in distribution using quantile regression", Labour Economics 12: 577-590.

W. Moore, S. Pedlow, P. Krishnamurty, and K. Wolter (2000), "National Longitudinal Survey of Youth 1997 (NLSY97) Technical Sampling Report", NCES (National Center for Education Statistics) (2005). Long-term trend major results. July 2005. Available at http:/ / nces.ed.gov/nationsreportcard/ltt/results2004/, accessed September 2007.

Neal, D. 2006. "Why has black-white skill convergence stopped?" In The Handbook of Economics of Education, vol. 1, ed. E. Hanushek and F. Welch. Amsterdam: North-Holland.

Segall, D. O. (1997). "Equating the CAT-ASVAB". In W. A. Sands, B. K. Waters, \& J. R. McBride (Eds.), Computerized adaptive testing: From inquiry to operation (pp. 181-198). Washington, DC: American Psychological Association.

Smith, J. and Welch, F. 1989. Black economic progress after Myrdal. Journal of Economic Literature 27, 519-64. 


\section{Appendix A: VARIAbles USEd AND their CONSTRUCTION}

- Observations (1997): Both the "cross-sectional sample" and the oversample of black and/or Hispanic respondents is used. In total there are 8984 observations in the data, which is $91.6 \%$ of the eligibles identified in the screening interview.

- Observations (1979): We use the cross section sample and the Hispanics and blacks from the supplemental sample. (The supplemental sample of economically disadvantaged non-black, non-Hispanic sample consisted of 1643 sample member in 1979 but was dropped after 1990). Hence we have a total of 9761 observations consisting of 6111 from the cross section and 3650 from the supplemental sample. We exclude the miliatry supplemental sample.

- Base Year Weights (1997 \& 1979): In the case of NLSY79, we use the 1979 cross section weights in the case of whites (R0216101) and the 1979 combined cross-section and supplemental sample weights for blacks and Hispanics. We use weights as they are generated in 1997 and 1979. In the case of NLSY97 we use the base year weights for the combined cross section and supplemental sample. We adjust the weights of immigrants based on age as described in the text.

- Work after graduation (1979 \& 1997): We construct this variable in the following manner. We examine a person when she is 22 or 23 years of age at the time of the interview and note her highest grade completed. (Due to variation in the timing of interviews, age may increase by 0,1 , or 2 between surveys.) If she had achieved the same highest grade completed by the age of 20 or less, we consider her to be in the universe of people who could have worked after "graduation" (workuniv $=1$ ). The variable work is coded as 1 if workuniv $=1$ and the individual have reported 14 weeks of work or more in either of the first 2 years after graduation. It is coded as 0 otherwise.

- Timing of school completion (1979 \& 1997): Again, the universe we consider are the people whose highest grade completed at age 22 or 23 is the same as the highest grade completed by age 20 or below. (workuniv $=1$ ). For these individuals, ontime $=1$ if the age when last in school equals highest grade completed by June plus six and 0 otherwise. (School completion is assumed to occur in June of given year.) The dummy early $=1$ if school leaving age is less than highest grade completed as of June plus six. late $=1$ if school leaving age exceeds the highest grade completed in June plus six.

- AFQT scores. (NLSY97): The 1997 cohort was administered the CAT-ASVAB.version of the test in 1997-98. The test was computerized unlike the 1980 test which was a paper and pencil test. For comparability, Daniel Segall created a comparison between the paper and pencil test and the computerized test. We use AFQT scores as computed under his methodology so as to be able to compare AFQT scores across the 2 samples. $^{34}$

\footnotetext{
${ }^{34}$ The NLSY 1997 does not have AFQT score as designated by the DOD. Instead they have a self created variable that mimics what the DOD does to various parts of the CAT-ASVAB. It is not comparable to the AFQT in 1979.
} 
(NLSY79).The NLSY79 AFQT scores are used directly. They are age standardized in the same way as the 1997 scores.

- Age standardizing AFQT scores. (1979 \& 1997): Since age could play a role in determining the score one gets on the test conditional on cognitive skills, we age standardize the AFQT scores as follows. We take 16 year olds and compute percentiles for their AFQT scores. We can now associate a percentile with an AFQT score. We then compute percentiles for every other age group. We assume that the percentile a person is placed in at (say) age 14 is the same as the percentile the person would have been placed in at age 16. We then associate the percentile with the AFQT score. Basically we create a function applying percentiles to AFQT scores using 16 year olds. For every other age group, we compute percentiles within that age group and then apply the above mentioned function to get their age standardized AFQT scores. We used 16 year olds as the base group because that is the age group with the most overlap in the 2 samples.

- Presence of biological Parents at age 14: (mom_only, dad_only, mom_dad, neitherMom_Dad).

${ }^{35}$ In 1979 this variable is constructed using a retrospective question to age 14 [R0001900]. In 1997 the variable [R1205300] is constructed using the household roster generated based on the screener interview. In 1997 this variable therefore refers to the age of respondents during the screening interview - typically between 12 and 16. In 1979 and 1997 there are 19 and 31 respondents respectively in the full sample for whom this information is missing. We assign these individuals to the largest category (living with both biological mother and father).

- Race: Information on race and ethnicity is taken from the screener interviews. In both surveys the variable combines ethnicity and race information and gives priority to Hispanic ethnicity over race classification.

- 1979 [R02147.00]: The 1979 race/ethnicity code does not allow for mixed race.

- 1997 [R14826.00]: The 1997 race/ethnicity code allows for mixed race/other classification. 83 respondents fall into this category. We eliminate these from the analysis since there is no counterpart in the 1979.

- Mother's Highest Grade Completed, Father's Highest grade Completed. In both cohorts, we use the same strategy to identify father and mother's highest grade completed. The variables are based on a screener interview question. If the response to the screener question in 1979 and 1997 is missing, we use the demographic roster information collected each year.

- Wage: The actual wage variable used for the 1979 cohort is the hourly wage variable. This variable denotes the hourly wage in cents and has been CPI adjusted for 2003. We recoded real wage values below $\$ 3.00$ as $\$ 3.00$ and values above $\$ 200.00$ to $\$ 200.00$.

${ }^{35}$ Respondents living with "neither" parent were typically living with grandparents or other relatives. 
- Residualized wages: for the 1979 cohort we compute experience and education adjusted wages in the following manner: regress the log of hourly wage on a cubic of potential experience (defined as age minus highest grade completed at age 22 minus 6) by education group. Education groups are less than 12 years of education, exactly 12 years of education and more than 12 years of education. From these regressions we compute the predicted log wage for a common experience of 23 and year 2002 and add the residual. In this manner we regression adjust wages to reflect experience 23, year 2002 values.

- High School Diploma and GED Information: In 1979 a question is asked each year whether the person has a GED or a HS diploma (respondents can also answer both, but there are so few of them them that we include these respondents under the HS Diploma category). If they respond in the affirmative, then they were asked when they received the HS Diploma or GED. We use answers to these questions to construct indicators for HS Diploma and for GED by age 22. If respondents reported a degree one year, but not in the following year we take that respondent to have obtained the degree as stated in the prior interview. Hence if someone responds affirmatively to having a degree once, that person is considered to have obtained that degree for the rest of the time in the sample. In the 1997 sample, we use the answers from questions about the Highest Degree Completed to back out whether a person received a HS Diploma or a GED by age 22.

\section{APPENDIX B:COMPARABILITY OF AFQT-SCORES ACROSS NLSY79 AND NLSY97}

Two major problems arise in making the AFQT-scores comparable across the NLSY79 and NLSY97 cohort. First, the ASVAB changed from a paper and pencil (P\&P) format in 1980 to a computer adminstered (CAT) format in 1997. Second, NLSY79 sample members were between 15 and 23 years old when they took the test. Test takers in the NLSY97 were between 12 and 18 years olds and thus typically were younger than their NLSY79 counterparts.

To make the AFQT scores comparable we perform two "equipercentile" procedures. The first method is based on the work of Daniel Segall (1997), who matches test scores of individuals across percentiles based on a study of individuals who were randomly administered either the P\&P or the CAT. As noted above, Segall kindly provided us with the results of mapping within age P\&P (1979) scores for the NLSY79 sample into equivalent CAT (1997) scores The second equipercentile procedure adjusts for the variation in age at test taking. For this purpose we use the overlap between the age ranges of NLSY79 and NLSY97 test takers. The most overlap exists for age 16 with 1329 respondents in 1997 taking the test at age 16 and 1324 respondents in 1980 taking the test at age 16. For each sample, we perform an equipercentile mapping to age 16 of the scores of respondents who took the test age other ages. Specifically, in the case of the NLSY79 sample, persons who took the test at age a who scored in the q'th percentile among age a test takers were assigned the qth percentile value for NLSY79 sample members who took the test at age 16. A corresponding set of assignments were made for 
the NLSY97 sample. This procedure assumes that the relative rankings of individuals in the AFQT-distribution on average do not depend on when they took the test. It also assumes that the level of cognitive skills in adulthood associated with the qth percentile in the age 16 test taker distribution is the same as that for the qth percentile in the age a distribution.

Table B.1 provides evidence that the joint distribution of observables and the AFQT score is indeed similar across ages in both surveys. We estimate regressions of the standardized AFQT-scores on interaction of the birth years with various observables used in the anlysis. If the joint distribution of observables and percentile score conditional on age varies across age, then we would expect that interacting age (or equivalently birth-year) with observables would predict the age standardized AFQT scores. Table B.1 shows the F-statistic for excluding various sets of interactions between observables and birth years for various specifications and both the NLSY79 and NLSY97. Table B.1 strongly suggests that there is no variation in the relationship between observables and the AFQT score across cohorts within either the NLSY79 and NLSY97.

\section{Appendix C: FAmily Structure in the NLSY SAmples AND IN THE Census}

Based on the NLSY79 and the NLSY97 we report a sizeable decline in the fraction of children living with their families during adolescence. This appendix compares our findings with statistics on the family structure between 1980 and 2000 generated using 14 years olds from both the 1 and 5\% IPUMS samples in both census years. The IPUMS allows one to generate a measure of social parenthood but not biological parenthood. This measure includes step-parents and adoptive parents. It is generated based on an algorithm exploiting various survey responses from the Census on various questions regarding family structure, age, whether a women has given birth, how many children survived, last name and other indicators (see www.ipums.org). This algorithm changes over time and it is not clear how comparable the variables are. The measures of family structure from the NLSY used throughout the paper refer to biological parenthood and are based on survey responses obtained during the screening interview. Due to differences in the questions, it is possible to construct measures that are strictly comparable across cohorts only for the biological parent structure. However, we can also generate an approximate social measure based on the survey responses. The ambiguity arises because in 1997 we can not distinguish individuals living with one vs. two adoptive parents if they do not have biological parents. This problem arises only for a small number of cases (103) and we assign them to the largest group - both mother and father present. Note that the family structure question in 1979 is retrospective and refers to family structure at age 14. The family structure measures for the 1997 cohort are obtained during the screening interview and refer to the age at the screening interview, ie 12-16 years of age. Table C reports the social family structure measures for 1980-2000 from the IPUMS sample and the biological and social family structure measures from the 1979 and 1997 NLSY cohort. 
The IPUMS statistics are weighted by the weights (perwt) provided by the Census and the NLSY variables are weighted by the cross-sectional weights.

The results in Table $C$ provide additional evidence for the break-up of the traditional family. The results from the NLSY and from the Census are roughly consistent, even though in the NLSY we typically find more individuals living with two (social) parents. 


\begin{tabular}{|lcc|}
\hline \multicolumn{2}{|c|}{ Table 3.0 SAMPLE ATTRITION } \\
\hline Reason for exclusion & NLSY 1979 & NLSY 1997 \\
(Birthyears 1957-1964) & (Birthyears 1980-1984) \\
No excluded cases & 12,682 & 8,984 \\
Excluded oversampled White male and female & 9,757 & 8,984 \\
& & \\
Excluded "Other" races & 9,757 & 8,901 \\
Excluded if age of entry to US $>$ 16 years & 9,661 & 8,901 \\
Ought to be present at age 22 & & $\mathbf{7 , 1 4 8}$ \\
& $\mathbf{9 , 6 6 1}$ & $\mathbf{1 0 0 . 0 0 \%}$ \\
\hline Present at age 22 & $\mathbf{1 0 0 . 0 0 \%}$ & 6,085 \\
Highest grade completed & 9,228 & $85.13 \%$ \\
AFQT & $95.52 \%$ & 6,014 \\
& 9,201 & $84.14 \%$ \\
\end{tabular}

Notes: Ought to be present at age 22 is calculated using birth year information of respondents. In the 1979 cohort we expect to observe everyone at age 22. in the 1997 cohort, since the last year of interview is 2005, we only expect people born on or before 1983 to reach the age of 22 in the data. AFQT here means age standardized AFQT. Note that a small number of cases in both cohorts are lost due to a death prior to age 22 . 


\begin{tabular}{|c|c|c|c|c|c|c|c|c|c|c|}
\hline \multicolumn{11}{|c|}{$\frac{\text { Table 3.1 Characteristics by Attrition Status at Age } 22}{N L S Y 1979}$} \\
\hline & $(1)$ & $(2)$ & (3) & $(4)$ & $(5)$ & (6) & $(7)$ & $(8)$ & $(9)$ & $(10)$ \\
\hline & $\mathrm{N}$ & Pooled & Attriters & Stayers & $\begin{array}{l}\text { Attriters- } \\
\text { Stayers }\end{array}$ & $\mathrm{N}$ & Pooled & Attriters & Stayers & $\begin{array}{l}\text { Attriters- } \\
\text { Stayers }\end{array}$ \\
\hline \multicolumn{11}{|l|}{ Race } \\
\hline White & 4,899 & $78.90 \%$ & $79.82 \%$ & $78.86 \%$ & $\begin{array}{c}0.96 \\
(2.0442)\end{array}$ & 3,741 & $71.19 \%$ & $75.30 \%$ & $70.42 \%$ & $\begin{array}{c}4.88 \\
(1.4699)^{* * *}\end{array}$ \\
\hline Black & 2,911 & $14.75 \%$ & $11.84 \%$ & $14.89 \%$ & $\begin{array}{c}-3.05 \\
(1.7765)^{*}\end{array}$ & 1,895 & $15.68 \%$ & $13.44 \%$ & $16.09 \%$ & $\begin{array}{c}-2.65 \\
(1.1807)^{* * *}\end{array}$ \\
\hline Hispanic & 1,851 & $6.35 \%$ & $8.35 \%$ & $6.25 \%$ & $\begin{array}{c}2.10 \\
(1.2210)^{*}\end{array}$ & 1,512 & $13.13 \%$ & $11.25 \%$ & $13.48 \%$ & $\begin{array}{c}-2.23 \\
(1.0968)^{* *}\end{array}$ \\
\hline \multicolumn{11}{|l|}{ Sample } \\
\hline Cross-Sectional Sample & 6,082 & $84.64 \%$ & $83.74 \%$ & $84.68 \%$ & $\begin{array}{c}-0.942 \\
(1.8065)\end{array}$ & 5,352 & $87.07 \%$ & $90.04 \%$ & $86.52 \%$ & $\begin{array}{c}3.52 \\
(1.0892)^{* * *}\end{array}$ \\
\hline Supplemental Sample & 3,579 & $15.36 \%$ & $16.26 \%$ & $15.32 \%$ & $\begin{array}{c}0.942 \\
(1.8065)\end{array}$ & 1,796 & $12.93 \%$ & $9.96 \%$ & $13.48 \%$ & $\begin{array}{c}-3.52 \\
(1.0892)^{* * *}\end{array}$ \\
\hline \multicolumn{11}{|l|}{ Parental Years of Schooling } \\
\hline \multicolumn{11}{|l|}{ Father } \\
\hline Years completed (average) & 8,215 & 12.09 & 12.19 & 12.09 & $\begin{array}{c}0.10 \\
(0.1780)\end{array}$ & 6,115 & 13.07 & 12.92 & 13.1 & $\begin{array}{c}-0.18 \\
(0.1054)^{*}\end{array}$ \\
\hline Missing & 1446 & $10.00 \%$ & $13.24 \%$ & $9.84 \%$ & $\begin{array}{c}3.40 \\
(1.5025)^{* *}\end{array}$ & 1,033 & $10.84 \%$ & $11.35 \%$ & $10.74 \%$ & $\begin{array}{c}0.61 \\
(1.0096)\end{array}$ \\
\hline Mother & & & & & & & & & & \\
\hline Years completed (average) & 9,038 & 11.78 & 11.73 & 11.79 & $\begin{array}{c}-0.06 \\
(0.1292)\end{array}$ & 6,886 & 13.01 & 12.73 & 13.06 & $\begin{array}{c}-0.33 \\
(0.0892)^{* * *}\end{array}$ \\
\hline Missing & 623 & $5.12 \%$ & $7.14 \%$ & $5.03 \%$ & $\begin{array}{c}2.11 \\
(1.1046)^{*}\end{array}$ & 262 & $3.05 \%$ & $3.38 \%$ & $2.99 \%$ & $\begin{array}{c}0.39 \\
(0.5584)\end{array}$ \\
\hline \multicolumn{11}{|l|}{ Parental Presence at age 14} \\
\hline Mother only & 2,378 & $18.54 \%$ & $18.69 \%$ & $18.54 \%$ & $\begin{array}{c}-0.15 \\
(1.9472)\end{array}$ & 2,817 & $35.67 \%$ & $32.64 \%$ & $36.24 \%$ & $\begin{array}{c}-3.60 \\
(1.5555)^{* *}\end{array}$ \\
\hline Father only & 278 & $2.98 \%$ & $4.09 \%$ & $2.93 \%$ & $\begin{array}{c}1.16 \\
(0.8518)\end{array}$ & 418 & $6.36 \%$ & $7.35 \%$ & $6.18 \%$ & $\begin{array}{c}1.17 \\
(0.7927)\end{array}$ \\
\hline Mother and Father & 6,545 & $75.38 \%$ & $73.33 \%$ & $75.48 \%$ & $\begin{array}{c}-2.15 \\
(2.1581)\end{array}$ & 3,473 & $52.75 \%$ & $54.37 \%$ & $52.45 \%$ & $\begin{array}{c}1.92 \\
(1.6216)\end{array}$ \\
\hline Neither Mother nor Father & 460 & $3.09 \%$ & $3.89 \%$ & $3.05 \%$ & $\begin{array}{c}0.84 \\
(0.8673)\end{array}$ & 440 & $5.22 \%$ & $5.64 \%$ & $5.14 \%$ & $\begin{array}{c}0.50 \\
(0.7223)\end{array}$ \\
\hline Total & 9,661 & & $4.57 \%$ & $95.43 \%$ & & 7,148 & & $15.74 \%$ & $84.26 \%$ & \\
\hline
\end{tabular}

Reported statistics are generated by attrition status at age 22 and weighted using the the base year sample weights for NLSY79 and NLSY97 respectively adjusted for year of entry into the US. For each statistic the difference between the attriter and stayers is reported with standard errors. Difference statistically significant at the .01 level $(* *), .05$ level $(* *)$ or .10 level $(*)$. Std errors reported in parenthesis. 


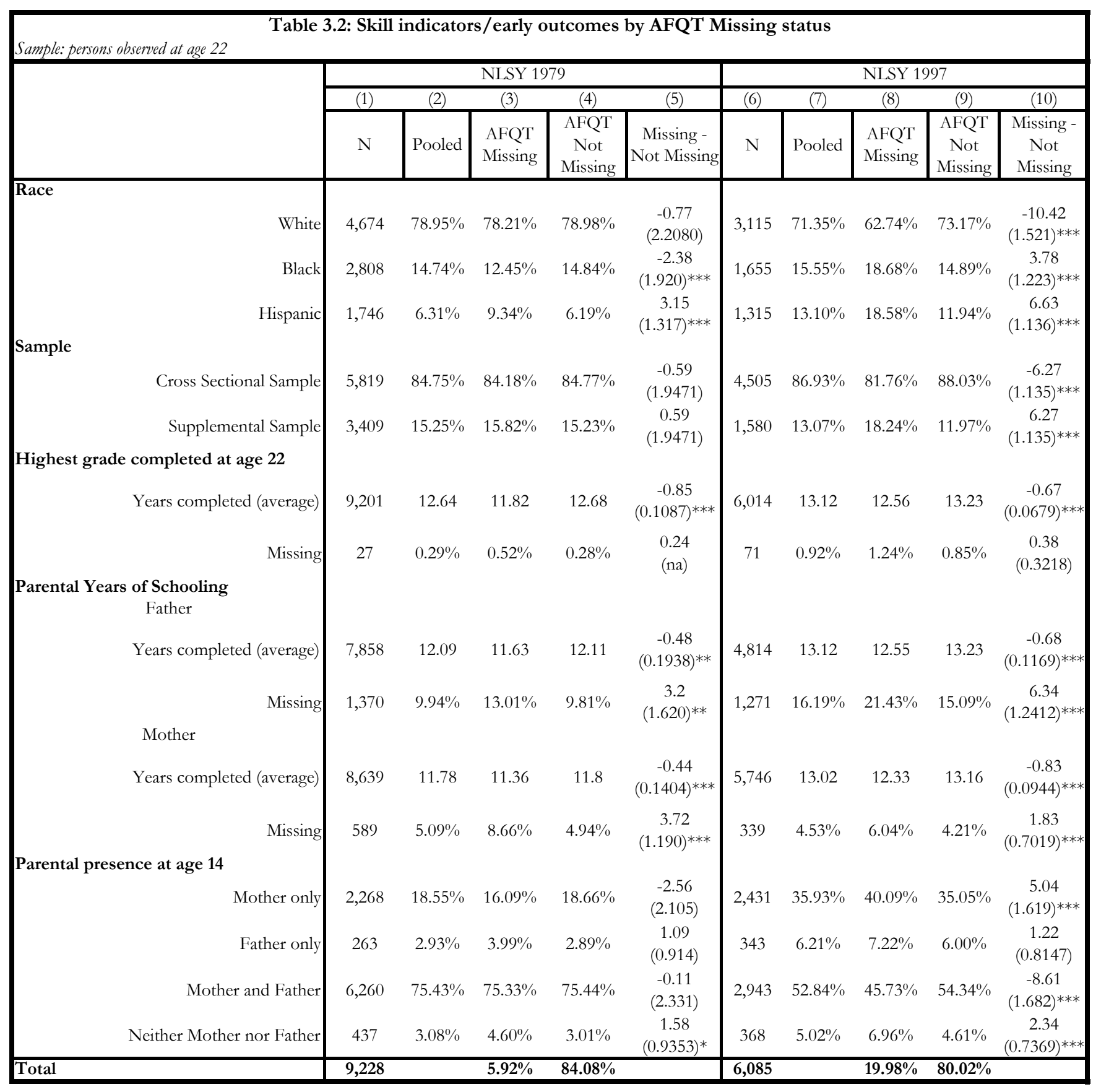

Reported statistics are generated for groups defined by observed AFQT test score and weighted using the attrition adjusted weights generated by the authors to account for attrition by age 22 in both years. For each statistic the difference between the attriter and stayers is reported. *** denote rejecting the difference to be 0 at a $1 \%$, ** at a $5 \%$ significance level, *** at a $1 \%$ significance level. Std error reported in parenthesis. 


\begin{tabular}{|c|c|c|c|c|c|c|c|c|c|}
\hline \multicolumn{10}{|c|}{ Table 3.3 Summary Statistics } \\
\hline \multicolumn{4}{|c|}{ Panel A: Statistics for Full Sample } & & & & & & \\
\hline Variable & 1979 & 1997 & $\begin{array}{c}\text { Difference } \\
(1997-1979)\end{array}$ & & & & & & \\
\hline AFQT & 42.35 & 44.19 & $\begin{array}{c}1.84 \\
(0.472)^{* * *}\end{array}$ & & & & & & \\
\hline HGC at age 22 & 12.64 & 13.02 & $\begin{array}{c}0.38 \\
(0.034)^{* * *}\end{array}$ & & & & & & \\
\hline GED at age 22 & $5.80 \%$ & $7.28 \%$ & $\begin{array}{c}1.48 \\
(0.410)^{* * *}\end{array}$ & & & & & & \\
\hline HS Diploma at age 22 & $78.54 \%$ & $80.15 \%$ & $\begin{array}{c}1.61 \\
(0.681)^{* *}\end{array}$ & & & & & & \\
\hline $\mathrm{HGC}>=14$ at age 22 & $31.11 \%$ & $39.79 \%$ & $\begin{array}{c}8.68 \\
(0.795)^{* * *}\end{array}$ & & & & & & \\
\hline Enrolled at age 22 & $20.38 \%$ & $29.95 \%$ & $\begin{array}{c}9.57 \\
(0.714)^{* * *}\end{array}$ & & & & & & \\
\hline Father's HGC & 12.09 & 12.81 & $\begin{array}{c}0.72 \\
(0.055)^{* * *}\end{array}$ & & & & & & \\
\hline Mother's HGC & 11.77 & 12.71 & $\begin{array}{c}0.94 \\
(0.0420)^{* * *}\end{array}$ & & & & & & \\
\hline Mother only & $18.57 \%$ & $35.66 \%$ & $\begin{array}{c}17.09 \\
(0.6803)^{* * *}\end{array}$ & & & & & & \\
\hline Father only & $3.02 \%$ & $5.94 \%$ & $\begin{array}{c}2.92 \\
(0.319)^{* * *}\end{array}$ & & & & & & \\
\hline Mother and Father & $75.23 \%$ & $52.98 \%$ & $\begin{array}{c}-22.25 \\
(0.731)^{* * *}\end{array}$ & & & & & & \\
\hline Neither Mother nor Father & $3.18 \%$ & $5.42 \%$ & $\begin{array}{c}2.24 \\
(0.315)^{* * *}\end{array}$ & & & & & & \\
\hline Work after leave school & $83.11 \%$ & $84.94 \%$ & $\begin{array}{c}1.83 \\
(0.907)^{* *} \\
\end{array}$ & & & & & & \\
\hline \multicolumn{10}{|c|}{ Panel B: Statistics by race } \\
\hline \multirow[b]{2}{*}{ Variable } & \multicolumn{3}{|c|}{ White } & \multicolumn{3}{|c|}{ Black } & \multicolumn{3}{|c|}{ Hispanic } \\
\hline & 1979 & 1997 & $\begin{array}{c}\text { Difference } \\
(1997-1979)\end{array}$ & 1979 & 1997 & $\begin{array}{c}\text { Difference } \\
(1997-1979)\end{array}$ & 1979 & 1997 & $\begin{array}{c}\text { Difference } \\
(1997-1979)\end{array}$ \\
\hline AFQT & 48.08 & 50.44 & $\begin{array}{c}2.36 \\
(0.644)^{* * *}\end{array}$ & 18.75 & 25.45 & $\begin{array}{c}6.7 \\
(0.610)^{* * *}\end{array}$ & 26.06 & 32.20 & $\begin{array}{c}6.14 \\
(0.873)^{* * *}\end{array}$ \\
\hline HGC at age 22 & 12.81 & 13.26 & $\begin{array}{c}0.45 \\
(0.049)^{* * *}\end{array}$ & 12.11 & 12.41 & $\begin{array}{c}0.30 \\
(0.058)^{* * *}\end{array}$ & 11.71 & 12.54 & $\begin{array}{c}0.83 \\
(0.074)^{* * *}\end{array}$ \\
\hline GED at age 22 & 0.06 & 0.07 & $\begin{array}{c}1.37 \\
(0.575)^{* * *}\end{array}$ & 0.07 & 0.10 & $\begin{array}{c}3.27 \\
(0.836)^{* * *}\end{array}$ & 0.07 & 0.06 & $\begin{array}{c}-1.01 \\
(0.917)\end{array}$ \\
\hline HS Diploma at age 22 & 0.82 & 0.83 & $\begin{array}{c}1.39 \\
(0.928)\end{array}$ & 0.69 & 0.72 & $\begin{array}{c}2.52 \\
(1.394)^{*}\end{array}$ & 0.62 & 0.76 & $\begin{array}{c}14.06 \\
(1.672)^{* * *}\end{array}$ \\
\hline HGC $>=14$ at age 22 & 0.34 & 0.45 & $\begin{array}{c}11.39 \\
(1.169)^{* * *}\end{array}$ & 0.22 & 0.27 & $\begin{array}{c}5.47 \\
(1.296)^{* * *}\end{array}$ & 0.18 & 0.28 & $\begin{array}{c}10.04 \\
(1.594)^{* * *}\end{array}$ \\
\hline Enrolled at age 22 & 0.22 & 0.33 & $\begin{array}{c}10.98 \\
(1.053)^{* * *}\end{array}$ & 0.15 & 0.23 & $\begin{array}{c}7.84 \\
(1.163)^{* * *}\end{array}$ & 0.16 & 0.25 & $\begin{array}{c}9.42 \\
(1.516)^{* * *}\end{array}$ \\
\hline Father's HGC & 12.48 & 13.35 & $\begin{array}{c}0.87 \\
(0.071)^{* * *}\end{array}$ & 10.64 & 12.29 & $\begin{array}{c}1.65 \\
(0.091)^{* * *}\end{array}$ & 9.59 & 10.52 & $\begin{array}{c}0.93 \\
(0.141)^{* * *}\end{array}$ \\
\hline Mother's HGC & 12.12 & 13.20 & $\begin{array}{c}1.08 \\
(0.054)^{* * *}\end{array}$ & 11.00 & 12.43 & $\begin{array}{c}1.43 \\
(0.070)^{* * *}\end{array}$ & 9.07 & 10.69 & $\begin{array}{c}1.62 \\
(0.120)^{* * *}\end{array}$ \\
\hline Mother only & 0.14 & 0.30 & $\begin{array}{c}16.05 \\
(0.955)^{* * *}\end{array}$ & 0.38 & 0.60 & $\begin{array}{c}21.3 \\
(1.485)^{* * *}\end{array}$ & 0.27 & 0.35 & $\begin{array}{c}8.11 \\
(1.734)^{* * *}\end{array}$ \\
\hline Father only & 0.03 & 0.07 & $\begin{array}{c}3.39 \\
(0.489)^{* * *}\end{array}$ & 0.03 & 0.05 & $\begin{array}{c}2.17 \\
(0.569)^{* * *}\end{array}$ & 0.02 & 0.04 & $\begin{array}{c}1.96 \\
(0.683)^{* * *}\end{array}$ \\
\hline Mother and Father & 0.81 & 0.59 & $\begin{array}{c}-21.99 \\
(1.049)^{* * *}\end{array}$ & 0.50 & 0.25 & $\begin{array}{c}-24.87 \\
(1.437)^{* * *}\end{array}$ & 0.66 & 0.56 & $\begin{array}{c}-9.49 \\
(1.815)^{* * *}\end{array}$ \\
\hline Neither Mother nor Father & 0.02 & 0.05 & $\begin{array}{c}2.55 \\
(0.395)^{* * *}\end{array}$ & 0.09 & 0.10 & $\begin{array}{c}1.4 \\
(0.899)^{* *}\end{array}$ & 0.05 & 0.04 & $\begin{array}{c}-0.58 \\
(0.742)\end{array}$ \\
\hline Work after leave school & 0.87 & 0.88 & $\begin{array}{c}1.3 \\
(1.228)^{*}\end{array}$ & 0.68 & 0.75 & $\begin{array}{c}6.32 \\
(1.934)^{* * *}\end{array}$ & 0.80 & 0.84 & $\begin{array}{c}4.68 \\
(2.030)^{* *}\end{array}$ \\
\hline
\end{tabular}

Notes: Weighted means presented. Weights used are attrition-afqt adjusted weights created by the authors. Summary stats presented regardless of presence at age 22, except those variables which are measured at age 22 (HGC and Enrollment). 1997 data has another race category "Other" due to small numbers in that category we do not display it in this table 
Table 3.3 Summary Statistics (contd)

Panel C: Statistics by race and sex

\begin{tabular}{|c|c|c|c|c|c|c|c|c|c|}
\hline \multirow[b]{2}{*}{ Males } & \multicolumn{3}{|c|}{ White } & \multicolumn{3}{|c|}{ Black } & \multicolumn{3}{|c|}{ Hispanic } \\
\hline & 1979 & 1997 & $\begin{array}{c}\text { Difference } \\
(1997-1979)\end{array}$ & 1979 & 1997 & $\begin{array}{c}\text { Difference } \\
(1997-1979)\end{array}$ & 1979 & 1997 & $\begin{array}{l}\text { Difference } \\
(1997-1979)\end{array}$ \\
\hline AFQT & 48.57 & 50.05 & $\begin{array}{c}1.48 \\
(0.940)\end{array}$ & 17.95 & 23.55 & $\begin{array}{c}5.6 \\
(0.8882)^{* * *}\end{array}$ & 27.51 & 32.39 & $\begin{array}{c}4.88 \\
(1.3000)^{* * *}\end{array}$ \\
\hline HGC at age 22 & 12.74 & 13.04 & $\begin{array}{c}0.30 \\
(0.0672)^{* * *}\end{array}$ & 11.89 & 12.06 & $\begin{array}{c}0.17 \\
(0.0822)^{* *}\end{array}$ & 11.70 & 12.45 & $\begin{array}{c}0.75 \\
(0.1027)^{* * *}\end{array}$ \\
\hline Enrolled at age 22 & $24.51 \%$ & $30.89 \%$ & $\begin{array}{c}6.38 \\
(1.5101)^{* * *}\end{array}$ & $13.21 \%$ & $17.45 \%$ & $\begin{array}{c}4.24 \\
(1.5406)^{* * *}\end{array}$ & $15.61 \%$ & $25.61 \%$ & $\begin{array}{c}10.00 \\
(2.2197)^{* * *}\end{array}$ \\
\hline Father's HGC & 12.55 & 13.37 & $\begin{array}{c}0.82 \\
(0.1004)^{* * *}\end{array}$ & 10.71 & 12.17 & $\begin{array}{c}1.46 \\
(0.1245)^{* * *}\end{array}$ & 9.65 & 10.68 & $\begin{array}{c}1.03 \\
(0.2018)^{* * *}\end{array}$ \\
\hline Mother's HGC & 12.18 & 13.16 & $\begin{array}{c}0.98 \\
(0.0764)^{* * *}\end{array}$ & 11.09 & 12.47 & $\begin{array}{c}1.38 \\
(0.0987)^{* * *}\end{array}$ & 9.21 & 10.75 & $\begin{array}{c}1.54 \\
(0.1761)^{* * *}\end{array}$ \\
\hline Mother only & $13.47 \%$ & $28.57 \%$ & $\begin{array}{c}15.10 \\
(1.2370)^{* * *}\end{array}$ & $37.37 \%$ & $58.93 \%$ & $\begin{array}{c}21.56 \\
(2.0041)^{* * *}\end{array}$ & $28.60 \%$ & $34.32 \%$ & $\begin{array}{c}5.72 \\
(2.4200)^{* *}\end{array}$ \\
\hline Father only & $3.72 \%$ & $6.93 \%$ & $\begin{array}{c}3.21 \\
(0.6909)\end{array}$ & $2.96 \%$ & $4.58 \%$ & $\begin{array}{c}1.62 \\
(0.7774)^{* * *}\end{array}$ & $2.92 \%$ & $4.82 \%$ & $\begin{array}{c}1.90 \\
(1.0366)^{*}\end{array}$ \\
\hline Mother and Father & $80.88 \%$ & $60.11 \%$ & $\begin{array}{c}-20.77 \\
(1.3795)^{* * *}\end{array}$ & $51.08 \%$ & $26.33 \%$ & $\begin{array}{c}-24.75 \\
(1.9434)^{* * *}\end{array}$ & $65.03 \%$ & $56.56 \%$ & $\begin{array}{c}-8.47 \\
(2.5352)^{* * *}\end{array}$ \\
\hline $\begin{array}{l}\text { Neither Mother nor } \\
\text { Father }\end{array}$ & $1.93 \%$ & $4.40 \%$ & $\begin{array}{c}2.47 \\
(0.5341)^{* * *}\end{array}$ & $8.58 \%$ & $10.16 \%$ & $\begin{array}{c}1.58 \\
(1.1945)\end{array}$ & $3.45 \%$ & $4.30 \%$ & $\begin{array}{c}0.85 \\
(1.0166)\end{array}$ \\
\hline Work after leave school & $84.65 \%$ & $89.08 \%$ & $\begin{array}{c}4.43 \\
(1.7276)^{* *}\end{array}$ & $72.43 \%$ & $75.58 \%$ & $\begin{array}{c}3.15 \\
(2.6373) \\
\end{array}$ & $84.13 \%$ & $84.31 \%$ & $\begin{array}{c}0.18 \\
(2.9703) \\
\end{array}$ \\
\hline
\end{tabular}

\begin{tabular}{|c|c|c|c|c|c|c|c|c|c|}
\hline \multirow[b]{2}{*}{ Females } & \multicolumn{3}{|c|}{ White } & \multicolumn{3}{|c|}{ Black } & \multicolumn{3}{|c|}{ Hispanic } \\
\hline & 1979 & 1997 & \begin{tabular}{|c|} 
Difference \\
$(1997-1979)$
\end{tabular} & 1979 & 1997 & $\begin{array}{c}\text { Difference } \\
(1997-1979)\end{array}$ & 1979 & 1997 & $\begin{array}{l}\text { Difference } \\
(1997-1979)\end{array}$ \\
\hline AFQT & 47.58 & 50.85 & $\begin{array}{c}3.27 \\
(0.8801)^{* * *}\end{array}$ & 18.93 & 27.38 & $\begin{array}{c}8.45 \\
(0.8350)^{* * *}\end{array}$ & 24.59 & 31.98 & $\begin{array}{c}7.39 \\
(1.1608)^{* * *}\end{array}$ \\
\hline HGC at age 22 & 12.89 & 13.51 & $\begin{array}{c}0.62 \\
(0.0697)^{* * *}\end{array}$ & 12.33 & 12.78 & $\begin{array}{c}0.45 \\
(0.0806)^{* * *}\end{array}$ & 11.71 & 12.66 & $\begin{array}{c}0.95 \\
(0.1077)^{* * *}\end{array}$ \\
\hline Enrolled at age 22 & $19.09 \%$ & $34.85 \%$ & $\begin{array}{c}15.76 \\
(1.4612)^{* * *}\end{array}$ & $16.08 \%$ & $27.95 \%$ & $\begin{array}{c}11.87 \\
(1.7318)^{* * *}\end{array}$ & $15.46 \%$ & $24.07 \%$ & $\begin{array}{c}8.61 \\
(2.0710)^{* * *}\end{array}$ \\
\hline Father's HGC & 12.40 & 13.33 & $\begin{array}{c}0.93 \\
(0.1001)^{* * *}\end{array}$ & 10.57 & 12.42 & $\begin{array}{c}1.85 \\
(0.1315)^{* * *}\end{array}$ & 9.54 & 10.30 & $\begin{array}{c}0.76 \\
(0.1970)^{* * *}\end{array}$ \\
\hline Mother's HGC & 12.06 & 13.26 & $\begin{array}{c}1.20 \\
(0.0764)\end{array}$ & 10.92 & 12.38 & $\begin{array}{c}1.46 \\
(0.0995)^{* * *}\end{array}$ & 8.93 & 10.61 & $\begin{array}{c}1.68 \\
(0.1631)^{* * *}\end{array}$ \\
\hline Mother only & $15.10 \%$ & $32.25 \%$ & $\begin{array}{c}17.15 \\
(1.2998)^{* * *}\end{array}$ & $39.03 \%$ & $60.15 \%$ & $\begin{array}{c}21.12 \\
(2.0144)^{* * *}\end{array}$ & $25.57 \%$ & $36.39 \%$ & $\begin{array}{c}10.82 \\
(2.3304)^{* * *}\end{array}$ \\
\hline Father only & $2.53 \%$ & $6.07 \%$ & $\begin{array}{c}3.54 \\
(0.6211)^{* * *}\end{array}$ & $2.34 \%$ & $5.09 \%$ & $\begin{array}{c}2.75 \\
(0.7609)^{* * *}\end{array}$ & $2.06 \%$ & $3.95 \%$ & $\begin{array}{c}1.89 \\
(0.8829)^{* *}\end{array}$ \\
\hline Mother and Father & $80.33 \%$ & $56.98 \%$ & $\begin{array}{c}-23.35 \\
(1.4089)^{* * *}\end{array}$ & $49.36 \%$ & $24.24 \%$ & $\begin{array}{c}-25.12 \\
(1.9372)^{* * *}\end{array}$ & $66.08 \%$ & $55.40 \%$ & $\begin{array}{c}-10.68 \\
(2.4507)^{* * *}\end{array}$ \\
\hline $\begin{array}{l}\text { Neither Mother nor } \\
\text { Father }\end{array}$ & $2.05 \%$ & $4.70 \%$ & $\begin{array}{c}2.65 \\
(0.5545)^{* * *}\end{array}$ & $9.26 \%$ & $10.52 \%$ & $\begin{array}{c}1.26 \\
(1.2265)\end{array}$ & $6.29 \%$ & $4.26 \%$ & $\begin{array}{c}-2.03 \\
(1.1002)^{*}\end{array}$ \\
\hline Work after leave school & $88.97 \%$ & $86.82 \%$ & $\begin{array}{c}-2.15 \\
(1.7770)\end{array}$ & $64.31 \%$ & $73.69 \%$ & $\begin{array}{c}9.38 \\
(2.8406)^{* * *}\end{array}$ & $74.42 \%$ & $84.09 \%$ & $\begin{array}{c}9.67 \\
(3.0974)^{* * *}\end{array}$ \\
\hline
\end{tabular}

Notes: Weighted means presented. Weights used are attrition-afqt adjusted weights created by the authors. Summary stats presented regardless of presence at age 22, except those variables which are measured at age 22 (HGC and Enrollment). 1997 data has another race category "Other" - due to small numbers in that category we do not display it in this table 


\begin{tabular}{|c|c|c|c|c|c|c|c|c|c|}
\hline \multicolumn{10}{|c|}{ Statistics by race and sex } \\
\hline \multirow[b]{2}{*}{ Males } & \multicolumn{3}{|c|}{ White } & \multicolumn{3}{|c|}{ Black } & \multicolumn{3}{|c|}{ Hispanic } \\
\hline & 1979 & 1997 & \begin{tabular}{|c|} 
Difference \\
$(1997-1979)$ \\
\end{tabular} & 1979 & 1997 & $\begin{array}{c}(1997- \\
1070) \\
\end{array}$ & 1979 & 1997 & $\begin{array}{c}\text { Difference } \\
(1997-1979) \\
\end{array}$ \\
\hline GED at age 22 & $5.81 \%$ & $8.05 \%$ & $\begin{array}{c}2.24 \\
(0.8492)^{* * *}\end{array}$ & $8.22 \%$ & $12.90 \%$ & $\begin{array}{c}4.68 \\
(1.305)^{* * *}\end{array}$ & $8.59 \%$ & $6.55 \%$ & $\begin{array}{c}-2.04 \\
(1.3979)\end{array}$ \\
\hline HS Diploma at age 22 & $79.90 \%$ & $81.40 \%$ & $\begin{array}{c}1.50 \\
(1.3539)\end{array}$ & $64.20 \%$ & $64.56 \%$ & $\begin{array}{c}0.35 \\
(2.0673)\end{array}$ & $60.27 \%$ & $75.32 \%$ & $\begin{array}{c}15.05 \\
(2.4385)^{* * *}\end{array}$ \\
\hline HGC $>=14$ at age 22 & $33.27 \%$ & $39.43 \%$ & $\begin{array}{c}6.16 \\
(1.6315)^{* * *}\end{array}$ & $18.16 \%$ & $20.89 \%$ & $\begin{array}{c}2.73 \\
(1.7039)\end{array}$ & $18.03 \%$ & $24.48 \%$ & $\begin{array}{c}6.45 \\
(2.2330)^{* * *}\end{array}$ \\
\hline Enrolled at age 22 & $24.51 \%$ & $30.89 \%$ & $\begin{array}{c}6.38 \\
(1.5101)^{* * *}\end{array}$ & $13.21 \%$ & $17.45 \%$ & $\begin{array}{c}4.24 \\
(1.5406)^{* * *}\end{array}$ & $15.61 \%$ & $25.61 \%$ & $\begin{array}{c}10.00 \\
(2.2197)^{* * *}\end{array}$ \\
\hline \multirow[b]{2}{*}{ Females } & \multicolumn{3}{|c|}{ White } & \multicolumn{3}{|c|}{ Black } & \multicolumn{3}{|c|}{ Hispanic } \\
\hline & 1979 & 1997 & \begin{tabular}{|c|} 
Difference \\
$(1997-1979)$
\end{tabular} & 1979 & 1997 & $\begin{array}{c}(1997- \\
1070)\end{array}$ & 1979 & 1997 & $\begin{array}{c}\text { Difference } \\
(1997-1979) \\
\end{array}$ \\
\hline GED at age 22 & $5.18 \%$ & $5.62 \%$ & $\begin{array}{c}0.44 \\
(0.7730)\end{array}$ & $5.54 \%$ & $7.15 \%$ & $\begin{array}{c}1.61 \\
(1.0365)\end{array}$ & $5.62 \%$ & $5.48 \%$ & $\begin{array}{c}-0.14 \\
(1.1825)\end{array}$ \\
\hline HS Diploma at age 22 & $83.40 \%$ & $84.75 \%$ & $\begin{array}{c}1.35 \\
(1.2641)\end{array}$ & $73.63 \%$ & $78.97 \%$ & $\begin{array}{c}5.34 \\
(1.8385)\end{array}$ & $64.41 \%$ & $77.88 \%$ & $\begin{array}{c}13.47 \\
(2.2926)\end{array}$ \\
\hline HGC $>=14$ at age 22 & $34.55 \%$ & $51.55 \%$ & $\begin{array}{c}17.00 \\
(1.6656)\end{array}$ & $24.91 \%$ & $33.69 \%$ & $\begin{array}{c}8.78 \\
(1.9329)\end{array}$ & $18.87 \%$ & $34.02 \%$ & $\begin{array}{c}15.15 \\
(2.2763)\end{array}$ \\
\hline Enrolled at age 22 & $19.09 \%$ & $34.85 \%$ & $\begin{array}{c}15.76 \\
(1.4612)^{* * *} \\
\end{array}$ & $16.08 \%$ & $27.95 \%$ & $\begin{array}{c}11.87 \\
(1.732)^{* * *} \\
\end{array}$ & $15.46 \%$ & $24.07 \%$ & $\begin{array}{c}8.61 \\
(2.0710)^{* * *} \\
\end{array}$ \\
\hline
\end{tabular}




\begin{tabular}{|c|c|c|c|c|}
\hline \multicolumn{5}{|c|}{$\begin{array}{l}\text { Table 4.1 The Distribution of Propensit } \\
\text { Skill Models }\end{array}$} \\
\hline & Race, Sex & $\begin{array}{l}\text { (1) }+ \text { Family } \\
\text { Background }\end{array}$ & $\begin{array}{c}(2)+ \\
\text { AFQT, } \\
\text { HGC }\end{array}$ & $\begin{array}{l}\text { (3) }+ \text { Work } \\
\text { Transition }\end{array}$ \\
\hline & (1) & (2) & (3) & (4) \\
\hline Smallest & 0.75 & 0.002 & 0.001 & 0.000 \\
\hline 2nd Smallest & 0.75 & 0.002 & 0.001 & 0.000 \\
\hline $1 \%$ & 0.75 & 0.01 & 0.01 & 0.004 \\
\hline $5 \%$ & 0.75 & 0.08 & 0.07 & 0.03 \\
\hline $10 \%$ & 0.75 & 0.16 & 0.15 & 0.05 \\
\hline $25 \%$ & 0.75 & 0.36 & 0.3 & 0.2 \\
\hline $50 \%$ & 0.77 & 0.7 & 0.6 & 0.51 \\
\hline $75 \%$ & 0.94 & 1.2 & 1.23 & 1.18 \\
\hline $90 \%$ & 1.66 & 2.14 & 2.14 & 2.26 \\
\hline $95 \%$ & 1.89 & 2.95 & 3.12 & 3.49 \\
\hline $99 \%$ & 1.89 & 6.01 & 6.25 & 7.12 \\
\hline 2nd Largest & 1.89 & 19.53 & 18.38 & 45.32 \\
\hline Largest & 1.89 & 22.06 & 32.65 & 90.8 \\
\hline Mean & 1 & 1 & 1 & 1 \\
\hline
\end{tabular}

1) This table describes the distribution of weights used to generate the counterfactual distributions described in the paper, with the exception that the weights used in the paper are capped at a max of 10 . These propensity weights are estimated on the sample with reported AFQT scores and we report the distribution of weights for a selected, representative subset of propensity models. 


\begin{tabular}{|c|c|c|c|c|c|c|}
\hline \multicolumn{7}{|c|}{$\begin{array}{l}\text { Table 5.1 Comparison of Actual Employment Rates of } 1979 \text { Cohort with } \\
\text { Counterfactual Rates based on characteristics of } 1997 \text { cohort. }^{1}\end{array}$} \\
\hline & \multirow{2}{*}{\multicolumn{2}{|c|}{$\begin{array}{l}\text { Observed LFP in } \\
\text { NLSY } 79\end{array}$}} & \multicolumn{4}{|c|}{ Counterfactual minus observed LFP-Rates ${ }^{3}$} \\
\hline \multirow[b]{2}{*}{ Percentile } & & & \multirow{2}{*}{$\frac{\text { Model } 4.6^{3}}{\text { Sample } 1}$} & \multicolumn{2}{|c|}{ Model $4.4^{3}$} & \multirow{2}{*}{$\frac{\text { Model } 4.5^{3}}{\text { Sample } 1}$} \\
\hline & Sample 1 & Sample 2 & & Sample 1 & Sample 2 & \\
\hline Male Total & $\begin{array}{c}0.919 \\
(0.0041)\end{array}$ & $\begin{array}{c}0.917 \\
(0.0041)\end{array}$ & $\begin{array}{c}0.005 \\
(0.0047)\end{array}$ & $\begin{array}{c}0.001 \\
(0.0036)\end{array}$ & $\begin{array}{c}0.005 \\
(0.0037)\end{array}$ & $\begin{array}{c}0.001 \\
(0.0041)\end{array}$ \\
\hline White & $\begin{array}{c}0.931 \\
(0.0049)\end{array}$ & $\begin{array}{c}0.930 \\
(0.0049)\end{array}$ & $\begin{array}{c}0.001 \\
(0.0060)\end{array}$ & $\begin{array}{c}0.001 \\
(0.0045)\end{array}$ & $\begin{array}{c}0.003 \\
(0.0047)\end{array}$ & $\begin{array}{c}-0.001 \\
(0.0053)\end{array}$ \\
\hline Black & $\begin{array}{c}0.854 \\
(0.0089)\end{array}$ & $\begin{array}{c}0.849 \\
(0.0090)\end{array}$ & $\begin{array}{c}0.027 \\
(0.0097)^{* * *}\end{array}$ & $\begin{array}{c}0.001 \\
(0.0096)\end{array}$ & $\begin{array}{c}0.012 \\
(0.0102)\end{array}$ & $\begin{array}{c}0.008 \\
(0.0104)\end{array}$ \\
\hline Hispanic & $\begin{array}{c}0.909 \\
(0.0093)\end{array}$ & $\begin{array}{c}0.902 \\
(0.0096)\end{array}$ & $\begin{array}{c}0.022 \\
(0.0078)^{* * *}\end{array}$ & $\begin{array}{c}0.018 \\
(0.0075)^{* *}\end{array}$ & $\begin{array}{c}0.031 \\
(0.0071)^{* * *}\end{array}$ & $\begin{array}{c}0.022 \\
(0.0075)^{* * *}\end{array}$ \\
\hline Female Total & $\begin{array}{c}0.838 \\
(0.0056)\end{array}$ & $\begin{array}{c}0.837 \\
(0.0056)\end{array}$ & $\begin{array}{c}-0.007 \\
(0.0070)\end{array}$ & $\begin{array}{c}-0.006 \\
(0.0059)\end{array}$ & $\begin{array}{c}-0.004 \\
(0.0058)\end{array}$ & $\begin{array}{c}-0.006 \\
(0.0062)\end{array}$ \\
\hline White & $\begin{array}{c}0.841 \\
(0.0068)\end{array}$ & $\begin{array}{c}0.840 \\
(0.0067)\end{array}$ & $\begin{array}{c}-0.015 \\
(0.0088)^{*}\end{array}$ & $\begin{array}{c}-0.010 \\
(0.0077)\end{array}$ & $\begin{array}{c}-0.009 \\
(0.0077)\end{array}$ & $\begin{array}{c}-0.012 \\
(0.0082)\end{array}$ \\
\hline Black & $\begin{array}{c}0.832 \\
(0.0089)\end{array}$ & $\begin{array}{c}0.830 \\
(0.0087)\end{array}$ & $\begin{array}{c}0.014 \\
(0.0151)\end{array}$ & $\begin{array}{c}0.007 \\
(0.0116)\end{array}$ & $\begin{array}{c}0.011 \\
(0.0118)\end{array}$ & $\begin{array}{c}0.015 \\
(0.0108)\end{array}$ \\
\hline Hispanic & 0.821 & 0.819 & 0.024 & 0.012 & 0.018 & 0.016 \\
\hline & $(0.0117)$ & $(0.0117)$ & $(0.0138)^{*}$ & $(0.0118)$ & $(0.0115)$ & $(0.0115)$ \\
\hline Total & $\begin{array}{c}0.877 \\
(0.0036)\end{array}$ & $\begin{array}{c}0.876 \\
(0.0035)\end{array}$ & $\begin{array}{c}0.000 \\
(0.0042)\end{array}$ & $\begin{array}{c}-0.001 \\
(0.0035)\end{array}$ & $\begin{array}{c}0.002 \\
(0.0035)\end{array}$ & $\begin{array}{c}-0.001 \\
(0.0036)\end{array}$ \\
\hline
\end{tabular}

1) Employment Rate is measured by reference to a valid wage observation. An individual is coded to have a valid wage observation if the average hourly rate of pay lies between $\$ 3$ and $\$ 200$ (in 2003 real values) in a given year. Reported percentages refer to shares with valid wages in years with positive responses between 1998-2004. Sample 1 includes respondents with observed AFQT scores. Sample 2 includes those with missing AFQT scores. All statistics are weighted by the cross-sectional weights. Specifications estimated on sample 1 are in addition weighted to account for both attrition by age 22 and AFQT-non response. Specifications estimated on Sample 2 are in addition weighted to account for attrition by age 22. Standard errors are bootstrapped with 200 repetitions. Bootstrap stratified on NLSY cohort, race and gender. Units are sampled at the individual level. * refers to significance at $10 \%,{ }^{* *}$ at $5 \%$, and $* * *$ at $1 \%$ level.

2) Measured against corresponding sample reported in columns 1 and 2.

3) All specifications match on race and gender. Model 4.4 (eq 4.4) refers to the specification matching on schooling, parental education and family structure. Model 4.5 (eq. 4.5) matches schooling, parental education, family structre, and the AFQT-scores. Model 4.6 refers to the full specification (eq 4.6) matching on schooling, AFQT scores, parental education, family structure and the school-work transition variables. 


\begin{tabular}{|c|c|c|c|c|c|c|}
\hline \multicolumn{7}{|c|}{$\begin{array}{l}\text { Table 5.2 Comparison of Actual Wages of } 1979 \text { Cohort with Counterfactual } \\
\text { Wage distributions based on characteristics of } 1997 \text { cohort. }\end{array}$} \\
\hline \multirow[b]{3}{*}{ Percentile } & \multirow{2}{*}{\multicolumn{2}{|c|}{$\begin{array}{c}\text { Observed Wage } \\
\text { distribution in NLSY } \\
1979\end{array}$}} & \multicolumn{4}{|c|}{ Counterfactual minus Actual Wages ${ }^{3}$} \\
\hline & & & \multirow{2}{*}{$\frac{\text { Model } 4.6^{3}}{\text { Sample } 1}$} & \multicolumn{2}{|c|}{ Model $4.4^{3}$} & \multirow{2}{*}{$\frac{\text { Model } 4.5^{3}}{\text { Sample } 1}$} \\
\hline & Sample 1 & Sample 2 & & Sample 1 & Sample 2 & \\
\hline $5 \%$ & $\begin{array}{c}6.230 \\
(0.0295)\end{array}$ & $\begin{array}{c}6.228 \\
(0.0297)\end{array}$ & $\begin{array}{c}0.023 \\
(0.0282)\end{array}$ & $\begin{array}{c}0.014 \\
(0.0279)\end{array}$ & $\begin{array}{c}0.007 \\
(0.0291)\end{array}$ & $\begin{array}{c}0.014 \\
(0.0279)\end{array}$ \\
\hline $10 \%$ & $\begin{array}{c}6.491 \\
(0.0109)\end{array}$ & $\begin{array}{c}6.487 \\
(0.0108)\end{array}$ & $\begin{array}{c}0.019 \\
(0.0154)\end{array}$ & $\begin{array}{c}0.035 \\
(0.0140)^{* *}\end{array}$ & $\begin{array}{c}0.031 \\
(0.0133)^{* *}\end{array}$ & $\begin{array}{c}0.023 \\
(0.0132)^{*}\end{array}$ \\
\hline $25 \%$ & $\begin{array}{c}6.846 \\
(0.0089)\end{array}$ & $\begin{array}{c}6.841 \\
(0.0086)\end{array}$ & $\begin{array}{c}0.049 \\
(0.0131)^{* * *}\end{array}$ & $\begin{array}{c}0.073 \\
(0.0111)^{* * *}\end{array}$ & $\begin{array}{c}0.073 \\
(0.0101)^{* * *}\end{array}$ & $\begin{array}{c}0.063 \\
(0.0111)^{* * *}\end{array}$ \\
\hline $50 \%$ & $\begin{array}{c}7.268 \\
(0.0089)\end{array}$ & $\begin{array}{c}7.265 \\
(0.0089)\end{array}$ & $\begin{array}{c}0.063 \\
(0.0131)^{* * *}\end{array}$ & $\begin{array}{c}0.081 \\
(0.0115)^{* * *}\end{array}$ & $\begin{array}{c}0.079 \\
(0.0112)^{* * *}\end{array}$ & $\begin{array}{c}0.074 \\
(0.0119)^{* * *}\end{array}$ \\
\hline $75 \%$ & $\begin{array}{c}7.665 \\
(0.0086)\end{array}$ & $\begin{array}{c}7.663 \\
(0.0082)\end{array}$ & $\begin{array}{c}0.049 \\
(0.0140)^{* * *}\end{array}$ & $\begin{array}{c}0.065 \\
(0.0146)^{* * *}\end{array}$ & $\begin{array}{c}0.061 \\
(0.0134)^{* * *}\end{array}$ & $\begin{array}{c}0.056 \\
(0.0139)^{* * *}\end{array}$ \\
\hline & 8.042 & 8.039 & 0.088 & 0.097 & 0.093 & 0.094 \\
\hline $90 \%$ & $(0.0143)$ & $(0.0137)$ & $(0.0208)^{* * *}$ & $(0.0203)^{* * *}$ & $(0.0197)^{* * *}$ & $(0.0203)^{* * *}$ \\
\hline $95^{\circ}$ & 8.331 & 8.327 & 0.110 & 0.129 & 0.129 & 0.124 \\
\hline $95 \%$ & $(0.0236)$ & $(0.0229)$ & $(0.0331)^{* * *}$ & $(0.0329) * * *$ & $(0.0317)^{* * *}$ & $(0.0326)^{* * *}$ \\
\hline Mean & $\begin{array}{c}7.265 \\
(0.0082)\end{array}$ & $\begin{array}{c}7.261 \\
(0.0081)\end{array}$ & $\begin{array}{c}0.058 \\
(0.0121)^{* * *}\end{array}$ & $\begin{array}{c}0.074 \\
(0.0110)^{* * *}\end{array}$ & $\begin{array}{c}0.072 \\
(0.0103)^{* * *}\end{array}$ & $\begin{array}{c}0.067 \\
(0.0112)^{* * *}\end{array}$ \\
\hline
\end{tabular}

1) Sample 1 includes only respondents with observed AFQT scores. Sample 2 includes those with missing AFQT scores. Reported wage distributions are conditional on reporting positive wages.

Wages are regression standardized to year $=2002$ and experience $=23$. Wages are inflation adjusted to 1990 using the CPI-U. All statistics are weighted by the cross-sectional weights. Specifications estimated on sample 1 are in addition weighted to account for attrition by age 22 and AFQT-non response. Sample 2 are in addition weighted to account for attrition by age 22. Standard errors: bootstrapped with 200 repetitions. Bootstrap stratified on NLSY cohort, race and gender. Units are sampled at the individual level. * refers to significance at $10 \%$, ${ }^{* *}$ at $5 \%$, and $* * *$ at $1 \%$ level.

2) Measured against corresponding sample reported in columns 1 and 2.

3) All Specifications match on race and gender. Model 4.4 (eq 4.4) refers to the specification matching on schooling, parental education and family structure. Model 4.5 (eq. 4.5) matches schooling, parental education, family structre, and the AFQT-scores. Model 4.6 refers to the full specification (eq 4.6) matching on schooling, AFQT scores, parental education, family structure and the school-work transition variables. 


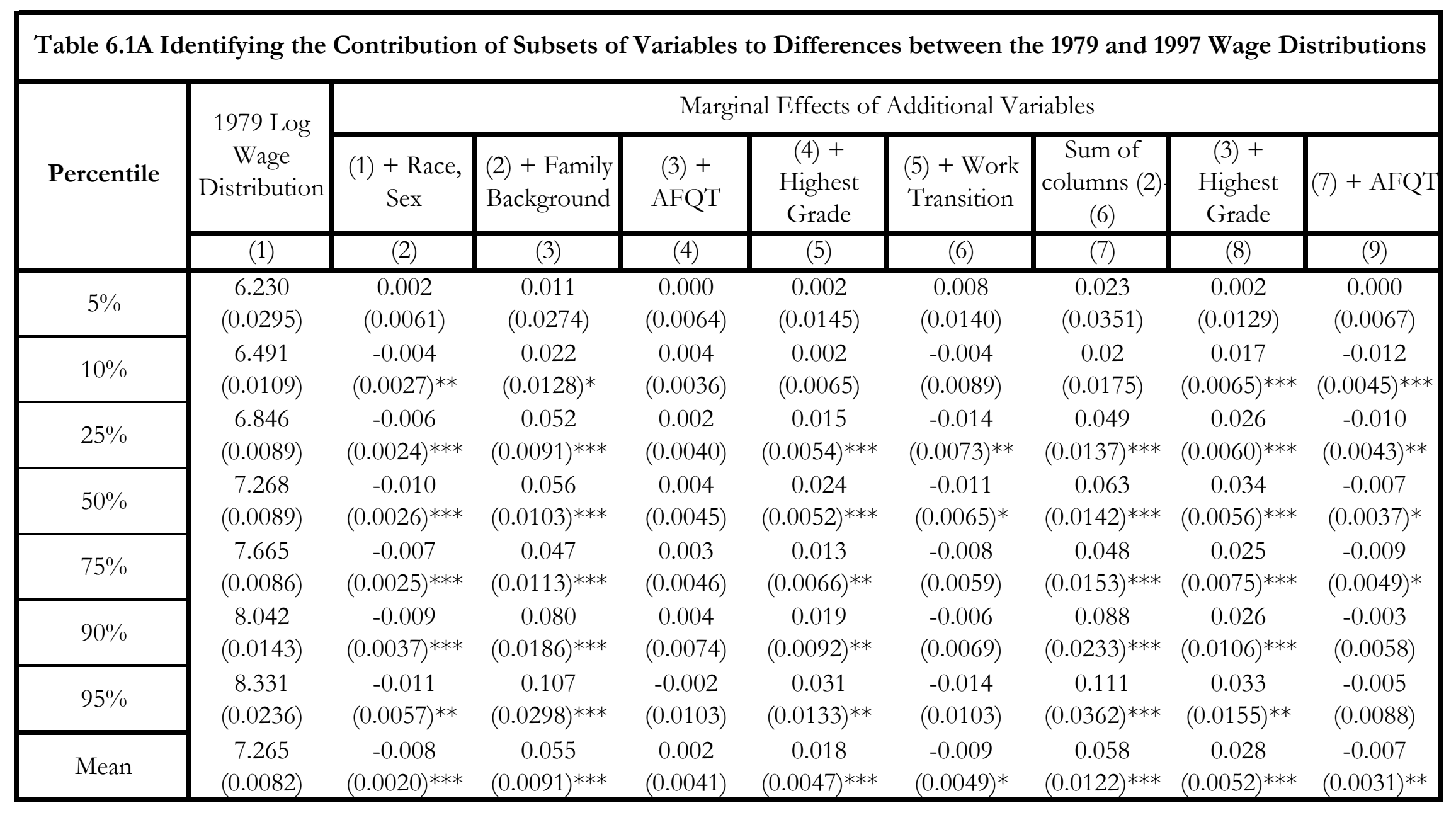

1. Estimated on respondents with non-missing AFQT scores (Sample 1). Reported wage distributions are conditional on reporting positive wages. Wages are regression standardized to year $=2002$ and experience $=23$. Wages are inflation adjusted to 1990 using the CPI-U. Standard errors: bootstrapped with 200 repetitions. Bootstrap stratified on NLSY cohort, race and gender. Units are sampled at the individual level. All statistics are weighted by NLSY cross-sectional weights adjusted for attrition by age 22 and non-response to the AFQT variable.

2. Columns $2-8$ show the incremental contribution of relevant variables in the title of each column. 


\begin{tabular}{|c|c|c|c|c|c|c|c|c|}
\hline \multirow[b]{2}{*}{ Percentile } & \multirow{2}{*}{$\begin{array}{c}1979 \text { Log } \\
\text { Wage } \\
\text { Distributi } \\
\text { on }\end{array}$} & \multicolumn{7}{|c|}{ Marginal Effects of Additional Variables } \\
\hline & & $\begin{array}{l}\text { (1) + Family } \\
\text { Background }\end{array}$ & (2) + AFQT & $\begin{array}{c}(3)+ \\
\text { Highest } \\
\text { Grade }\end{array}$ & $\begin{array}{c}(4)+\text { Work } \\
\text { Transition }\end{array}$ & $\begin{array}{c}\text { Sum of } \\
\text { columns (2) } \\
(5)\end{array}$ & $\begin{array}{c}(2)+ \\
\text { Highest } \\
\text { Grade }\end{array}$ & $\begin{array}{l}(6)+ \\
\text { AFQT }\end{array}$ \\
\hline & $(1)$ & (2) & (3) & (4) & $(5)$ & (6) & $(7)$ & (8) \\
\hline \multicolumn{9}{|c|}{ PANEL A: Males } \\
\hline \multicolumn{9}{|l|}{ White Male } \\
\hline $5 \%$ & $\begin{array}{c}6.468 \\
(0.0325\end{array}$ & $\begin{array}{c}0.030 \\
(0.0413)\end{array}$ & $\begin{array}{c}-0.007 \\
(0.0137)\end{array}$ & $\begin{array}{c}0.003 \\
(0.0155)\end{array}$ & $\begin{array}{c}0.014 \\
(0.0254)\end{array}$ & $\begin{array}{c}0.04 \\
(0.0527)\end{array}$ & $\begin{array}{c}0.010 \\
(0.0139)\end{array}$ & $\begin{array}{c}-0.014 \\
(0.0151)\end{array}$ \\
\hline $10 \%$ & $\begin{array}{c}6.753 \\
(0.0239)\end{array}$ & $\begin{array}{c}0.049 \\
(0.0230)^{* *}\end{array}$ & $\begin{array}{c}-0.012 \\
(0.0123)\end{array}$ & $\begin{array}{c}0.010 \\
(0.0116)\end{array}$ & $\begin{array}{c}0.005 \\
(0.0171)\end{array}$ & $\begin{array}{c}0.052 \\
(0.0333)^{*}\end{array}$ & $\begin{array}{c}0.015 \\
(0.0099)\end{array}$ & $\begin{array}{c}-0.016 \\
(0.0111)\end{array}$ \\
\hline $25 \%$ & $\begin{array}{c}7.121 \\
(0.0170)\end{array}$ & $\begin{array}{c}0.042 \\
(0.0187)^{* *}\end{array}$ & $\begin{array}{c}-0.016 \\
(0.0092)^{*}\end{array}$ & $\begin{array}{c}0.016 \\
(0.0096)^{*}\end{array}$ & $\begin{array}{c}0.010 \\
(0.0149)\end{array}$ & $\begin{array}{c}0.052 \\
(0.0274)^{* *}\end{array}$ & $\begin{array}{c}0.024 \\
(0.0113)^{* *}\end{array}$ & $\begin{array}{c}-0.024 \\
(0.0088)^{* * *}\end{array}$ \\
\hline $50 \%$ & $\begin{array}{c}7.490 \\
(0.0128)\end{array}$ & $\begin{array}{c}0.035 \\
(0.0168)^{* *}\end{array}$ & $\begin{array}{c}-0.016 \\
(0.0077)^{* *}\end{array}$ & $\begin{array}{c}0.020 \\
(0.0072)^{* *}\end{array}$ & $\begin{array}{c}-0.005 \\
(0.0092)\end{array}$ & $\begin{array}{c}0.034 \\
(0.0219)\end{array}$ & $\begin{array}{c}0.014 \\
(0.0079)^{*}\end{array}$ & $\begin{array}{c}-0.010 \\
(0.0063)\end{array}$ \\
\hline $75 \%$ & $\begin{array}{c}7.870 \\
(0.0181)\end{array}$ & $\begin{array}{c}0.048 \\
(0.0234)^{* *}\end{array}$ & $\begin{array}{c}-0.013 \\
(0.0107)\end{array}$ & $\begin{array}{c}0.013 \\
(0.0091)\end{array}$ & $\begin{array}{c}-0.013 \\
(0.0107)\end{array}$ & $\begin{array}{c}0.035 \\
(0.0293)\end{array}$ & $\begin{array}{c}0.014 \\
(0.0113)\end{array}$ & $\begin{array}{c}-0.014 \\
(0.0079) *\end{array}$ \\
\hline $90 \%$ & $\begin{array}{c}8.255 \\
(0.0286)\end{array}$ & $\begin{array}{c}0.110 \\
(0.0445)^{* *}\end{array}$ & $\begin{array}{c}-0.015 \\
(0.0156)\end{array}$ & $\begin{array}{c}0.026 \\
(0.0214)\end{array}$ & $\begin{array}{c}-0.024 \\
(0.0159)\end{array}$ & $\begin{array}{c}0.097 \\
(0.0542)^{*}\end{array}$ & $\begin{array}{c}0.023 \\
(0.0237)\end{array}$ & $\begin{array}{c}-0.012 \\
(0.0120)\end{array}$ \\
\hline $95 \%$ & $\begin{array}{c}8.566 \\
(0.0426)\end{array}$ & $\begin{array}{c}0.177 \\
(0.0964) *\end{array}$ & $\begin{array}{c}-0.018 \\
(0.0251)\end{array}$ & $\begin{array}{c}0.057 \\
(0.0406)\end{array}$ & $\begin{array}{c}-0.036 \\
(0.0246)\end{array}$ & $\begin{array}{c}0.18 \\
(0.1103)\end{array}$ & $\begin{array}{c}0.044 \\
(0.0420)\end{array}$ & $\begin{array}{c}-0.005 \\
(0.0179)\end{array}$ \\
\hline Mean & $\begin{array}{c}7.498 \\
(0.0133)\end{array}$ & $\begin{array}{c}0.051 \\
(0.0197)^{* *}\end{array}$ & $\begin{array}{c}-0.014 \\
(0.0083) *\end{array}$ & $\begin{array}{c}0.019 \\
(0.0077)^{* *}\end{array}$ & $\begin{array}{c}-0.005 \\
(0.0081)\end{array}$ & $\begin{array}{c}0.051 \\
(0.0241)^{* *}\end{array}$ & $\begin{array}{c}0.021 \\
(0.0098)^{* *}\end{array}$ & $\begin{array}{c}-0.017 \\
(0.0000)\end{array}$ \\
\hline Black Male & & & & & & & & \\
\hline $5 \%$ & $\begin{array}{c}6.193 \\
(0.0555)\end{array}$ & $\begin{array}{c}-0.049 \\
(0.0842)\end{array}$ & $\begin{array}{c}0.026 \\
(0.0274)\end{array}$ & $\begin{array}{c}0.002 \\
(0.0302)\end{array}$ & $\begin{array}{c}0.033 \\
(0.0752)\end{array}$ & $\begin{array}{c}0.012 \\
(0.1200)\end{array}$ & $\begin{array}{c}0.012 \\
(0.0337)\end{array}$ & $\begin{array}{c}0.015 \\
(0.0288)\end{array}$ \\
\hline $10 \%$ & $\begin{array}{c}6.431 \\
(0.0234)\end{array}$ & $\begin{array}{c}-0.015 \\
(0.0274)\end{array}$ & $\begin{array}{c}0.012 \\
(0.0102)\end{array}$ & $\begin{array}{c}0.007 \\
(0.0118)\end{array}$ & $\begin{array}{c}0.010 \\
(0.0251)\end{array}$ & $\begin{array}{c}0.014 \\
(0.0403)\end{array}$ & $\begin{array}{c}0.009 \\
(0.0135)\end{array}$ & $\begin{array}{c}0.010 \\
(0.0088)\end{array}$ \\
\hline $25 \%$ & $\begin{array}{c}6.733 \\
(0.0176)\end{array}$ & $\begin{array}{c}0.037 \\
(0.0202)\end{array}$ & $\begin{array}{c}0.009 \\
(0.0080)\end{array}$ & $\begin{array}{c}0.004 \\
(0.0097)\end{array}$ & $\begin{array}{c}0.000 \\
(0.0144)\end{array}$ & $\begin{array}{c}0.05 \\
(0.0278)^{*}\end{array}$ & $\begin{array}{c}0.006 \\
(0.0108)\end{array}$ & $\begin{array}{c}0.007 \\
(0.0062)\end{array}$ \\
\hline $50 \%$ & $\begin{array}{c}7.081 \\
(0.0185)\end{array}$ & $\begin{array}{c}0.064 \\
(0.0317)^{* *}\end{array}$ & $\begin{array}{c}0.023 \\
(0.0160)\end{array}$ & $\begin{array}{c}0.013 \\
(0.0136)\end{array}$ & $\begin{array}{c}-0.003 \\
(0.0198)\end{array}$ & $\begin{array}{c}0.097 \\
(0.0429)^{* *}\end{array}$ & $\begin{array}{c}0.016 \\
(0.0154)\end{array}$ & $\begin{array}{c}0.021 \\
(0.0131)\end{array}$ \\
\hline $75 \%$ & $\begin{array}{c}7.470 \\
(0.0207)\end{array}$ & $\begin{array}{c}0.105 \\
(0.0302)^{* * *}\end{array}$ & $\begin{array}{c}0.019 \\
(0.0155)\end{array}$ & $\begin{array}{c}0.006 \\
(0.0143)\end{array}$ & $\begin{array}{c}0.000 \\
(0.0154)\end{array}$ & $\begin{array}{c}0.13 \\
(0.0399)^{* * *}\end{array}$ & $\begin{array}{c}0.011 \\
(0.0150)\end{array}$ & $\begin{array}{c}0.014 \\
(0.0124)\end{array}$ \\
\hline $90 \%$ & $\begin{array}{c}7.793 \\
(0.0314)\end{array}$ & $\begin{array}{c}0.129 \\
(0.0400)^{* * *}\end{array}$ & $\begin{array}{c}0.038 \\
(0.0265)\end{array}$ & $\begin{array}{c}0.000 \\
(0.0194)\end{array}$ & $\begin{array}{c}0.002 \\
(0.0202)\end{array}$ & $\begin{array}{c}0.169 \\
(0.0556)^{* * *}\end{array}$ & $\begin{array}{c}0.001 \\
(0.0186)\end{array}$ & $\begin{array}{c}0.036 \\
(0.0266)\end{array}$ \\
\hline Mean & $\begin{array}{c}8.064 \\
(0.0417) \\
7.104 \\
(0.0179)\end{array}$ & $\begin{array}{c}0.092 \\
(0.0544)^{*} \\
0.057 \\
(0.0245)^{* *}\end{array}$ & $\begin{array}{c}0.041 \\
(0.0374) \\
0.022 \\
(0.0131)\end{array}$ & $\begin{array}{c}0.000 \\
(0.0262) \\
0.008 \\
(0.0110)\end{array}$ & $\begin{array}{c}0.022 \\
(0.0239) \\
0.001 \\
(0.0143)\end{array}$ & $\begin{array}{c}0.155 \\
(0.0749)^{* *} \\
0.088 \\
(0.0331)^{* *}\end{array}$ & $\begin{array}{c}-0.003 \\
(0.0251) \\
0.011 \\
(0.0123)\end{array}$ & $\begin{array}{c}0.044 \\
(0.0313) \\
0.019 \\
(0.0000)\end{array}$ \\
\hline Hispanic Male & & & & & & & & \\
\hline $5 \%$ & $\begin{array}{c}6.350 \\
(0.0417)\end{array}$ & $\begin{array}{c}-0.032 \\
(0.0928)\end{array}$ & $\begin{array}{c}0.016 \\
(0.0321)\end{array}$ & $\begin{array}{c}-0.030 \\
(0.0697)\end{array}$ & $\begin{array}{c}-0.034 \\
(0.0619)\end{array}$ & $\begin{array}{c}-0.08 \\
(0.1354)\end{array}$ & $\begin{array}{c}-0.005 \\
(0.0460)\end{array}$ & $\begin{array}{c}-0.010 \\
(0.0416)\end{array}$ \\
\hline $10 \%$ & $\begin{array}{c}6.525 \\
(0.0272)\end{array}$ & $\begin{array}{c}0.039 \\
(0.0366)\end{array}$ & $\begin{array}{c}0.011 \\
(0.0145)\end{array}$ & $\begin{array}{c}-0.001 \\
(0.0176)\end{array}$ & $\begin{array}{c}-0.024 \\
(0.0237)\end{array}$ & $\begin{array}{c}0.025 \\
(0.0492)\end{array}$ & $\begin{array}{c}0.033 \\
(0.0179)\end{array}$ & $\begin{array}{c}-0.022 \\
(0.0150)\end{array}$ \\
\hline $25 \%$ & $\begin{array}{c}6.913 \\
(0.0286)\end{array}$ & $\begin{array}{c}0.071 \\
(0.0310)^{* *}\end{array}$ & $\begin{array}{c}0.009 \\
(0.0154)\end{array}$ & $\begin{array}{c}-0.001 \\
(0.0172)\end{array}$ & $\begin{array}{c}-0.053 \\
(0.0227)^{* *}\end{array}$ & $\begin{array}{c}0.026 \\
(0.0448)\end{array}$ & $\begin{array}{c}0.021 \\
(0.0170)\end{array}$ & $\begin{array}{c}-0.013 \\
(0.0137)\end{array}$ \\
\hline $50 \%$ & $\begin{array}{c}7.293 \\
(0.0293)\end{array}$ & $\begin{array}{c}0.095 \\
(0.0273)^{* * *}\end{array}$ & $\begin{array}{c}0.008 \\
(0.0129)\end{array}$ & $\begin{array}{c}0.000 \\
(0.0122)\end{array}$ & $\begin{array}{c}-0.020 \\
(0.0162)\end{array}$ & $\begin{array}{c}0.083 \\
(0.0364)^{* *}\end{array}$ & $\begin{array}{c}0.026 \\
(0.0152)\end{array}$ & $\begin{array}{c}-0.018 \\
(0.0121)\end{array}$ \\
\hline $75 \%$ & $\begin{array}{c}7.676 \\
(0.0331)\end{array}$ & $\begin{array}{c}0.119 \\
(0.0360)^{* * *}\end{array}$ & $\begin{array}{c}0.001 \\
(0.0201)\end{array}$ & $\begin{array}{c}-0.001 \\
(0.0169)\end{array}$ & $\begin{array}{c}-0.019 \\
(0.0164)\end{array}$ & $\begin{array}{c}0.1 \\
(0.0475)^{* *}\end{array}$ & $\begin{array}{c}0.017 \\
(0.0205)\end{array}$ & $\begin{array}{c}-0.017 \\
(0.0178)\end{array}$ \\
\hline $90 \%$ & $\begin{array}{c}8.040 \\
(0.0497)\end{array}$ & $\begin{array}{c}0.198 \\
(0.0605)^{* * *}\end{array}$ & $\begin{array}{c}0.004 \\
(0.0325)\end{array}$ & $\begin{array}{c}-0.010 \\
(0.0274)\end{array}$ & $\begin{array}{c}-0.045 \\
(0.0277)^{*}\end{array}$ & $\begin{array}{c}0.147 \\
(0.0790)^{* *}\end{array}$ & $\begin{array}{c}0.019 \\
(0.0311)\end{array}$ & $\begin{array}{c}-0.024 \\
(0.0289)\end{array}$ \\
\hline Mean & $\begin{array}{c}8.315 \\
(0.0596) \\
7.291 \\
(0.0254)\end{array}$ & $\begin{array}{c}0.158 \\
(0.0858)^{*} \\
0.098 \\
(0.0289)^{* * *}\end{array}$ & $\begin{array}{c}0.000 \\
(0.0283) \\
0.006 \\
(0.0139)\end{array}$ & $\begin{array}{c}0.003 \\
(0.0399) \\
0.001 \\
(0.0118)\end{array}$ & $\begin{array}{c}-0.006 \\
(0.0455) \\
-0.027 \\
(0.0127)^{* *}\end{array}$ & $\begin{array}{c}0.155 \\
(0.1087) \\
0.078 \\
(0.0365)^{* *}\end{array}$ & $\begin{array}{c}0.003 \\
(0.0383) \\
0.022 \\
(0.0124)\end{array}$ & $\begin{array}{c}0.000 \\
(0.0264) \\
-0.014 \\
(0.0000)\end{array}$ \\
\hline
\end{tabular}




\begin{tabular}{|c|c|c|c|c|c|c|c|c|}
\hline \multicolumn{9}{|c|}{$\begin{array}{c}\text { Table 6.1B (contd): Identifying the Contribution of Subsets of Variables to Differences between the } 1979 \\
\text { and } 1997 \text { Wage Distributions by Race and Sex }\end{array}$} \\
\hline \multirow[b]{2}{*}{ Percentile } & \multirow{2}{*}{$\begin{array}{l}1979 \text { Log } \\
\text { Wage } \\
\text { Distribution }\end{array}$} & \multicolumn{7}{|c|}{ Marginal Effects of Additional Variables } \\
\hline & & $\begin{array}{l}\text { (1) + Family } \\
\text { Background }\end{array}$ & $\begin{array}{l}(2)+ \\
\text { AFQT }\end{array}$ & $\begin{array}{c}(3)+ \\
\text { Highest } \\
\text { Grade }\end{array}$ & $\begin{array}{c}\text { (4) }+ \text { Work } \\
\text { Transition }\end{array}$ & $\begin{array}{c}\text { Sum of } \\
\text { columns } \\
2,3,4 \text { and } 5\end{array}$ & $\begin{array}{c}(2)+ \\
\text { Highest } \\
\text { Grade }\end{array}$ & $(7)+$ AFQT \\
\hline & (1) & (2) & (3) & (4) & (5) & (6) & (7) & (8) \\
\hline \multicolumn{9}{|c|}{ PANEL B: Females } \\
\hline \multicolumn{9}{|l|}{ White Female } \\
\hline $5 \%$ & $\begin{array}{c}5.869 \\
(0.0792)\end{array}$ & $\begin{array}{c}0.079 \\
(0.0975)\end{array}$ & $\begin{array}{c}-0.019 \\
(0.0163)\end{array}$ & $\begin{array}{c}-0.092 \\
(0.0611)\end{array}$ & $\begin{array}{c}0.021 \\
(0.0459)\end{array}$ & $\begin{array}{c}-0.011 \\
(0.1249)\end{array}$ & $\begin{array}{c}-0.111 \\
(0.0555)^{* *}\end{array}$ & $\begin{array}{c}0.000 \\
(0.0230)\end{array}$ \\
\hline $10 \%$ & $\begin{array}{c}6.407 \\
(0.0165)\end{array}$ & $\begin{array}{c}0.005 \\
(0.0294)\end{array}$ & $\begin{array}{c}0.000 \\
(0.0047)\end{array}$ & $\begin{array}{c}-0.002 \\
(0.0155)\end{array}$ & $\begin{array}{c}-0.028 \\
(0.0204)\end{array}$ & $\begin{array}{c}-0.025 \\
(0.0393)\end{array}$ & $\begin{array}{c}0.001 \\
(0.0129)\end{array}$ & $\begin{array}{c}-0.003 \\
(0.0083)\end{array}$ \\
\hline $25 \%$ & $\begin{array}{c}6.733 \\
(0.0134)\end{array}$ & $\begin{array}{c}0.038 \\
(0.0204)\end{array}$ & $\begin{array}{c}0.000 \\
(0.0062)\end{array}$ & $\begin{array}{c}0.011 \\
(0.0106)\end{array}$ & $\begin{array}{c}-0.028 \\
(0.0137)^{* *}\end{array}$ & $\begin{array}{c}0.021 \\
(0.0275)\end{array}$ & $\begin{array}{c}0.026 \\
(0.0113)^{* *}\end{array}$ & $\begin{array}{c}-0.015 \\
(0.0067)^{* *}\end{array}$ \\
\hline $50 \%$ & $\begin{array}{c}7.115 \\
(0.0178)\end{array}$ & $\begin{array}{c}0.059 \\
(0.0201)^{* *}\end{array}$ & $\begin{array}{c}0.001 \\
(0.0080)\end{array}$ & $\begin{array}{c}0.032 \\
(0.0115)^{* * *}\end{array}$ & $\begin{array}{c}-0.019 \\
(0.0113)^{*}\end{array}$ & $\begin{array}{c}0.073 \\
(0.0270)^{* * *}\end{array}$ & $\begin{array}{c}0.041 \\
(0.0131)^{* * *}\end{array}$ & $\begin{array}{c}-0.009 \\
(0.0070)\end{array}$ \\
\hline $75 \%$ & $\begin{array}{c}7.528 \\
(0.0189)\end{array}$ & $\begin{array}{c}0.059 \\
(0.0208)^{* *}\end{array}$ & $\begin{array}{c}0.001 \\
(0.0057)\end{array}$ & $\begin{array}{c}0.040 \\
(0.0132)^{* * *}\end{array}$ & $\begin{array}{c}-0.011 \\
(0.0099)\end{array}$ & $\begin{array}{c}0.089 \\
(0.0272)^{* * *}\end{array}$ & $\begin{array}{c}0.045 \\
(0.0137)^{* * *}\end{array}$ & $\begin{array}{c}-0.005 \\
(0.0059)\end{array}$ \\
\hline $90 \%$ & $\begin{array}{c}7.884 \\
(0.0212)\end{array}$ & $\begin{array}{c}0.050 \\
(0.0232)^{* *}\end{array}$ & $\begin{array}{c}0.006 \\
(0.0079)\end{array}$ & $\begin{array}{c}0.042 \\
(0.0270)^{*}\end{array}$ & $\begin{array}{c}0.016 \\
(0.0140)\end{array}$ & $\begin{array}{c}0.114 \\
(0.0391)^{* * *}\end{array}$ & $\begin{array}{c}0.052 \\
(0.0259)^{* *}\end{array}$ & $\begin{array}{c}-0.004 \\
(0.0106)\end{array}$ \\
\hline $95 \%$ & $\begin{array}{c}8.138 \\
(0.0290)\end{array}$ & $\begin{array}{c}0.051 \\
(0.0345)\end{array}$ & $\begin{array}{c}0.008 \\
(0.0119)\end{array}$ & $\begin{array}{c}0.094 \\
(0.0314)^{* * *}\end{array}$ & $\begin{array}{c}0.011 \\
(0.0193)\end{array}$ & $\begin{array}{c}0.164 \\
(0.0519)^{* * *}\end{array}$ & $\begin{array}{c}0.105 \\
(0.0329)^{* * *}\end{array}$ & $\begin{array}{c}-0.003 \\
(0.0151)\end{array}$ \\
\hline Mean & $\begin{array}{c}7.128 \\
(0.0142)\end{array}$ & $\begin{array}{c}0.039 \\
(0.0154)^{* *}\end{array}$ & $\begin{array}{c}0.001 \\
(0.0046)\end{array}$ & $\begin{array}{c}0.025 \\
(0.0086)^{* * *}\end{array}$ & $\begin{array}{c}-0.012 \\
(0.0078)\end{array}$ & $\begin{array}{c}0.053 \\
(0.0198)^{* * *}\end{array}$ & $\begin{array}{c}0.034 \\
(0.0086)^{* * *}\end{array}$ & $\begin{array}{c}-0.008 \\
(0.0000)\end{array}$ \\
\hline Black Female & & & & & & & & \\
\hline $5 \%$ & $\begin{array}{c}6.102 \\
(0.0610)\end{array}$ & $\begin{array}{c}-0.008 \\
(0.0925)\end{array}$ & $\begin{array}{c}0.020 \\
(0.0497)\end{array}$ & $\begin{array}{c}0.023 \\
(0.0346)\end{array}$ & $\begin{array}{c}0.046 \\
(0.0544)\end{array}$ & $\begin{array}{c}0.081 \\
(0.1232)\end{array}$ & $\begin{array}{c}0.000 \\
(0.0389)\end{array}$ & $\begin{array}{c}0.043 \\
(0.0384)\end{array}$ \\
\hline $10 \%$ & $\begin{array}{c}6.359 \\
(0.0132)\end{array}$ & $\begin{array}{c}0.018 \\
(0.0281)\end{array}$ & $\begin{array}{c}0.017 \\
(0.0144)\end{array}$ & $\begin{array}{c}0.004 \\
(0.0110)\end{array}$ & $\begin{array}{c}0.008 \\
(0.0156)\end{array}$ & $\begin{array}{c}0.047 \\
(0.0369)\end{array}$ & $\begin{array}{c}0.017 \\
(0.0168)\end{array}$ & $\begin{array}{c}0.004 \\
(0.0082)\end{array}$ \\
\hline $25 \%$ & $\begin{array}{c}6.599 \\
(0.0169)\end{array}$ & $\begin{array}{c}0.062 \\
(0.0206)^{* * *}\end{array}$ & $\begin{array}{c}0.016 \\
(0.0160)\end{array}$ & $\begin{array}{c}0.005 \\
(0.0097)\end{array}$ & $\begin{array}{c}-0.004 \\
(0.0149)\end{array}$ & $\begin{array}{c}0.079 \\
(0.0316)^{* *}\end{array}$ & $\begin{array}{c}0.024 \\
(0.0141)^{*}\end{array}$ & $\begin{array}{c}-0.002 \\
(0.0126)\end{array}$ \\
\hline $50 \%$ & $\begin{array}{c}6.936 \\
(0.0170)\end{array}$ & $\begin{array}{c}0.070 \\
(0.0250)^{* * *}\end{array}$ & $\begin{array}{c}0.043 \\
(0.0258)^{*}\end{array}$ & $\begin{array}{c}0.011 \\
(0.0123)\end{array}$ & $\begin{array}{c}-0.004 \\
(0.0181)\end{array}$ & $\begin{array}{c}0.12 \\
(0.0421)^{* * *}\end{array}$ & $\begin{array}{c}0.045 \\
(0.0198)^{* *}\end{array}$ & $\begin{array}{c}0.009 \\
(0.0208)\end{array}$ \\
\hline $75 \%$ & $\begin{array}{c}7.314 \\
(0.0185)\end{array}$ & $\begin{array}{c}0.095 \\
(0.0304)^{* * *}\end{array}$ & $\begin{array}{c}0.063 \\
(0.0253)^{* *}\end{array}$ & $\begin{array}{c}0.005 \\
(0.0112)\end{array}$ & $\begin{array}{c}-0.013 \\
(0.0134)\end{array}$ & $\begin{array}{c}0.15 \\
(0.0432)^{* * *}\end{array}$ & $\begin{array}{c}0.040 \\
(0.0199)^{* *}\end{array}$ & $\begin{array}{c}0.028 \\
(0.0212)\end{array}$ \\
\hline $90 \%$ & $\begin{array}{c}7.662 \\
(0.0231)\end{array}$ & $\begin{array}{c}0.072 \\
(0.0276)^{* * *}\end{array}$ & $\begin{array}{c}0.058 \\
(0.0293)^{*}\end{array}$ & $\begin{array}{c}0.002 \\
(0.0124)\end{array}$ & $\begin{array}{c}-0.013 \\
(0.0123)\end{array}$ & $\begin{array}{c}0.119 \\
(0.0439)^{* *}\end{array}$ & $\begin{array}{c}0.030 \\
(0.0182)^{*}\end{array}$ & $\begin{array}{c}0.029 \\
(0.0235)\end{array}$ \\
\hline $95 \%$ & $\begin{array}{c}7.854 \\
(0.0250)\end{array}$ & $\begin{array}{c}0.027 \\
(0.0355)\end{array}$ & $\begin{array}{c}0.093 \\
(0.0431)^{* *}\end{array}$ & $\begin{array}{c}0.002 \\
(0.0197)\end{array}$ & $\begin{array}{c}0.000 \\
(0.0175)\end{array}$ & $\begin{array}{c}0.122 \\
(0.0617)^{* *}\end{array}$ & $\begin{array}{c}0.040 \\
(0.0282)\end{array}$ & $\begin{array}{c}0.054 \\
(0.0366)\end{array}$ \\
\hline Mean & $\begin{array}{c}6.966 \\
(0.0153)\end{array}$ & $\begin{array}{c}0.060 \\
(0.0183)^{* * *}\end{array}$ & $\begin{array}{c}0.039 \\
(0.0166)^{* *}\end{array}$ & $\begin{array}{c}0.006 \\
(0.0078)\end{array}$ & $\begin{array}{c}-0.005 \\
(0.0099)\end{array}$ & $\begin{array}{c}0.1 \\
(0.0277)^{* * *}\end{array}$ & $\begin{array}{c}0.032 \\
(0.0119)^{* * *}\end{array}$ & $\begin{array}{c}0.014 \\
(0.0000)\end{array}$ \\
\hline Hispanic Female & & & & & & & & \\
\hline $5 \%$ & $\begin{array}{c}6.121 \\
(0.0734)\end{array}$ & $\begin{array}{c}0.011 \\
(0.0639)\end{array}$ & $\begin{array}{c}0.040 \\
(0.0356)\end{array}$ & $\begin{array}{c}0.014 \\
(0.0407)\end{array}$ & $\begin{array}{c}0.041 \\
(0.0623)\end{array}$ & $\begin{array}{c}0.106 \\
(0.1043)\end{array}$ & $\begin{array}{c}0.082 \\
(0.0504)^{*}\end{array}$ & $\begin{array}{c}-0.029 \\
(0.0337)\end{array}$ \\
\hline $10 \%$ & $\begin{array}{c}6.396 \\
(0.0198)\end{array}$ & $\begin{array}{c}0.040 \\
(0.0236)^{*}\end{array}$ & $\begin{array}{c}0.010 \\
(0.0150)\end{array}$ & $\begin{array}{c}0.032 \\
(0.0190)^{*}\end{array}$ & $\begin{array}{c}0.009 \\
(0.0255)\end{array}$ & $\begin{array}{c}0.091 \\
(0.0423)^{* *}\end{array}$ & $\begin{array}{c}0.045 \\
(0.0220)^{* *}\end{array}$ & $\begin{array}{c}-0.004 \\
(0.0105)\end{array}$ \\
\hline $25 \%$ & $\begin{array}{c}6.692 \\
(0.0235)\end{array}$ & $\begin{array}{c}0.089 \\
(0.0318)^{* *}\end{array}$ & $\begin{array}{c}0.039 \\
(0.0204)^{*}\end{array}$ & $\begin{array}{c}0.034 \\
(0.0181)^{*}\end{array}$ & $\begin{array}{c}0.016 \\
(0.0254)\end{array}$ & $\begin{array}{c}0.178 \\
(0.0490)^{* * *}\end{array}$ & $\begin{array}{c}0.073 \\
(0.0237)^{* * *}\end{array}$ & $\begin{array}{c}0.000 \\
(0.0113)\end{array}$ \\
\hline $50 \%$ & $\begin{array}{c}7.078 \\
(0.0261)\end{array}$ & $\begin{array}{c}0.118 \\
(0.0256)^{* * *}\end{array}$ & $\begin{array}{c}0.025 \\
(0.0146)^{*}\end{array}$ & $\begin{array}{c}0.024 \\
(0.0135)^{*}\end{array}$ & $\begin{array}{c}-0.012 \\
(0.0157)\end{array}$ & $\begin{array}{c}0.155 \\
(0.0360)^{* * *}\end{array}$ & $\begin{array}{c}0.046 \\
(0.0169)^{* * *}\end{array}$ & $\begin{array}{c}0.003 \\
(0.0092)\end{array}$ \\
\hline $75 \%$ & $\begin{array}{c}7.468 \\
(0.0292)\end{array}$ & $\begin{array}{c}0.127 \\
(0.0346)^{* * *}\end{array}$ & $\begin{array}{c}0.038 \\
(0.0227)^{*}\end{array}$ & $\begin{array}{c}0.001 \\
(0.0135)\end{array}$ & $\begin{array}{c}-0.011 \\
(0.0179)\end{array}$ & $\begin{array}{c}0.155 \\
(0.0471)^{* * *}\end{array}$ & $\begin{array}{c}0.033 \\
(0.0202)^{*}\end{array}$ & $\begin{array}{c}0.006 \\
(0.0123)\end{array}$ \\
\hline $90 \%$ & $\begin{array}{c}7.827 \\
(0.0432)\end{array}$ & $\begin{array}{c}0.142 \\
(0.0504)^{* * *}\end{array}$ & $\begin{array}{c}0.052 \\
(0.0253)^{* *}\end{array}$ & $\begin{array}{c}-0.010 \\
(0.0176)\end{array}$ & $\begin{array}{c}-0.026 \\
(0.0305)\end{array}$ & $\begin{array}{c}0.158 \\
(0.0665)^{* *}\end{array}$ & $\begin{array}{c}0.027 \\
(0.0223)\end{array}$ & $\begin{array}{c}0.016 \\
(0.0171)\end{array}$ \\
\hline $95 \%$ & $\begin{array}{c}8.061 \\
(0.0484)\end{array}$ & $\begin{array}{c}0.118 \\
(0.0372)^{* * *}\end{array}$ & $\begin{array}{c}0.005 \\
(0.0215)\end{array}$ & $\begin{array}{c}0.000 \\
(0.0150)\end{array}$ & $\begin{array}{c}-0.019 \\
(0.0246)\end{array}$ & $\begin{array}{c}0.104 \\
(0.0517)^{* *}\end{array}$ & $\begin{array}{c}0.004 \\
(0.0161)\end{array}$ & $\begin{array}{c}0.001 \\
(0.0142)\end{array}$ \\
\hline Mean & $\begin{array}{c}7.087 \\
(0.0227)\end{array}$ & $\begin{array}{c}0.102 \\
(0.0237)^{* * *}\end{array}$ & $\begin{array}{c}0.033 \\
(0.0141)^{* *}\end{array}$ & $\begin{array}{c}0.017 \\
(0.0104)^{*}\end{array}$ & $\begin{array}{c}-0.008 \\
(0.0141)\end{array}$ & $\begin{array}{c}0.144 \\
(0.0327)^{* * *}\end{array}$ & $\begin{array}{c}0.047 \\
(0.0133)^{* * *}\end{array}$ & $\begin{array}{c}0.003 \\
(0.0000)\end{array}$ \\
\hline
\end{tabular}




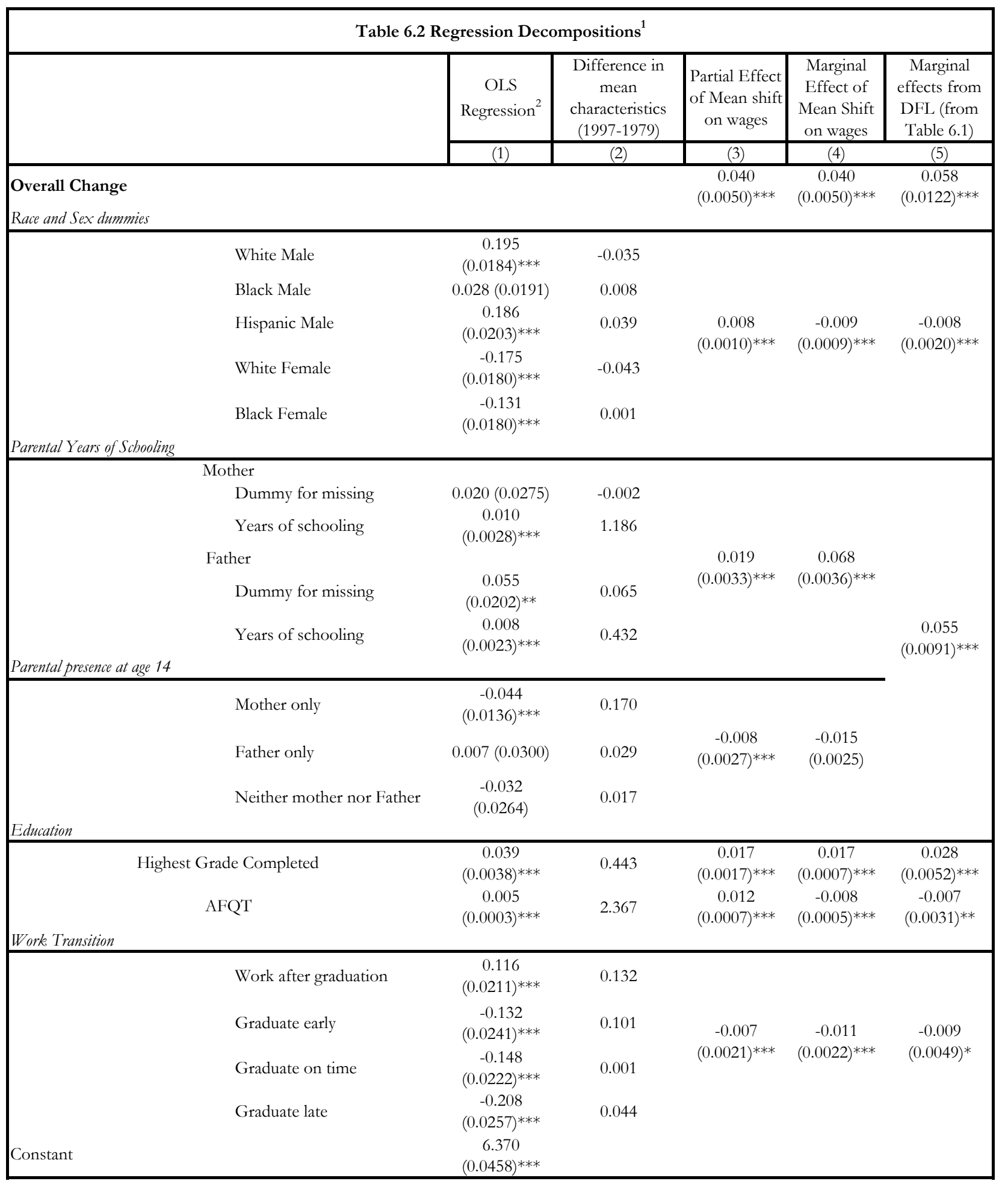

1) The sample excludes respondents without valid AFQT scores and attriters by age 22. The excluded category in the regression specification are white males, with both mother and father present at age 14 and who did not graduate by age 20 . Observations are weighted using the cross-section weights provided by the NLSY adjusted to account for attrition by age 22 and AFQT non-response. Standard errors in parenthesis. *** significant at $1 \%, * *$ significant at $5 \%, *$ significant $10 \%$

2) $\quad \mathrm{R}-\mathrm{sq}=0.197, \mathrm{~F}(18,23865)=185.48, \mathrm{~N}=23884$. 


\begin{tabular}{|c|c|c|c|c|c|c|c|c|c|c|c|c|}
\hline \multicolumn{13}{|c|}{ Table 6.3 Regression Decompositions by Race ${ }^{1}$} \\
\hline \multicolumn{13}{|l|}{ PANEL A: Males } \\
\hline & \multicolumn{4}{|c|}{ White } & \multicolumn{4}{|c|}{$\overline{\text { Black }}$} & \multicolumn{4}{|c|}{ Hispanic } \\
\hline & $\begin{array}{c}\text { OLS } \\
\text { Regression } \\
\text { Coef }\end{array}$ & $\begin{array}{c}\text { Difference in } \\
\text { mean } \\
\text { characteristics } \\
(1997-1979)\end{array}$ & $\begin{array}{c}\text { Partial Effect } \\
\text { of Mean shift } \\
\text { on wages }\end{array}$ & $\begin{array}{c}\text { Marginal } \\
\text { Effect of } \\
\text { Mean Shift } \\
\text { on wages } \\
\end{array}$ & $\begin{array}{c}\text { OLS } \\
\text { Regression }\end{array}$ & $\begin{array}{c}\text { Difference in } \\
\text { mean } \\
\text { characteristics } \\
(1997-1979)\end{array}$ & $\begin{array}{c}\text { Partial } \\
\text { Effect of } \\
\text { Mean shift } \\
\text { on wages } \\
\end{array}$ & $\begin{array}{c}\text { Marginal } \\
\text { Effect of } \\
\text { Mean Shift } \\
\text { on wages } \\
\end{array}$ & $\begin{array}{c}\text { OLS } \\
\text { Regression }\end{array}$ & $\begin{array}{c}\text { Difference in } \\
\text { mean } \\
\text { characteristics } \\
(1997-1979)\end{array}$ & \begin{tabular}{|c|} 
Partial Effect \\
of Mean \\
shift on \\
wages \\
\end{tabular} & $\begin{array}{c}\text { Marginal } \\
\text { Effect of } \\
\text { Mean Shift } \\
\text { on wages } \\
\end{array}$ \\
\hline & $(1)$ & $(2)$ & (3) & $(4)$ & (5) & $(6)$ & $(7)$ & $(8)$ & (9) & $(10)$ & \begin{tabular}{|l|}
$(11)$ \\
\end{tabular} & $(12)$ \\
\hline $\begin{array}{l}\text { Overall Change } \\
\text { Parental Years of Schooling }\end{array}$ & & & $\begin{array}{c}0.028 \\
(0.0097)^{* * *}\end{array}$ & $\begin{array}{c}0.028 \\
(0.0097)^{* * *}\end{array}$ & & & $\begin{array}{c}0.055 \\
(0.0126)^{* * *}\end{array}$ & $\begin{array}{c}0.055 \\
(0.0077)^{* * *}\end{array}$ & & & $\begin{array}{c}0.104 \\
(0.0138)^{* * *}\end{array}$ & $\begin{array}{c}0.104 \\
(0.0084)^{* * *}\end{array}$ \\
\hline Mother & & & & & & & & & & & & \\
\hline Dummy for missing & $\begin{array}{c}0.011 \\
(0.0561)\end{array}$ & -0.008 & & & $\begin{array}{c}0.069 \\
(0.0577)\end{array}$ & -0.027 & & & $\begin{array}{c}-0.005 \\
(0.0553)\end{array}$ & -0.038 & & \\
\hline $\begin{array}{l}\text { Years of schooling } \\
\text { Father }\end{array}$ & $\begin{array}{c}0.013 \\
(0.0051)^{* *}\end{array}$ & 1.244 & 0.027 & 0.072 & $\begin{array}{c}0.004 \\
(0.0060)\end{array}$ & 1.489 & 0.005 & 0.058 & $\begin{array}{c}0.025 \\
(0.0063)^{* * *}\end{array}$ & 2.056 & 0.053 & 0.102 \\
\hline Dummy for missing & $\begin{array}{c}0.096 \\
(0.0499)^{* *}\end{array}$ & 0.053 & & & $\begin{array}{c}-0.029 \\
(0.0358)\end{array}$ & 0.055 & & & $\begin{array}{c}-0.009 \\
(0.0436)\end{array}$ & -0.004 & & \\
\hline $\begin{array}{l}\text { Years of schooling } \\
\text { Parental presence at age } 14\end{array}$ & $\begin{array}{c}0.011 \\
(0.0039)^{* * *}\end{array}$ & 0.534 & & & $\begin{array}{c}0.003 \\
(0.0052)\end{array}$ & 0.841 & & & $\begin{array}{c}0.001 \\
(0.0053)\end{array}$ & 1.204 & & \\
\hline Mother only & $\begin{array}{c}-0.072 \\
(0.0252)^{* * *}\end{array}$ & 0.153 & & & $\begin{array}{c}-0.041 \\
(0.0241)\end{array}$ & 0.208 & & & $\begin{array}{c}-0.019 \\
(0.0354)\end{array}$ & 0.035 & & \\
\hline Father only & $\begin{array}{c}-0.031 \\
(0.0517)\end{array}$ & 0.026 & $\begin{array}{c}-0.013 \\
(0.0045)^{* * *}\end{array}$ & $\begin{array}{c}-0.022 \\
(0.0042)^{* * *}\end{array}$ & $\begin{array}{c}-0.124 \\
(0.0734)\end{array}$ & 0.016 & $\begin{array}{c}-0.011 \\
(0.0055)^{* *}\end{array}$ & $\begin{array}{c}-0.016 \\
(0.0051)^{* * *}\end{array}$ & $\begin{array}{c}0.096 \\
(0.1087)\end{array}$ & 0.035 & $\begin{array}{c}0.003 \\
(0.0042)\end{array}$ & $\begin{array}{c}-0.001 \\
(0.0043)\end{array}$ \\
\hline $\begin{array}{l}\text { Neither mother nor Father } \\
\text { Education }\end{array}$ & $\begin{array}{c}-0.041 \\
(0.0579)\end{array}$ & 0.022 & & & $\begin{array}{c}-0.041 \\
(0.0532)\end{array}$ & 0.014 & & & $\begin{array}{c}-0.052 \\
(0.0724)\end{array}$ & 0.003 & & \\
\hline Highest Grade Completed & $\begin{array}{c}0.048 \\
(0.0066))^{* * *}\end{array}$ & 0.413 & $\begin{array}{c}0.020 \\
(0.0027)^{* * *}\end{array}$ & $\begin{array}{c}0.012 \\
(0.0008)^{* * *}\end{array}$ & $\begin{array}{c}0.059 \\
(0.0078)\end{array}$ & 0.076 & $\begin{array}{c}0.004 \\
(0.0006)^{* * *}\end{array}$ & $\begin{array}{c}-0.012 \\
(0.0009)^{* * *}\end{array}$ & $\begin{array}{c}0.027 \\
(0.0099)^{* * *}\end{array}$ & 0.584 & $\begin{array}{c}0.016 \\
(0.0058)^{* * *}\end{array}$ & $\begin{array}{c}0.016 \\
(0.0021)^{* * *}\end{array}$ \\
\hline $\begin{array}{r}\text { AFQT } \\
\text { Work Transition } \\
\end{array}$ & $\begin{array}{c}0.005 \\
(0.0004)^{* * *}\end{array}$ & 2.308 & $\begin{array}{c}0.011 \\
(0.0010)^{* * *}\end{array}$ & $\begin{array}{c}-0.015 \\
(0.0013)^{* * *}\end{array}$ & $\begin{array}{c}0.008 \\
(0.0007)\end{array}$ & 5.979 & $\begin{array}{c}0.049 \\
(0.0044)^{* * *}\end{array}$ & $\begin{array}{c}0.024 \\
(0.0022)^{* * *}\end{array}$ & $\begin{array}{c}0.005 \\
(0.0010)^{* * *}\end{array}$ & 5.680 & $\begin{array}{c}0.031 \\
(0.0060)^{* * *}\end{array}$ & $\begin{array}{c}-0.008 \\
(0.0014)^{* * *}\end{array}$ \\
\hline Work after graduation & $\begin{array}{c}0.139 \\
(0.0433)^{* * *}\end{array}$ & 0.169 & & & $\begin{array}{c}0.068 \\
(0.0373)\end{array}$ & 0.197 & & & $\begin{array}{c}0.155 \\
(0.0712)^{* *}\end{array}$ & 0.148 & & \\
\hline Graduate early & $\begin{array}{c}-0.231 \\
(0.0489)^{* * *}\end{array}$ & 0.134 & -0.017 & -0.020 & $\begin{array}{c}0.013 \\
(0.0552)\end{array}$ & 0.146 & 0.008 & 0.001 & $\begin{array}{c}-0.075 \\
(0.0796)\end{array}$ & 0.152 & 0.002 & -0.006 \\
\hline Graduate on time & $\begin{array}{c}-0.169 \\
(0.0463)^{* * *}\end{array}$ & 0.006 & $(0.0049)^{* * *}$ & $(0.0052)^{* * *}$ & $\begin{array}{c}-0.062 \\
(0.0381)\end{array}$ & 0.004 & $(0.0075)$ & $(0.0074)$ & $\begin{array}{c}-0.293 \\
(0.0790)^{* * *}\end{array}$ & 0.053 & $(0.0081)$ & $(0.0086)$ \\
\hline Graduate late & $\begin{array}{c}-0.273 \\
(0.0480)^{* * *}\end{array}$ & 0.032 & & & $\begin{array}{c}-0.077 \\
(0.0407)\end{array}$ & 0.088 & & & $\begin{array}{c}-0.225 \\
(0.0671)^{* * *}\end{array}$ & -0.027 & & \\
\hline $\begin{array}{l}\text { Constant } \\
\text { R-sq } \\
\text { Observations }\end{array}$ & $\begin{array}{c}6.404 \\
(0.0824)^{* * *} \\
0.1614 \\
5997\end{array}$ & & & & $\begin{array}{c}6.198 \\
(0.1069) \\
0.1621 \\
3539\end{array}$ & & & & $\begin{array}{c}6.641 \\
(0.1129) \\
0.1494 \\
2235\end{array}$ & & & \\
\hline
\end{tabular}




\begin{tabular}{|c|c|c|c|c|c|c|c|c|c|c|c|c|}
\hline \multicolumn{13}{|c|}{ Table 6.3 Regression Decompositions by Race ${ }^{1}$} \\
\hline \multicolumn{13}{|l|}{ PANEL B: Females } \\
\hline & \multicolumn{4}{|c|}{ White } & \multicolumn{4}{|c|}{ Black } & \multicolumn{4}{|c|}{ Hispanic } \\
\hline & $\begin{array}{c}\text { OLS } \\
\text { Regression }\end{array}$ & $\begin{array}{c}\text { Difference in } \\
\text { mean } \\
\text { characteristics } \\
(1997-1979)\end{array}$ & $\begin{array}{c}\text { Partial Effect } \\
\text { of Mean shift } \\
\text { on wages }\end{array}$ & $\begin{array}{c}\text { Marginal } \\
\text { Effect of } \\
\text { Mean Shift } \\
\text { on wages }\end{array}$ & $\begin{array}{c}\text { OLS } \\
\text { Regression }\end{array}$ & $\begin{array}{c}\text { Difference in } \\
\text { mean } \\
\text { characteristics } \\
(1997-1979)\end{array}$ & $\begin{array}{c}\text { Partial } \\
\text { Effect of } \\
\text { Mean shift } \\
\text { on wages }\end{array}$ & $\begin{array}{c}\text { Marginal } \\
\text { Effect of } \\
\text { Mean Shift } \\
\text { on wages }\end{array}$ & $\begin{array}{c}\text { OLS } \\
\text { Regression }\end{array}$ & $\begin{array}{c}\text { Difference in } \\
\text { mean } \\
\text { characteristics } \\
(1997-1979)\end{array}$ & \begin{tabular}{|c|} 
Partial \\
Effect of \\
Mean shift \\
on wages
\end{tabular} & $\begin{array}{c}\text { Marginal } \\
\text { Effect of } \\
\text { Mean Shift } \\
\text { on wages }\end{array}$ \\
\hline & $(1)$ & $(2)$ & (3) & $(4)$ & $(5)$ & \begin{tabular}{|c|}
$(6)$ \\
\end{tabular} & $(7)$ & $(8)$ & $(9)$ & \begin{tabular}{|l|}
$(10)$ \\
\end{tabular} & $(11)$ & $(12)$ \\
\hline $\begin{array}{l}\text { Overall Change } \\
\text { Parental Years of Schooling }\end{array}$ & & & $\begin{array}{c}0.047 \\
(0.0093)^{* * *}\end{array}$ & $\begin{array}{c}0.047 \\
(0.0093)^{* * *}\end{array}$ & & & $\begin{array}{c}0.097 \\
(0.0091)^{* * *}\end{array}$ & $\begin{array}{c}0.097 \\
(0.0040)^{* * *}\end{array}$ & & & $\begin{array}{c}0.132 \\
(0.0128)^{* * *}\end{array}$ & $\begin{array}{c}0.132 \\
(0.0036)^{* * *}\end{array}$ \\
\hline \multicolumn{13}{|l|}{ Mother } \\
\hline Dummy for missing & $\begin{array}{c}0.052 \\
(0.0542)\end{array}$ & 0.012 & \multirow{4}{*}{$\begin{array}{c}0.025 \\
(0.0072)^{* * *}\end{array}$} & \multirow{4}{*}{$\begin{array}{c}0.061 \\
(0.0067)^{* * *}\end{array}$} & $\begin{array}{c}-0.015 \\
(0.0417)\end{array}$ & -0.009 & \multirow{4}{*}{$\begin{array}{c}0.008 \\
(0.0074)\end{array}$} & \multirow{4}{*}{$\begin{array}{c}0.061 \\
(0.0067)^{* * *}\end{array}$} & $\begin{array}{c}-0.003 \\
(0.0730)\end{array}$ & -0.012 & \multirow{4}{*}{$\begin{array}{c}0.004 \\
(0.0127)\end{array}$} & \multirow{4}{*}{$\begin{array}{c}0.061 \\
(0.0118)^{* * *}\end{array}$} \\
\hline Years of schooling & $\begin{array}{c}0.008 \\
(0.0053)\end{array}$ & 1.310 & & & $\begin{array}{c}0.004 \\
(0.0047)\end{array}$ & 1.560 & & & $\begin{array}{c}0.009 \\
(0.0068)\end{array}$ & 2.087 & & \\
\hline Dummy for missing & $\begin{array}{c}0.123 \\
(0.0456)^{* * *}\end{array}$ & 0.060 & & & $\begin{array}{l}-0.007 \\
(0.0274)\end{array}$ & 0.082 & & & $\begin{array}{c}-0.079 \\
(0.0387)^{* *}\end{array}$ & 0.052 & & \\
\hline $\begin{array}{l}\text { Years of schooling } \\
\text { Parental presence at age } 14\end{array}$ & $\begin{array}{c}0.010 \\
(0.0040)^{* *}\end{array}$ & 0.641 & & & $\begin{array}{c}0.003 \\
(0.0042)\end{array}$ & 0.927 & & & $\begin{array}{c}-0.012 \\
(0.0064)^{* *}\end{array}$ & 0.850 & & \\
\hline Mother only & $\begin{array}{c}-0.061 \\
(0.0269)^{* * *}\end{array}$ & 0.176 & \multirow{3}{*}{$\begin{array}{l}-0.008 \\
(0.0056)\end{array}$} & \multirow{3}{*}{$\begin{array}{c}-0.015 \\
(0.0055)^{* * *}\end{array}$} & $\begin{array}{l}-0.003 \\
(0.0208)\end{array}$ & 0.199 & \multirow{3}{*}{$\begin{array}{l}-0.001 \\
(0.0048)\end{array}$} & \multirow{3}{*}{$\begin{array}{c}-0.010 \\
(0.0041)^{* *}\end{array}$} & $\begin{array}{c}0.120 \\
(0.0327)^{* * *}\end{array}$ & 0.106 & \multirow{3}{*}{$\begin{array}{c}0.016 \\
(0.0039)^{* * *}\end{array}$} & \multirow{3}{*}{$\begin{array}{c}0.015 \\
(0.0039)^{* * *}\end{array}$} \\
\hline Father only & $\begin{array}{c}0.072 \\
(0.0443)^{*}\end{array}$ & 0.039 & & & $\begin{array}{c}0.018 \\
(0.0538)\end{array}$ & 0.028 & & & $\begin{array}{c}0.110 \\
(0.0989)\end{array}$ & 0.015 & & \\
\hline $\begin{array}{l}\text { Neither mother nor Father } \\
\text { Education }\end{array}$ & $\begin{array}{c}0.009 \\
(0.0681)\end{array}$ & 0.015 & & & $\begin{array}{l}-0.043 \\
(0.0303)\end{array}$ & 0.017 & & & $\begin{array}{c}-0.100 \\
(0.0627)^{*}\end{array}$ & -0.015 & & \\
\hline Highest Grade Completed & $\begin{array}{c}0.022 \\
(0.0070)^{* * *}\end{array}$ & 0.704 & $\begin{array}{c}0.015 \\
(0.0047)^{* * *}\end{array}$ & $\begin{array}{c}0.020 \\
(0.0023)^{* * *}\end{array}$ & $\begin{array}{c}0.046 \\
(0.0068)^{* * *}\end{array}$ & 0.487 & $\begin{array}{c}0.022 \\
(0.0033)^{* * *}\end{array}$ & $\begin{array}{c}0.020 \\
(0.0013)^{* * *}\end{array}$ & $\begin{array}{c}0.057 \\
(0.0091)^{* * *}\end{array}$ & 0.829 & $\begin{array}{c}0.048 \\
(0.0076)^{* * *}\end{array}$ & $\begin{array}{c}0.054 \\
(0.0047)^{* * *}\end{array}$ \\
\hline $\begin{array}{r}\text { AFQT } \\
\text { Work Transition } \\
\end{array}$ & $\begin{array}{c}0.004 \\
(0.0005)^{* * *}\end{array}$ & 4.406 & $\begin{array}{c}0.018 \\
(0.0020)^{* * *}\end{array}$ & $\begin{array}{c}-0.011 \\
(0.0012)^{* * *}\end{array}$ & $\begin{array}{c}0.010 \\
(0.0008)^{* * *}\end{array}$ & 7.237 & $\begin{array}{c}0.070 \\
(0.0056)^{* * *}\end{array}$ & $\begin{array}{c}0.035 \\
(0.0027)^{* * *}\end{array}$ & $\begin{array}{c}0.007 \\
(0.0009)^{* * *}\end{array}$ & 7.644 & $\begin{array}{c}0.056 \\
(0.0071)^{* * *}\end{array}$ & $\begin{array}{c}0.006 \\
(0.0007)^{* * *}\end{array}$ \\
\hline Work after graduation & $\begin{array}{c}0.106 \\
(0.0466)^{* * *}\end{array}$ & 0.056 & \multirow{4}{*}{$\begin{array}{c}-0.003 \\
(0.0027)\end{array}$} & \multirow{4}{*}{$\begin{array}{c}-0.007 \\
(0.0032)^{* *}\end{array}$} & $\begin{array}{c}0.143 \\
(0.0269)^{* * *}\end{array}$ & 0.158 & \multirow{4}{*}{$\begin{array}{c}-0.002 \\
(0.0044)\end{array}$} & \multirow{4}{*}{$\begin{array}{c}-0.009 \\
(0.0039)^{* *}\end{array}$} & $\begin{array}{c}0.083 \\
(0.0410)^{* *}\end{array}$ & 0.165 & \multirow{4}{*}{$\begin{array}{c}0.008 \\
(0.0055)\end{array}$} & \multirow{4}{*}{$\begin{array}{c}-0.004 \\
(0.0049)\end{array}$} \\
\hline Graduate early & $\begin{array}{c}-0.118 \\
(0.0483)^{* *}\end{array}$ & 0.048 & & & $\begin{array}{c}-0.100 \\
(0.0361)^{* * *}\end{array}$ & 0.102 & & & $\begin{array}{c}-0.023 \\
(0.0528)\end{array}$ & 0.109 & & \\
\hline Graduate on time & $\begin{array}{c}-0.139 \\
(0.0482)^{* * *}\end{array}$ & -0.018 & & & $\begin{array}{c}-0.146 \\
(0.0283)^{* * *}\end{array}$ & -0.015 & & & $\begin{array}{c}-0.128 \\
(0.0431)^{* * *}\end{array}$ & 0.012 & & \\
\hline Graduate late & $\begin{array}{c}-0.141 \\
(0.0678)^{* *} \\
\end{array}$ & 0.041 & & & $\begin{array}{c}-0.219 \\
(0.0325)^{* * *}\end{array}$ & 0.077 & & & $\begin{array}{c}-0.146 \\
(0.0478)^{* * *}\end{array}$ & 0.008 & & \\
\hline Constant & $\begin{array}{c}6.425 \\
(0.0809)^{* * *}\end{array}$ & & & & $\begin{array}{c}6.171 \\
(0.0845)^{* * *}\end{array}$ & & & & $\begin{array}{c}6.253 \\
(0.1018)^{* * *}\end{array}$ & & & \\
\hline R-sq & 0.0743 & & & & 0.1966 & & & & 0.1667 & & & \\
\hline Observations & 5957 & & & & 3907 & & & & 2249 & & & \\
\hline
\end{tabular}

1) The sample excludes respondents without valid AFQT scores and attriters by age 22 . The excluded category in the regression specification are with both mother and father present at age 14 and who did not graduate by age 20 . Observations are weighted using the cross-section weights provided by the NLSY adjusted to account for attrition by age 22 and AFQT non-response. Standard errors in parenthesis. $* * *$

significant at $1 \%,{ }^{* *}$ significant at $5 \%,{ }^{*}$ significant $10 \%$ 
Fig 1: Predicted Changes in Log Wages

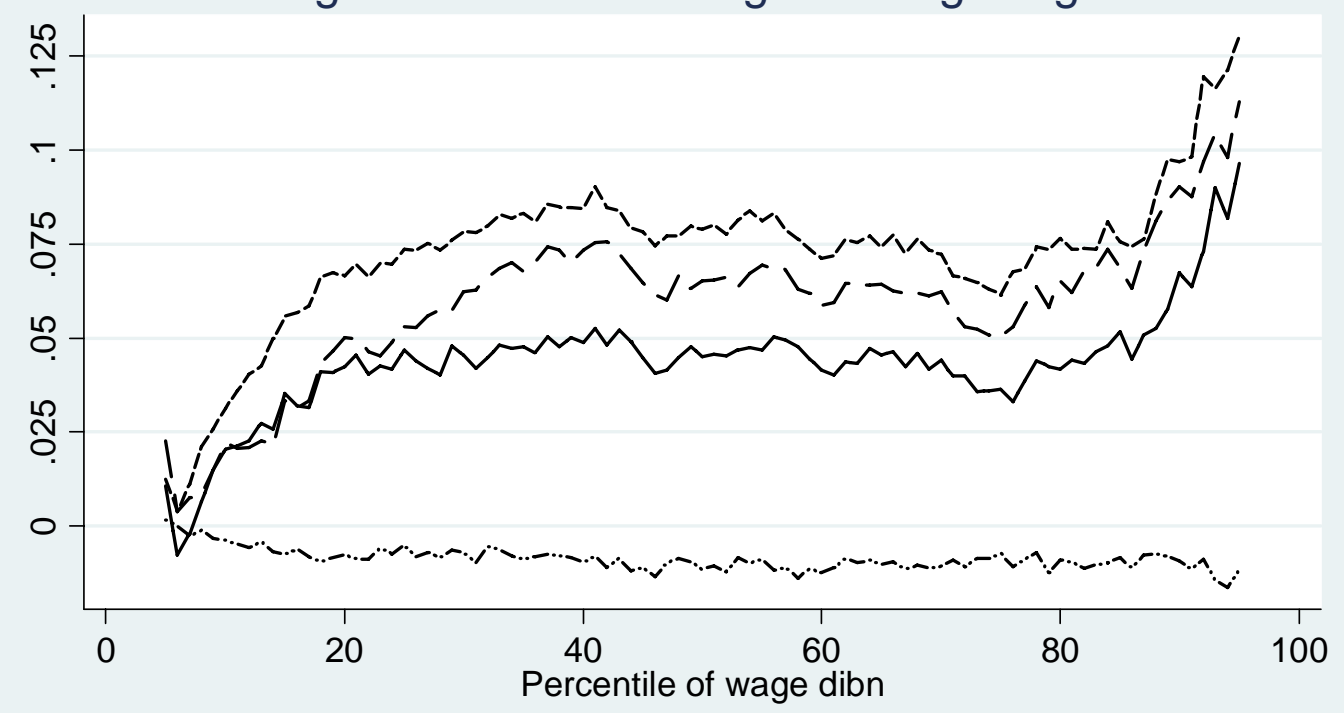

.........- 1. Race and gender only 2. +family background

------ 3. +AFQT and HGC $\quad---4 .+$ work transition

Depicted are changes in log wages predicted with various prediction variables

Fig 2 - 1: Predicted Change in Male Log Wages by Race
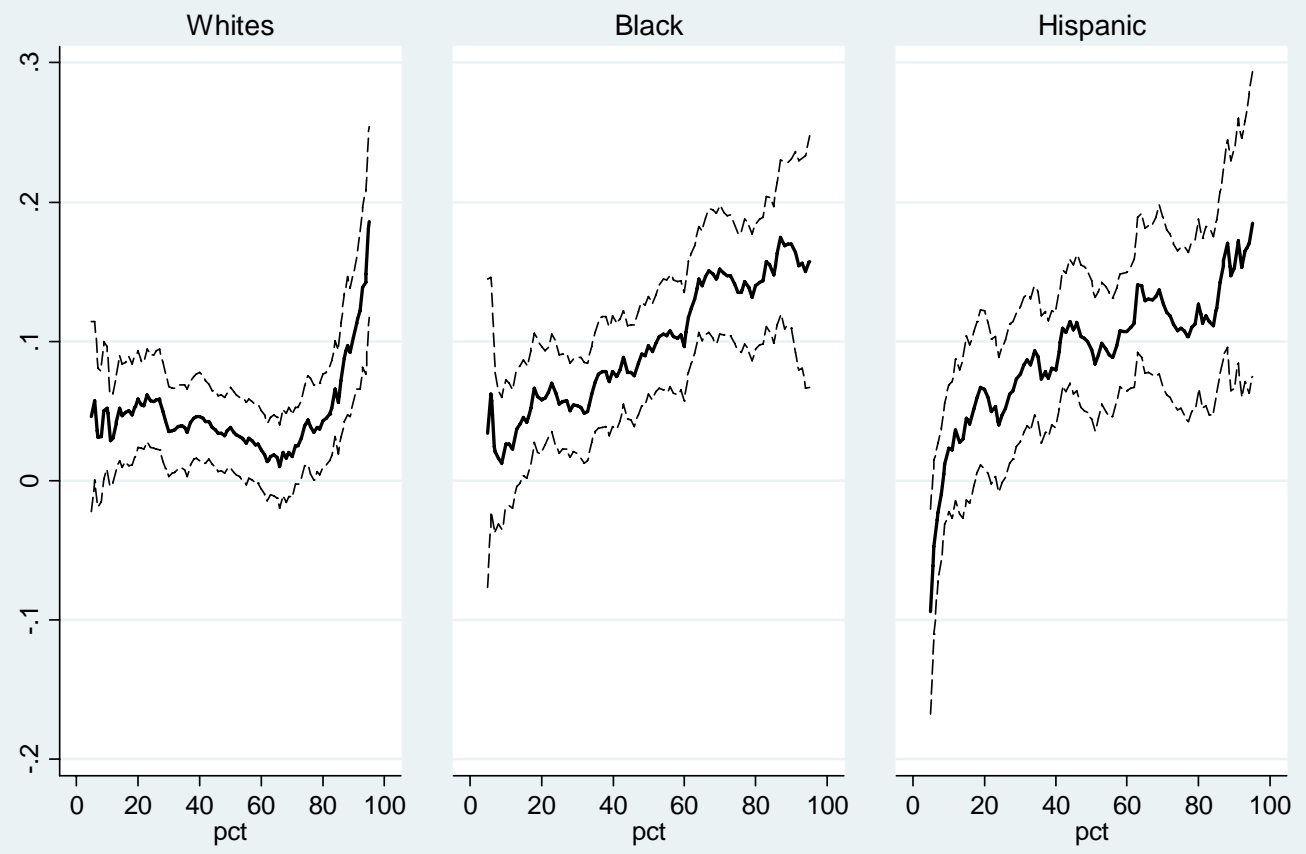
Fig 2 - 2: Predicted Change in Female Log Wages by Race
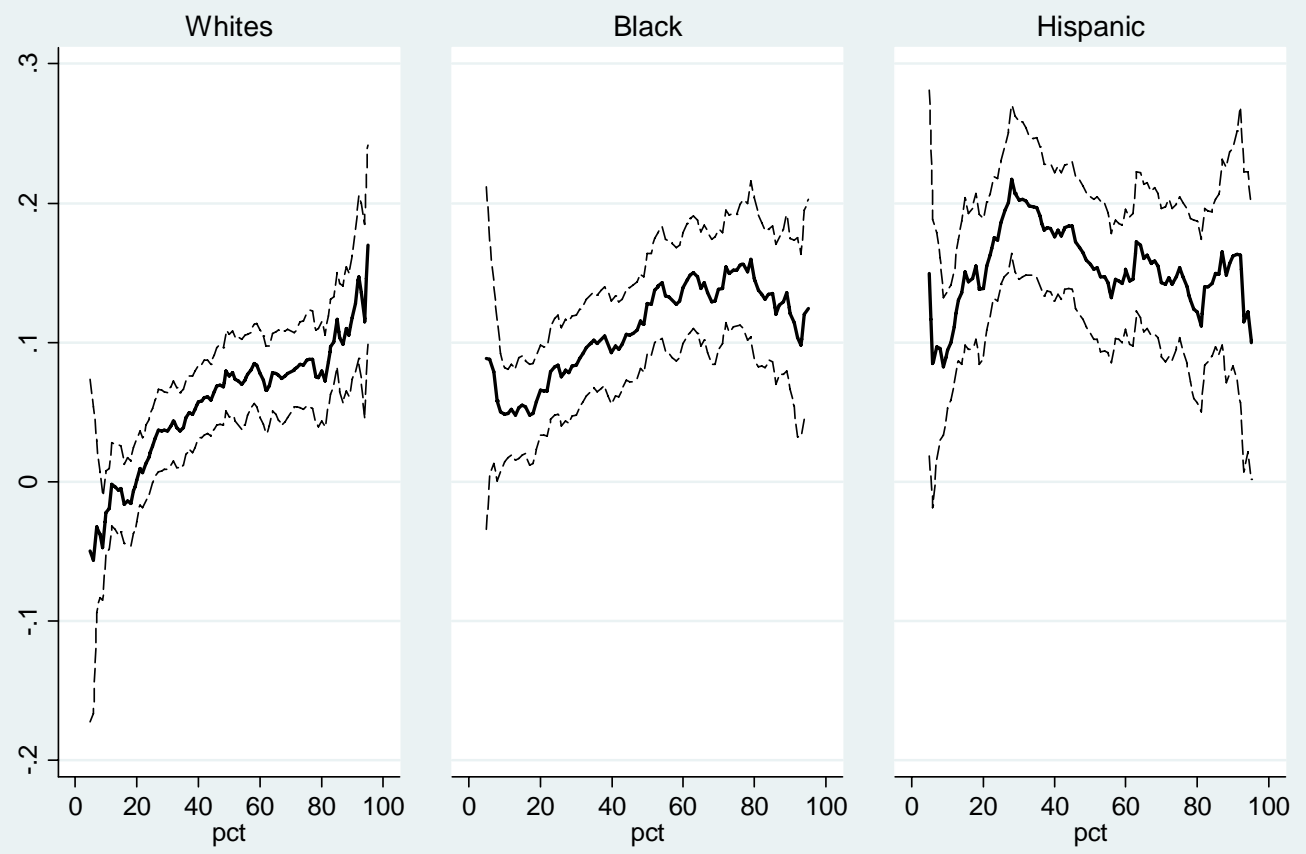


\begin{tabular}{|c|c|c|c|c|c|c|c|}
\hline \multicolumn{8}{|c|}{ Appendix B Table 1: Testing Age Standardization of AFQT Scores } \\
\hline & & \multicolumn{3}{|c|}{ NLSY 1979} & \multicolumn{3}{|c|}{ NLSY 1997} \\
\hline & & F-stat & $\begin{array}{c}\text { Degrees of } \\
\text { Freedom }\end{array}$ & $P$ value & F-stat & $\begin{array}{c}\text { Degrees of } \\
\text { Freedom }\end{array}$ & $\mathrm{P}$ value \\
\hline Specification 1 & Cohort X Race & 0.81 & 15,8903 & 0.67 & 0.5 & 6,5001 & 0.81 \\
\hline Specification 2 & Cohort X Parental HGC & 0.73 & 15,7337 & 0.76 & 0.64 & 6,3895 & 0.7 \\
\hline Specification 3 & Cohort X HGC & 0.74 & 8,6824 & 0.65 & 0.82 & 3,5005 & 0.48 \\
\hline
\end{tabular}

Notes: Reported are test statistics from three specifcations exploring whether the relationship between the AFQT-score and observed variables changes with age of test taking. Each F-test refers to the test whether the interaction of the age of test taking with observable characteristics is 0 in a linear Specification 1: regression of standardized afqt on cohort dummies, cohort dummies interacted with hgc, and hgc where hgc refers to highest grade Specification 2: regression of standardized afqt on cohort and race dummies, cohort dummies interacted with race.

Specification 3: regression of standardized afqt on cohort dummies, cohort dummies interacted with hgc, cohort dummies interacted with race, cohort dummies interacted with father's hgc, hgc and mother's hgc 


\begin{tabular}{|c|c|c|c|c|c|c|}
\hline \multicolumn{7}{|c|}{ Appendix B Table 2: Parental Presence at Age 14} \\
\hline \multirow{2}{*}{\multicolumn{2}{|c|}{ Living with at age 14: }} & \multicolumn{3}{|c|}{ Census } & \multirow{2}{*}{ NLSY79 } & \multirow{2}{*}{ NLSY97 } \\
\hline & & 1980 & 1990 & 2000 & & \\
\hline \multirow{4}{*}{$\begin{array}{c}\text { Social Mother and } \\
\text { Father }\end{array}$} & $\begin{array}{l}\text { Mother and } \\
\text { Father }\end{array}$ & 75.1 & 70.61 & 66.88 & 83.34 & 68.16 \\
\hline & Mother only & 17.02 & 18.61 & 20.15 & 12.77 & 24.19 \\
\hline & Father only & 2.44 & 3.44 & 5.06 & 1.39 & 3.74 \\
\hline & Neither & 5.44 & 7.35 & 7.91 & 2.5 & 3.92 \\
\hline \multirow{4}{*}{$\begin{array}{c}\text { Biological Parents } \\
\text { only }\end{array}$} & $\begin{array}{l}\text { Mother and } \\
\text { Father }\end{array}$ & .. & .. & .. & 75.16 & \\
\hline & Mother only & .. & .. & .. & 18.72 & 35.67 \\
\hline & Father only & .. & .. & .. & 3 & 6.36 \\
\hline & Neither & & & & 3.12 & 5.22 \\
\hline
\end{tabular}


Fig A-1: Observed and Counterfactual Log Wage Density for NLSY79 and NLSY97

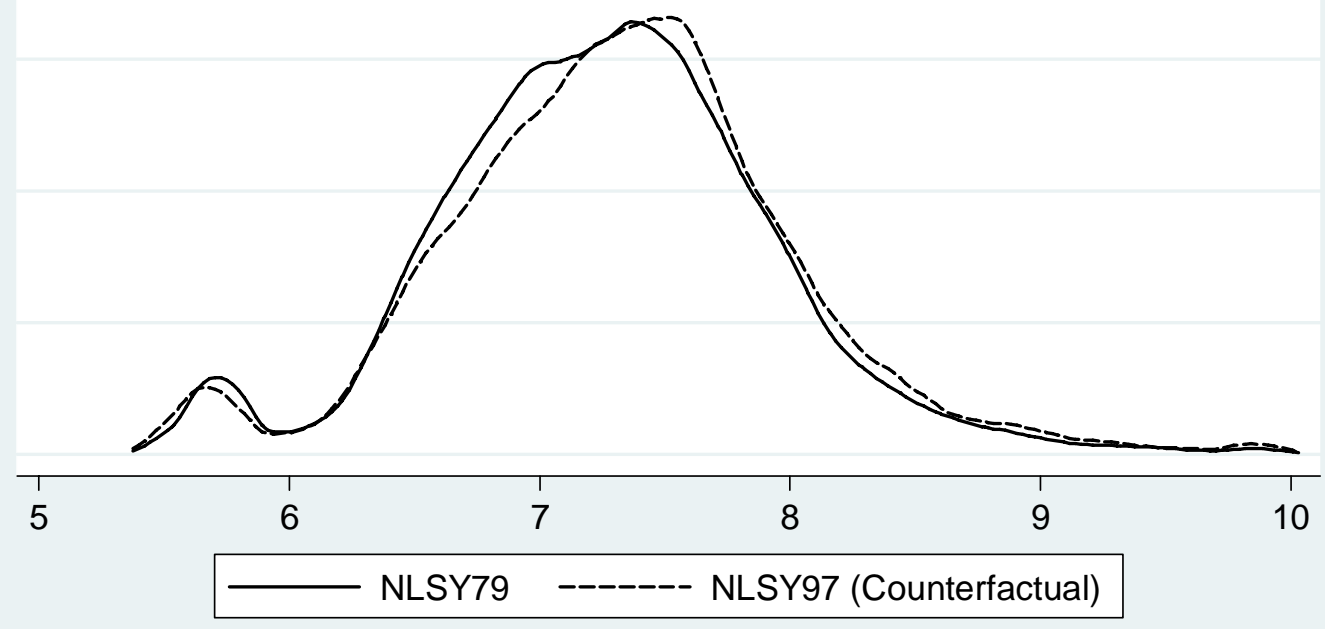

Counterfactual based on full prediction set as in specification 4.6, Sample 1

Density of log wages 'while working'. Log wages regression adjusted to year=2002, experience $=23$ Densities smoothed with Epanechnikov kernel (bw=0.075)

Figure A-2

Fig 3: Propensity weights by 1979 Wage Distribution

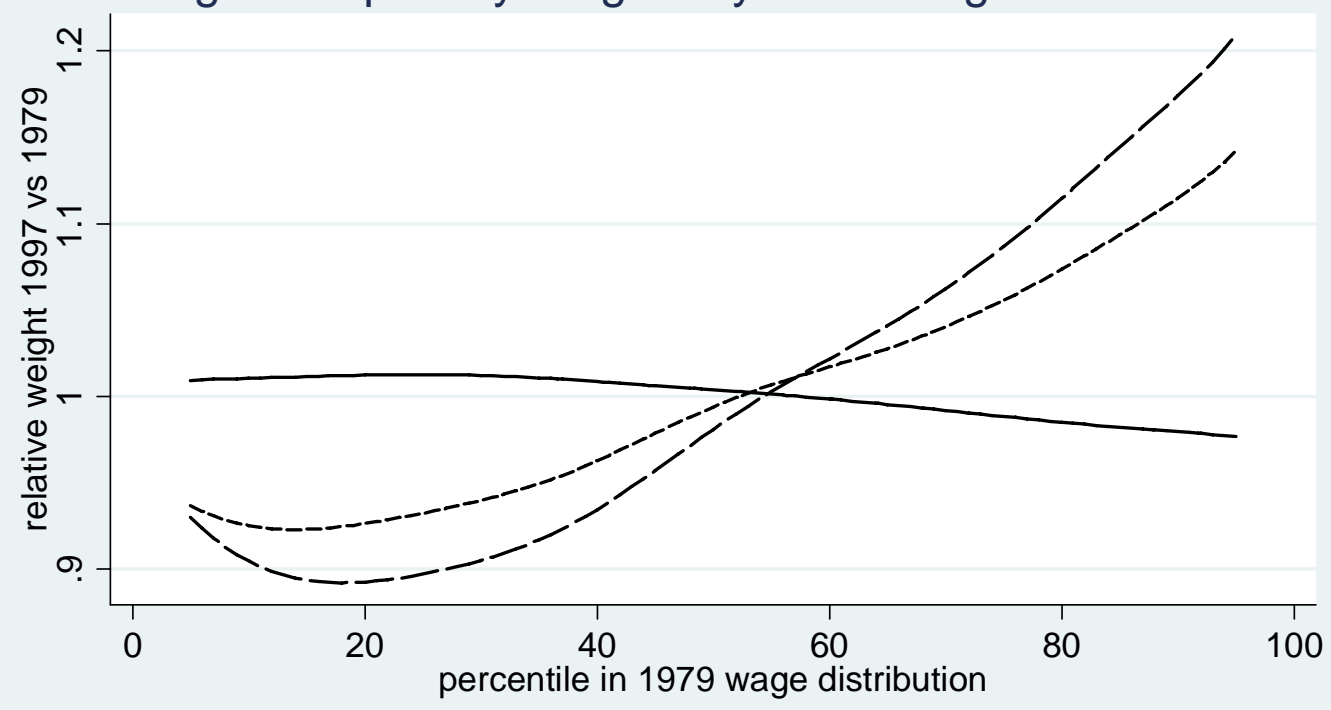

- Adjusting for (race, sex) composition
$----\quad+$ family background

kernel smoothed 